\title{
PRIMING IDEOLOGY: \\ WHY PRESIDENTIAL ELECTIONS AFFECT U.S. JUDGES
}

\author{
DANIEL L. Chen*
}

\begin{abstract}
U.S. Courts of Appeals judges elevate their dissents for ten months prior to Presidential elections. I develop a theoretical model showing that the salience of partisan identities can explain this pattern. I link judges to their states of residence, and exploit temporal variation in the importance of a state during the electoral season. Dissents are elevated in swing states and in states that count heavily to winning the election, when these states are competitive. U.S. Senate elections further elevate dissents. I link administrative data on case progression and frequency of campaign advertisements in judges' states of residence. Dissents occur shortly before publication, increase with monthly increases in campaign ads, and appear for cases whose legal topic, economic activity, is most heavily covered by campaign ads. Finally, I link the cases to their potential resolution in the Supreme Court. Dissents before elections appear on more marginal cases that cite discretionary miscellaneous issues and procedural (rather than substantive) arguments, which the Supreme Court appears to recognize and only partly remedy.
\end{abstract}

Keywords: Judicial Decision Making, Salience, Identity, JEL codes: D7, K0, Z1

\footnotetext{
*Daniel L. Chen, daniel.chen@iast.fr, Toulouse School of Economics, Institute for Advanced Study in Toulouse, University of Toulouse Capitole, Toulouse, France; dchen@law.harvard.edu, LWP, Harvard Law School. First draft: May 2009. Current draft: August 2016. Latest version at: http://nber.org/ dlchen/papers/Priming_Ideology.pdf I thank research assistants, numerous colleagues with helpful comments at economics faculties at Hebrew, Zurich, European University Institute, Stockholm IIES, Lucerne, Lausanne, INSEAD, Notre Dame, Maryland, Cyprus Business School, Duke, Stanford SITE (Psychology and Economics), NBER Summer Institute (Political Economy), Behavioral Public Economics Workshop, Econometric Society, Royal Economic Society, European Association for Decision Making, and Association for the Study of Religion, Economics, and Culture, at the political science and public policy faculties at Duke and the Midwest Political Science Association, and at law faculties at Harvard, Chicago, Duke, George Washington, George Mason, Vienna, American Law and Economics Association, Conference on Politics, Law, and Business, Italian Society for Law and Economics, Canadian Law and Economics Conference, Southeastern Law Scholars Conference. This project was conducted while I received financial support from the European Research Council, Agence Nationale de la Recherche, Swiss National Science Foundation, Institute for Humane Studies, John M. Olin Foundation, Ewing Marion Kauffman Foundation, and Templeton Foundation. I acknowledge financial support from the Petrie-Flom Center, Program on the Legal Profession, and the Center for American Political Studies at Harvard.
} 


\section{Introduction}

Social scientists have long speculated about whether individuals with different ideas select into different groups or whether groups impart a set of ideas. A growing number of economics studies have tested the causal links between group identity and economic decisions (Benjamin et al. 2010), social preferences (Fong and Luttmer 2009; Chen and Li 2009), charitable decisions (Benjamin et al. 2013), and moral decisions (Cohn et al. 2015), by making group identity salient in experimental settings. This paper explores the potential link between group identity and ideology in a high-stakes lawmaking setting. While market pressures may sometimes drive psychological biases in economic behavior towards the rational model and drive out ideological bias (List 2003; Gentzkow and Shapiro 2010; Mullainathan and Shleifer 2005; Groseclose and Milyo 2005; DellaVigna and Kaplan 2007), behavioral anomalies in the decision-making of common law judges can have permanent consequences through the establishment of precedent Gennaioli and Shleifer 2007; Baker and Mezzetti 2012), and undermine the legitimacy of law and legal compliance (Bénabou and Tirole 2012). The U.S. Courts of Appeals provide a relevant environment in which to study polarization (Atran et al. 2007; Montalvo and ReynalQuerol 2005; Bénabou 2012, Golub and Jackson 2012; Esteban and Ray 1994): since only $2-3 \%$ of their cases reach the U.S. Supreme Court, their decisions constitute the vast majority of cases that create the law and impact economic outcomes.1

Most U.S. judges believe there is no such thing as ideological bias. According to U.S. Courts of Appeals (U.S. Circuit Court) judges, only $5-15 \%$ of cases are legally indeterminate and, even in these difficult cases, they understand which arguments have greater plausibility (Edwards and Livermore 2008). Even if judges appointed by Democrats and Republicans ${ }^{2}$ vote in different ways, correlations between demographic characteristics and judicial decisions have multiple interpretations (Posner 1973; Cameron 1993; Kornhauser 1999): are judges simply following different philosophies, i.e., rules or reasonings (Falk and Tirole 2016 ${ }^{3}$, rather than demonstrating a bias towards particular outcomes? For instance, a judge can derive from first principles an adherence to a strict interpretation of the Constitution, while not necessarily hewing to the preferences of a political party for a certain policy outcome. The former approach could be called deontological, while the latter approach, consequentialist. Non-consequentialist

\footnotetext{
${ }^{1}$ There is also a related economic literature on bias by sports referees (Garicano et al. 2005 , Dohmen and Sauermann 2015, Pope et al. 2013) and traffic court judges (Shayo and Zussman 2011) and an experimental economics literature that finds that even when parties have the same information, they come to different conclusions about what a fair judicial decision should be and that they do so for self-serving reasons (Babcock et al. 1995).

${ }^{2}$ Judges are not supposed to have political affiliation, but for expositional brevity, I refer to judges appointed by Democratic or Republican Presidents as "Democrats" or "Republicans".

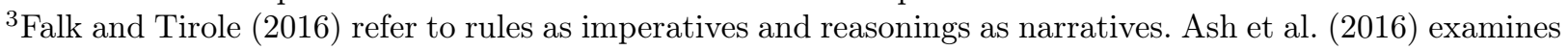
the effect of conservative legal thought on economic jurisprudence.
} 
and consequentialist motivations are difficult to distinguish in real world decision-making (Chen and Schonger 2013). Even if there is a bias towards particular outcomes, a separate but related question is whether this bias is conscious - also referred to as reflective, motivational, or Type II thinking (Kahneman 2011) - or unconscious - also referred to as automatic, cognitive, or Type I thinking. If the bias is due to Type I thinking rather than Type II, nudges like simple awareness or reminders could reduce bias (Sunstein and Thaler 2008). This paper identifies a channel for judicial partisanship that appears to be attributable to Type I thinking.

To minimize the influence of extrajudicial factors, lawmaking U.S. Courts of Appeals judges have life tenure. They are appointed to permanent seats at different locations within the Circuit where they do most of their writing, but are randomly assigned to panels of three for each case..$^{4}$ Because the Presidents from different parties appoint judges over time, the panels can be expected to bring together judges with different points of view. Seventy percent of panels have both Republicans and Democrats - yet only $8 \%$ of panels - not 70\% - have dissents, i.e., 2-1 decisions. These dissents occur among both politically unified and divided panels 5 suggesting that most of the time, judges do agree on what is right and just.

Using a roughly $5 \%$ random sample of 18,686 hand-coded cases from 1925 to 20026 Berdejo and Chen (2016) showed that the Presidential election cycle affects judicial decision-making in the U.S. Courts of Appeals. In this paper I show the same pattern, at the monthly level, for the universe of 293,868 cases I coded for dissents from 1950 to 2007.7 I also develop a model of priming of latent group identity to explain these findings. The Presidential election season can heighten partisan group identities. During this period, the media is saturated with political debate, as reflected by the number of newspaper articles mentioning both "Republican" and "Democrat" and the increasing number of campaign ads throughout the period. In the basic results, Courts of Appeals judges are twice as likely to dissent and vote along partisan lines, in the quarters leading up to a Presidential election relative to the quarters after the election (Berdejo and Chen 2016). For example, elections double the rate at which Democrats are more likely than Republicans to cast a liberal vote 8 Partisan voting also doubles on unified panels, which implies that Presidential elections shift the legal precedent $9^{9}$

To further interpret and benchmark these results, I discuss four observations. First, the quantitative impact on precedent is similar whether I compare to the period immediately

\footnotetext{
${ }^{4}$ In rare instances, more than three judges hear a case (e.g., the entire Circuit).

${ }^{5}$ As shorthand, "politically unified" panels are panels with three Democrats or three Republicans and "divided panels" are panels with at least one judge from each party.

${ }^{6}$ U.S. Courts of Appeals Database Project (http://www.cas.sc.edu/poli/juri/auburndata.htm)

${ }^{7}$ OpenJurist (http://openjurist.org)

${ }^{8}$ Election always refers to the Presidential election unless otherwise noted.

${ }^{9}$ In terms of its effects on the other legal outcomes, U.S. Courts of Appeals judges are $20 \%$ more likely to reverse the lower District Court decisions, which further impacts legal precedent (Berdejo and Chen 2016).
} 
before the election with the period immediately after the election, or compare it to all other periods, which suggests that the judges are not simply time-shifting their decisions, which they are limited in their ability to do. Second, a linear model of proximity to an election would attribute $6 \%$ of total criminal sentence length to the incentives of judges running for re-election (Huber and Gordon 2004; Gordon and Huber 2007) and 23\% of dissents from unelected U.S. Courts of Appeals judges to the President's electoral proximity. This suggests that among the 5-15\% of cases estimated to be legally indeterminate (Edwards and Livermore 2008), on average, all of them may be affected by elections ${ }^{10}$ Third, to understand the effect on an ideological scale, a one-decile shift in judicial ideology score has been found in elected state judges during election years (Hollibaugh Jr. 2011); I estimate at least a one-decile shift in U.S. Courts of Appeals judges' ideology scores before Presidential elections. While these effects among unelected judges may seem large relative to the effects for elected judges, partisanship may be heightened in a group decision-making setting. ${ }^{11}$ Fourth, since cases with dissents are 2-3 times more likely to be heard in the U.S. Supreme Court, the increase in dissents crowd the Supreme Court docket, which reduces the time it can spend on other cases, potentially affecting its decisions (Huang 2011). Taken together, these results suggest materially relevant bias. While judges reasonably use their judicial discretion to interpret the facts and the law using different philosophies, rules, or reasoning, these philosophies should not change before Presidential elections. If highly professional, life-tenured Courts of Appeals judges are susceptible to priming via the partisan nature of electoral cycles, then many others may be susceptible to priming regardless of professional norms against bias.

To characterize the mechanism for these effects, I link to all available datasets on: (1) biographies of judges, including their state of residence ${ }^{12}$, their elevation to or consideration for appointment to the Supreme Court ${ }^{13}$, and their predicted ideology: ${ }^{14}(2)$ a timeline of all milestones, including oral arguments in administrative data on U.S. courts: ${ }^{15}$ (3) potential subsequent appeal to and treatment by the U.S. Supreme Court ${ }^{16}$ (5) subsequent citations,

\footnotetext{
${ }^{10}$ In particular, three-judge Republican panels are 16 percentage points more likely to make conservative decisions while Democratic panels are 8 percentage points more likely to make liberal decisions, so either all of the legally indeterminate cases are affected or some legally determinate cases are also affected.

${ }^{11}$ It is also important to note that these are relative effects. For example, if unelected judges typically do not behave in a partisan manner, small changes in their behavior can seem relatively large.

${ }^{12}$ U.S. Courts of Appeals Database Project (http://www.cas.sc.edu/poli/juri/auburndata.htm) includes judicial biographies, but I hand-coded the judge's seat number to the actual state of residence. This data is merged by judge.

${ }^{13}$ I entered the list of U.S. Courts of Appeals judges considered for the Supreme Court (Nemacheck 2007).

${ }^{14}$ Judicial Common Space scores (Epstein et al. 2007). This data is merged by judge.

${ }^{15}$ Administrative Office of the U.S Courts. This data was available at the Interuniversity Consortium for Political and Social Research when I began the project in 2008. I merge the data by docket number.

${ }^{16}$ U.S. Courts of Appeals Database Project (http://www.cas.sc.edu/poli/juri/auburndata.htm) and its updates provide this linkage. This data is merged by case.
} 
including those made by future dissents: ${ }^{17}$ (6) the types of reasoning used in dissents: ${ }^{18}(7)$ state-level monthly campaign ads, including the topic of the ads ${ }^{19}$ and (8) political environment ${ }^{20}$ I also collected data on newspaper reports of U.S. Courts of Appeals Court cases ${ }^{21}$ and leverage monthly and cross-election variation, which Berdejo and Chen (2016) did not explore.

I find several results that are relevant to the priming hypothesis. First, behavioral changes are three times greater in close elections, non-existent in landslide elections, and reversed in wartime elections. Second, dissents vary with the closeness of the state's popular vote when the dissenting judge's state has more electoral votes. Third, the channel is through the dissenting judge rather than the other two judges on the panel (dissents do not vary significantly with the electoral conditions of the states of the other two judges on the panel). Fourth, a different set of elections, the timing of which varies by state-U.S. Senate elections-in the dissenting judge's state further elevate dissents. Fifth, increases in dissents before elections are twice as large in the time period since the 1970s-a magnitude that is consistent with the increase in polarization found in studies of the U.S. Congress (McCarty et al. 2006).

Next, I show that dissents are significantly elevated in each of the ten months before the Presidential election. Primaries have historically played an important role in Presidential elections. Before the modern era, party brokers would select Presidential candidates with little transparency. The alternative would have been a general election with a very wide field of candidates, which could result in "accidentally" electing someone who would not otherwise win. Primaries alleviate this problem by narrowing the choices to a few candidates. Since the primary season involves choosing a candidate to represent a particular party, candidates target more the extreme wings of their parties. Therefore the median voter for the party primary is further from the center than the median voter during the general election. As primaries attract media coverage and voter attention, the primary season highlights ideological differences between individuals in the same party (Goldberg 2016). Non-swing states-which are relatively less important during the general election-are also relatively more important during the primary season because many states allocate votes by proportional rule rather than by plurality. ${ }^{22}$ The relative elevation of the importance of non-swing states (further

\footnotetext{
${ }^{17}$ This data is hand-collected and merged by case.

${ }^{18}$ The extension to the U.S. Courts of Appeals Database Project (http://www.cas.sc.edu/poli/juri/auburndata.htm) includes this data.

${ }^{19}$ Wisconsin Ads Project. This data is merged by state and month.

${ }^{20} \mathrm{CQ}$ Voting and Elections Collection. This data is merged by state and election.

${ }^{21}$ This data is hand-collected, but not merged because I did not search for specific cases.

${ }^{22}$ Proportional rule means that, for example, a candidate who wins $51 \%$ of California's popular vote receives $51 \%$ of its delegates during the primaries (proportional rule) but $100 \%$ during the general election (plurality rule). One view for why Barack Obama won the Democratic nomination in 2008 over Hillary Clinton is that he focused more on the smaller states while she focused only on the big states during the primary season.
} 
elevated due to the importance of momentum) early in the election cycle can be seen in data on campaign advertisements. The primary season typically ends in the third month before the election, after which parties generally coalesce (at the nominating convention) around the candidate who will represent them in the general election. The nominating conventions can be viewed as a rally and call for party unity after a divisive primary, after which parties typically pivot to the center.

Four facts are consistent with this explanation. First, corresponding to these differences in local levels of political debate, dissents begin declining three months before Presidential elections in electorally non-pivotal states but remain elevated in electorally pivotal states. Second, increases in dissents track monthly increases in campaign ads in the dissenting judge's state of residence. These effects could be causal, but the number of campaign ads can also be correlated with other priming factors, e.g., partisan newspaper articles or television news, which increase with the importance of different states during different parts of the election cycle. Third, electoral cycles in judicial behavior do not appear when I substitute the date of publication with dates for any of seven earlier stages of a case, including the date of oral argument. This result suggests that the exact time at which a judge decides to dissent during Presidential elections occurs shortly before the publication of an opinion, rather than on the date of oral argument, which is usually the first time when panels of judges decide who will dissent. ${ }^{23}$ Fourth, this interpretation of a late decision is further supported by a similar electoral cycle in concurrences, which increase by $50 \%$ before Presidential elections. Concurrences are a different kind of dissent - they are disagreements about the reasoning, rather than the verdict, of the majority opinion. Like dissents, they require the writing of a separate opinion, and the decision to write a concurrence occurs after the first draft of the majority opinion has been circulated.

Election campaigns can activate chronic identities (Ansolabehere and Iyengar 1997), so the partisan environment can cause judges to view cases in a different light. Such influence may be implicit and subconscious. In electroencephalogram studies of political priming, subjects do not recall the stimulus (Morris et al. 2003); neurocorrelates of behavioral change in individuals are activated by advertisements that affect population behavior, even when individuals do not believe these advertisements would change people's behavior (Falk et al. 2012). However, when judges are explicitly primed in vignette studies, they control the influence of unconscious

Democrats allocate their delegates proportionally in every state during the primaries. Republicans also allocate their delegates proportionally in many states during the primaries.

${ }^{23}$ The judges confer immediately after the oral argument and determine how the case should be decided (Hart et al. 2006, Epstein et al. 2013). When the judges disagree, the greater number becomes the majority of the court on that case. In cases without oral arguments, these opinions are most often decided unanimously (Skotnicki 2012). 
bias (Rachlinski et al. 2009). Five facts are consistent with Type I thinking. First, experience significantly attenuates priming effects ${ }^{24}$ Significant attenuation due to experience has been interpreted by economic studies to indicate Type I bias (Mobius et al. 2011). Second, dissents increase most significantly on economic activity cases. These cases typically do not have judges dividing along political lines, but economic issues are salient in election campaigns: $70 \%$ of campaign ads mention economic policy. Cases on topics like civil rights and due process, which are generally politically divisive, do not increase in dissents before elections - only $0.26 \%$ of campaign ads mention civil rights and civil liberties. Third, previous associative links between legal enforcement and political decision-making - specifically, experience as a federal prosecutor (U.S. Attorneys or Assistant U.S. Attorneys) - magnify electoral cycles. ${ }^{25}$ Significant magnification due to previous associative links has been interpreted in psychological studies to indicate priming. The key mechanism is that an activated concept becomes more likely than before to influence conscious judgments (Bargh et al. 1995). Fourth, the majority opinions being dissented on are more likely to mention highly discretionary, miscellaneous legal issues, and are less likely to be cited in future dissents. Dissents have been interpreted by legal studies to indicate the presence of legal foment and innovation (Krishnakumar 2000) ${ }^{26}$ Fifth, dissents before elections are twice as likely to be reasoned on procedural rather than substantive grounds than those made at other times. I interpret these results together to suggest that more marginal cases receive dissents, and that the dissents appear to be more last minute and less reflective than dissents made in other time periods.

I also explore alternative explanations of electoral cycles: career concerns, reputational

\footnotetext{
${ }^{24}$ Berdejo and Chen (2016) find that while judges of all years of experience display significant increases in dissents, those with 1 or 2 years of experience display the sharpest increase.

${ }^{25}$ Judges who previously served as federal prosecutors (U.S. Attorneys or Assistant U.S. Attorneys) — who make partisan decisions about what aspects of federal law to prioritize enforcement - are more likely to display electoral cycles. Prosecutors in general have tremendous power in choosing how harshly or how leniently to go after someone. For example, the Department of Justice has no power of enforcement after it issues guidelines and prosecutors can choose what charges to file. They wield enormous power in the courtroom. U.S Attorneys are the top-ranked tier of prosecutors; they are appointed by the President and confirmed by the Senate. They play a large role in setting the law enforcement priorities for their jurisdiction. Nyhan and Rehavi (2015) documents that federal prosecutors are politically motivated. Their behavior reflect party politics in federal public corruption prosecutions (Gordon 2009). Federal prosecutors also often run for higher office (Engstrom 1971) (but U.S. Courts of Appeals judges do not run for office and once appointed rarely leave). During the time period of this study, judges came of age in a time when even Assistant U.S. Attorneys would leave with a change in Presidential administration (Lochner 2002). The following example illustrates how they can politically choose to enforce or not different aspects of federal law. They can prioritize specific types of crime - health care fraud, obscenity, immigration cases - which is a political choice (Perry Jr. 1998). It is possible that judges with other political experience are also more easily primed, but either the number of judges with other political experience is small in number or the degree to which their response exceeds that of other judges is not statistically significant.

${ }^{26}$ When a new precedent arises, a judge may dissent with the established precedent in one case. Even if the dissent has no precedential power, a subsequent dissent may cite this case to justify its dissent and push for legal change.
} 
capital, "get-out-the-vote", learning, mood, and shifts in case, litigant, or judge characteristics. A combination of institutional rules, empirical evidence, and logic precludes these mechanisms from fully explaining my results. First, Berdejo and Chen (2016) checks that the results are not due to shifts in the electoral cycle in any of over 100 case and litigant characteristics. In this paper, I also check that the results are not due to shifts in any of over 50 characteristics of judges either authoring or sitting on the case. Second, the results are not due to judges' time-shifting controversial cases: increases in dissents before elections are not matched one to one with decreases after elections. Third, the results are also not due to career concerns. Judges who are elevated to the Supreme Court or on the shortlist as a potential Supreme Court candidate are not more likely to dissent before Presidential elections. Nor are judges who are about to retire after the election more likely to dissent before elections. Fourth, there is no correlation between dissenting before the election and the candidate from one's party winning the election. Even if judges were motivated to get out the vote, behavioral changes should be observed in all states within a Circuit since decisions are promulgated at the Circuit - not state - level ${ }^{27}$ Instead, behavioral changes are greatest in electorally pivotal states where popular votes count heavily in the Presidential election and in media markets where campaign advertisements are greatest. Fifth, judges are also unlikely to signal to their state's electorate or politicians when they may be paying attention: No discernible effect is observed for elections of the most physically proximate politician - the state governor - and newspapers are also no more likely to report on Courts of Appeals decisions or their dissents before Presidential elections ${ }^{28}$ Sixth, the results are not about learning (Lenz 2009). In the first instance, judges are not supposed to be learning from elections, nor are they supposed to base their decisions on what they learn about political parties. Even if judges learn from elections, then elevated dissents should persist after the election, but they do not. Seventh, the results are not only about mood (Saunders Jr. 1993; Edmans et al. 2007; Simonsohn 2010 , Card and Dahl 2011), since mood shifts would affect all judges. However, I show that when judges who are close in ideology sit together but are from different parties, the rate at which they disagree triples before a Presidential election; and when judges from the same party sit together, if one dissents, the one with the ideology score more distant from the other party dissents more.

The remainder of the paper is structured as follows. Section 2 provides background on

\footnotetext{
${ }^{27}$ For example, consider the Sixth Circuit, which includes Michigan, Ohio, and Tennessee. Through random assignment, judges from all three states may be assigned to the same case, and the judge from Michigan or Ohio is more likely to dissent than the Tennessee judge.

${ }^{28}$ Furthermore, even if judges are changing legal precedent in order to make signals when their state's electorate or politicians are paying attention, this would make their activities all the more surprising, as they gain no benefit in likelihood of elevation to the Supreme Court.
} 
priming and on the U.S. Courts of Appeals. Section 3 presents the model of priming. Section 4 describes the data and estimation framework. Section 5 presents the main results. Section 6 investigates the priming hypothesis. Section 7 evaluates the role of heightened salience of partisan group identity. Section 8 investigates the impact on the development of law. Section 9 considers alternative mechanisms. Section 10 concludes.

\section{Background}

2.1 Priming Formal models in economics have incorporated cognitive effects like priming and salience (Laibson 2001, Bernheim and Rangel 2004; Bordalo et al. 2012a $\mid \mathrm{b}$, 2013a 2015), yet field evidence of priming is scarce ${ }^{29}$ Priming research in social psychology has been criticized ${ }^{30}$ for a lack of replicability ${ }^{31}$ The ideal empirical strategy for detecting priming in the field follows individual behavior over time as well as individual demographic characteristics before a prime to see if individuals from different groups diverge after the prime.

To fix ideas about priming, consider these canonical psychology studies: (i) cueing effects when a recovering drug addict walked by a subway station where he once bought drugs, the station functioned as a stimulus that triggered physical withdrawal symptoms (Laibson 2001); (ii) stereotype threat - when secondary school students taking a math exam were reminded of their gender in a word problem, it caused girls to perform worse than boys (Spencer et al. 1999); (iii) conceptual priming - when participants identified as likely to be sexual harassers were primed with the concept of power in a pronunciation task, they were more attracted to a female confederate (Bargh et al. 1995). The literature also refers to these phenomena as passive or implicit priming. The key mechanism is that an activated concept becomes more likely than before to influence conscious judgments.

Several aspects of my data overcome challenges that make the detection of priming effects in field data difficult. First, priming needs to be isolated from other mechanisms involving incentives or learning. Second, high-frequency data is needed, as primes are believed to be extremely short-lived; the longest laboratory study documents priming effects one week after the initial stimulus (Tulving et al. 1982, Ostergaard 1994; Hassin et al. 2007). Third, a large sample of individuals is needed, because individuals are very heterogeneous - conscious processing, directed by an individual's intentions and goals, can override the usual or habitual response to priming; while novices are more easily primed by news coverage (Krosnick and Kinder

\footnotetext{
${ }^{29}$ John List said, "I believe in priming. Psychologists have shown us the power of priming," and he tried "everything" to induce priming in field experiments, but could not. "Interview: John A. List," Federal Reserve Bank of Richmond Region Focus, Second/Third Quarter 2012.

30"The Sin of Bad Science," Financial Times, December 21, 2012.

${ }^{31}$ Daniel Kahneman, even though he is a "general believer" in priming effects, goes so far as to say that a "train wreck" is looming about the robustness of priming results. "Nobel Laureate Challenges Psychologists to Clean Up Their Act," Nature, October 3, 2012.
} 
1990). Furthermore, activation will only spread if an associative link has been formed, and the stronger the association, the wider and faster the activation will spread (Bargh and Chartrand 2000; Kimball 2005); the greater the concentration or number of primes, the stronger the overall priming effect (Srull and Wyer 1979).

Rich data on the contexts and characteristics of judicial decision-making in the Courts of Appeals allows me to examine whether the characteristics that make individuals more susceptible to priming in the lab are also found in the field. A sizable experimental literature on judges suggests that judicial decision-making is affected by heuristics, e.g., anchoring, status quo bias, and availability (Mussweiler and Strack 2000, Englich et al. 2005; Guthrie et al. 2007; Englich and Soder 2009; Mussweiler and Englich 2005). However, these papers rely on vignette studies; they typically survey sitting judges at judicial conferences or mail surveys to judges. Other studies related to priming document the role of mood or arousal in decisionmaking such as soccer outcomes and stock returns (Edmans et al. 2007), cloudy weather and stock prices (Saunders Jr. 1993), weather and college decisions (Simonsohn 2010), terrorism and small claims adjudication (Shayo and Zussman 2011), and football outcomes and family violence (Card and Dahl 2011) ${ }^{32}$ There is also a political science literature that examines priming (Druckman 2004), particularly whether an increase in the prominence of an issue leads individuals to increase the weight given to it in regression analyses of self-reported voting preferences. However, the increase in issue weight could also be due to learning as individuals learn about parties' positions (Lenz 2009). My research design is completely different in scope and context, and I examine a decision-maker's revealed preferences in a high-stakes setting, if not for the judge, certainly for the litigants and the society whose laws are being affected.

2.2 U.S. Courts of Appeals The U.S. Courts of Appeals (also known as the Federal Appellate Courts or Circuit Courts) rest near the apex of the U.S. common law system, where judges apply - and make - the law. Decisions in current cases become precedent for future cases in the same court and in lower courts of the same jurisdiction. There are three layers of federal courts: U.S. District, Circuit, and Supreme Court. The 94 U.S. District Courts serve as the general trial courts, where a jury is drawn to decide issues of facts ${ }^{33}$ If a party appeals the decision, the case goes up to a Circuit Court, which decides issues of law; they take facts as given from District Courts and have no juries. Courts of Appeals judges affirm or reverse the District Court decision, and often remand (send the case back to the lower court) the case for the lower court to decide in a manner consistent with the law set out in the Circuit Court

\footnotetext{
${ }^{32}$ Several recent papers also analyze the effect of football games (Eren and Mocan 2016; Chen and Spamann 2014), voice (Chen et al. 2016b a; Chen et al.|2016e), and names (Chen and Prescott 2016) on judicial decisions. The best prediction models of judges' decisions also include extraneous factors (Barry et al. 2016, Chen and Eagel 2016; Chen et al. 2016d c).

${ }^{33}$ In some instances, District judges can decide issues of fact even without juries.
} 
decision.

The 12 U.S. Circuit Courts 34 only hear cases that present new legal issues (only 10-20\% of District Court opinions are appealed) ${ }^{35}$ Cases that reach the Courts of Appeal are the more challenging and controversial cases with the greatest likelihood to set new precedent. At this level, there are no juries or re-evaluations of evidence $\sqrt[36]{6}$ These courts focus on new interpretations or distinctions of preceding cases or statutes, which expand or contract the space in which an actor is allowed to act (Gennaioli and Shleifer 2007). A recent case rejecting a Texas abortion statute highlights the policy-making function of U.S. Federal Courts ${ }^{37}$ Only 2-3\% of Courts of Appeals cases are heard again in the U.S. Supreme Court, so the roughly 170 elite Circuit Court judges decide the vast majority of cases that create the law, constitute law school curricula, and impact economic outcomes.38

Courts of Appeals judges are appointed for life by the U.S. President and are confirmed by the Senate. They preside in one of 12 U.S. Circuits and are appointed to particular geographic locations within the Circuit (called duty stations), where they do most of their writing. Three judges, out of a pool of 8 to 40 judges in a Circuit, are randomly assigned by a staffing office to each case. Because Presidents from different parties appoint judges over time, the three-judge panels can be expected to be politically divided, bringing together judges with different points of view. Seventy percent of panels have both Republicans and Democrats. Judges disagree relatively rarely: only $8 \%$ of panels have dissents, and these dissents occur among both politically divided and unified panels ${ }^{39}$ A judge who disagrees with the verdict must write a dissent explaining why. A judge who agrees with the verdict (affirm or reverse) but disagrees with the reasoning is said to concur and must also write an opinion explaining why. Dissents and concurrences cannot be cited as binding precedent and are costly in terms

\footnotetext{
${ }^{34}$ There is also a Federal Circuit, particularly known for its decisions on patent law, and it is not the subject of this study.

${ }^{35}$ Technically, Courts of Appeals must hear any case that is properly appealed whether or not there is a "new legal issue" as it is conventionally understood, but stare decisis means that the Circuit Court is unlikely to rule against precedent.

${ }^{36}$ In some instances, Courts of Appeals judges can also decide issues of fact, but almost always defer to the District judge or to the jury in the District Court.

${ }^{37}$ When the Fifth Circuit Court in March 2014 upheld a Texas statute requiring doctors in abortion clinics to obtain admitting privileges at local hospitals, one-third of Texas abortion clinics shut down, leaving only 22. A subsequent Texas statute required abortion clinics to meet the building standards of ambulatory surgery centers; the statute was allowed by the Fifth Circuit in the Fall of 2014 while it considered an appeal to invalidate the new statute. If upheld, the new statute would reduce the number of Texas abortion clinics to fewer than 10. A 2015-2016 Supreme Court case rejected the Texas statute (Whole Woman's Health v. Hellerstedt, 136 S. Ct. 1001).

${ }^{38}$ For example, eminent domain jurisprudence impacts economic growth (Belloni et al. 2011). Courts of Appeals decisions also have a causal effect on District Courts decisions (Chen et al.|2014a) and norms (Chen and Yeh 2014a; Chen et al. 2016f: Chen and Lind 2014).

${ }^{39}$ To be sure, the low rate of dissent may be due to the absence of any arguably ideological issue in many cases.
} 
of time and collegiality (Epstein et al. 2011). I focus on dissents for the majority of the paper, though I show that concurrences also display an electoral cycle effect.

When judges appointed by Democrats and Republicans vote in different ways, one interpretation is that they differ because they simply follow different legal philosophies - rules or reasonings (Falk and Tirole 2016) - rather than demonstrating bias. ${ }^{40}$ This approach can be called deontological, in that the decisions are guided by moral principles. In contrast, a preference for a particular outcome is known as consequentialist. These two motivations are difficult to distinguish in observational data. ${ }^{41}$ A variety of professional norms and institutional mechanisms are designed to limit the influence of extrajudicial factors, such as bias. ${ }^{42}$ Federal judges are restricted from any semblance of impropriety. They are prohibited from receiving honoraria or compensation for speeches, appearances, articles, or service to a profit or non-profit organization ${ }^{43}$ They are also prohibited from making speeches for political organizations, publicly endorsing or opposing candidates, soliciting funds, making contributions, or attending or purchasing tickets for events sponsored by political organizations or candidates ${ }_{4}^{44}$ They are further prohibited from personally participating in any fundraising activities, soliciting funds for any organization, or using or permitting the use of the prestige of their judicial office for fundraising purposes $4^{45}$ There is no prior evidence that Federal judges are part of Presidential elections or any election (with the unusual exception of Bush v. Gore). By contrast, state judges serve the parallel state court system and handle issues of state rather than federal law. Studies have documented electoral cycles in state courts - where judges are often elected and, if appointed, rarely have life tenure - so the natural interpretation of these results is the incentives facing elected judges (Huber and Gordon 2004, Gordon and Huber 2007; Berdejó and Yuchtman 2013).

Random assignment in Courts of Appeals has been examined in other work. ${ }^{46}$ Surveys of the Courts of Appeals find that case assignment procedures fall into two categories. In some courts, two to three weeks before oral arguments, a computer program randomly assigns available

\footnotetext{
${ }^{40}$ For instance, a judge can derive from first principles an adherence to a strict interpretation of the Constitution, while not necessarily hewing to the preferences of a political party for a certain policy outcome.

${ }^{41}$ Recent experimental and quasi-experimental methods using revealed preference can detect and distinguish deontological from consequentialist motivations (Chen and Schonger 2013, 2015: Chen et al. 2015b; Chen 2004, 2011). In this context, to identify the consequentialist motivations, one would have to hold fix the judges' deontological motivations for different reasonings, which should be held fixed.

${ }^{42}$ The concern is that the real and perceived influence of extrajudicial factors may erode court legitimacy and legal compliance (Bénabou and Tirole 2012) and lead to situations where the application of justice causes non-compliance to the law (Chen 2013).

${ }^{43}$ Guide to Judiciary Policy Canon 4H. http://www.uscourts.gov/uscourts/rulesandpolicies/conduct/vol02ach02.pdf

${ }^{44}$ Guide to Judiciary Policy Canon 5.

${ }^{45}$ Guide to Judiciary Policy Canon 4C.

${ }^{46}$ Chen and Yeh 2014b c; Chen et al. 2014b.
} 
judges (occasionally including any visiting judges from other Circuits or District Courts and, in rare instances, other Federal judges) to panels that will hear cases. In other courts, the random assignment of panels occurs before the random assignment of cases: panels of judges are set up to hear cases on a yearly basis, randomly assigned together by a computer program and given dates for hearings. There are "holes" left in some of the panels by the program into which visiting judges are inserted. Occasionally, if a panel of judges has previously looked at a case, it will be sent back to them (for example, if it was remanded by the Supreme Court to resolve a particular issue). If a judge must recuse himself or herself, the case is taken off the calendar and placed back in the pool for reassignment. Chen and Sethi (2011) use data from Boyd et al. (2010) and Sunstein et al. (2006), who code 19 case characteristics as determined by the lower court for 415 gender-discrimination Circuit Court cases, and find that case characteristics are uncorrelated with judicial panel composition. Several papers examine whether the sequence of judges assigned to cases in each Circuit Court mimics a random process. I refer the reader to those papers for tests of random assignment and for some responses to a few papers that suggest the courts do not follow random assignment (Hall 2010). For example, the string of judges assigned to cases cannot be statistically distinguished from a random string. Berdejo and Chen (2016) report omnibus tests of whether case and litigant characteristics vary over the electoral cycle, and the current paper does the same for the caseloads and characteristics of judges authoring or sitting on the panel.

\section{Model}

I present a model that yields the following predictions:

1. Priming increases the probability of dissent, as agents put greater weight on the group identity norm (Akerlof and Kranton 2000) ${ }^{47}$

2. The more ideologically polarized the environment (during close elections or in the recent time period), the greater the priming effect, holding judges' ideological baseline constant. The opposite is true during reduced ideological polarization, such as during landslide elections or wartime. 48

3. Politically divided panels should experience greater changes as priming moves judges further apart.

\footnotetext{
${ }^{47}$ It may seem odd to offer a formal model of priming, but since this paper uses the revealed preference approach, I follow the usual modeling of decision-makers' behavior as if they maximized an objective function and refrain from interpreting the function literally (Friedman and Savage 1948). More recently, and particularly in behavioral economics, models are understood in terms of an as-is component. For example, Fehr and Schmidt (1999) say that their "theory is motivated by the psychological evidence on social comparison and loss aversion," i.e., by evidence beyond behavior, in particular, the inner state of mind of the decision-maker. The greater weight can be due to Type I or Type II thinking. The increase in weight can be thought of as an increase in group cohesion (Chen 2006, 2010, 2014).

${ }^{48}$ Polarization can be modeled as extreme value differences (Esteban and Ray 1994 ; Duclos et al. 2004$)$.
} 
4. The greater the number of primes, the stronger the overall priming effect (the weight on group identity increases).

5. Experienced individuals would be less affected if conscious processing overrides the usual or habitual response to priming (the weight does not increase as much).

6. Individuals with previous associative links could be more affected by priming if activated concepts spread faster (the weight increases more).

7. Minority judges on divided panels will be particularly likely to increase their dissents.

8. Cases on topics associated with the prime should experience greater changes (e.g., economic policy constitutes $70 \%$ of campaign ads during elections).

9. Dissents generally occur in cases with weak legal precedent, but priming increases dissents more for those with strong legal precedent (i.e., less likely to be cited by subsequent dissents, less likely to contribute to the development of legal innovations, and less likely to be reversed by the Supreme Court).

10. Dissents based on procedural quibbles should increase more when primed than the increase in substantive dissents.

3.1 Ideology Consider a panel of three judges and denote each judge by a number. Let $Q_{0, i}, i \in\{1,2,3\}$, be each judge's ideology baseline. Let each judge belong to social group $G$, such as Republican or Democrat, and let $Q_{G}$ denote the ideology of social group $G$. Let $Q_{0, i}$ and $Q_{G, i} \in \mathbb{R}$, where $\mathbb{R}^{-}$denotes political left and $\mathbb{R}^{+}$denotes political right. ${ }^{49}$

I assume that $\left|Q_{G, i}\right|>\left|Q_{0, i}\right|$; in other words, I assume that the ideology of the party is always more extreme than the baseline ideology of the judges. In the United States, judges are far more moderate than politicians who run for office, which is reflected in the fact that 2-1 decisions constitute only $8 \%$ of cases even though judges from both parties sit together $70 \%$ of the time. I assume that the ideologies of the two parties $Q_{G}$ are equidistant from 0 , and that the judge chooses the party that is closer to her baseline ideology $Q_{0, i}$. This implies that $Q_{0, i} \cdot Q_{G, i} \geq 0$; in other words, it implies that $Q_{0, i}$ and $Q_{G, i}$ always have the same sign.

Let $s_{i}$ be strength of each judge's affiliation with her social group; $s_{i} \in[0,1]$, where 0 represents non-affiliation and 1 represents complete affiliation. Finally, let each judge's actual ideology $Q_{i}$ be a weighted average of $Q_{0, i}$ and $Q_{G}$ :

$$
Q_{i}=\left(1-s_{i}\right) Q_{0, i}+s_{i} Q_{G}
$$

Assume $Q_{i}$ is common knowledge; in other words, assume that each judge knows the ideological positioning of the other judges sitting on the panel. Furthermore, assume that a necessary condition for dissenting is being the judge whose ideology is the most distant from

\footnotetext{
${ }^{49}$ Assume also that $Q_{G, i} \neq 0$.
} 
the ideologies of the other two judges. Mathematically, judge $i$ is the judge whose ideology is the most distant from the other two judges if:

$$
\left|Q_{i}-Q_{j}\right|+\left|Q_{i}-Q_{k}\right| \geq \max \left[\left|Q_{j}-Q_{i}\right|+\left|Q_{j}-Q_{k}\right|,\left|Q_{k}-Q_{i}\right|+\left|Q_{k}-Q_{j}\right|\right]
$$

The two judges who are ideologically closer to each other are more likely to agree and form a coalition. Therefore, the ideological center of the panel is located closer to the two judges with similar ideology and farther from the judge whose ideology is the most distant. Judges dissent from particular agreements; therefore, the judge most likely to dissent is the one who is furthest from the ideological center of the panel. From this point forward, I analyze the judge who is most likely to dissent and refer to her as the decision-maker (DM) and her ideology as $Q$.

3.2 Dissent Consider the DM's decision about whether to dissent when sitting on a three-judge panel and hearing a case. Suppose that if the DM dissents, then she pays a cost $c \in \mathbb{R}^{+}$, and if she does not dissent, she pays a cost $(Q-\bar{Q})^{2}$, where $Q$ is the DM's ideology as defined above and $\bar{Q}$ is the average ideology of the other two judges on the panel $\left(\bar{Q}=\frac{Q_{j}+Q_{k}}{2}\right)$. I assume that there is no bargaining between judges and that costs are quadratic for tractability. I assume that the DM sits with a random distribution of panel judges whose ideologies are drawn from a normal distribution. In particular, let $\bar{Q}=\frac{Q_{j}+Q_{k}}{2} \sim N(0,1)$.

I assume that the DM wants to minimize costs, so pays min $\left[c,(Q-\bar{Q})^{2}\right]$. Therefore, the DM acts as follows:

$$
\begin{cases}\text { Dissents } & \text { if }(Q-\bar{Q})^{2} \geq c \\ \text { Does not dissent } & \text { if }(Q-\bar{Q})^{2}<c\end{cases}
$$

Letting $\Phi$ denote the standard normal cumulative distribution function, I can calculate the probability that $(Q-\bar{Q})^{2} \geq c$.

$$
\begin{aligned}
& P\left[(Q-\bar{Q})^{2} \geq c\right]=P(Q-\bar{Q} \leq-\sqrt{c} \vee Q-\bar{Q} \geq \sqrt{c})=P(Q-\bar{Q} \leq-\sqrt{c})+P(Q-\bar{Q} \geq \sqrt{c})= \\
& =P(\bar{Q} \geq Q+\sqrt{c})+P(\bar{Q} \leq Q-\sqrt{c})=1-P(\bar{Q}<Q+\sqrt{c})+P(\bar{Q} \leq Q-\sqrt{c})=1-\Phi(Q+\sqrt{c})+\Phi(Q-
\end{aligned}
$$

Therefore, the DM dissents with probability:

$$
P(\text { Dissent })=1-\Phi(Q+\sqrt{c})+\Phi(Q-\sqrt{c})
$$

Substituting in $Q=(1-s) Q_{0}+s Q_{G}$, the DM dissents with probability:

$$
P(\text { Dissent })=1-\Phi\left((1-s) Q_{0}+s Q_{G}+\sqrt{c}\right)+\Phi\left((1-s) Q_{0}+s Q_{G}-\sqrt{c}\right)
$$




\subsection{Comparative Statistics}

3.3.1 Effect of $c$ on the probability of dissent First, I analyze the effect of a change in $c$ on the probability of dissenting.

$$
\begin{aligned}
& \frac{\partial P(\text { Dissent })}{\partial c}=-\phi\left((1-s) Q_{0}+s Q_{G}+\sqrt{c}\right) \frac{1}{2} c^{-\frac{1}{2}}-\phi\left((1-s) Q_{0}+s Q_{G}-\sqrt{c}\right) \frac{1}{2} c^{-\frac{1}{2}}= \\
& =-\frac{1}{2} c^{-\frac{1}{2}} \frac{1}{\sqrt{2 \pi}} e^{-\frac{1}{2}\left((1-s) Q_{0}+s Q_{G}+\sqrt{c}\right)^{2}}-\frac{1}{2} c^{-\frac{1}{2}} \frac{1}{\sqrt{2 \pi}} e^{-\frac{1}{2}\left((1-s) Q_{0}+s Q_{G}-\sqrt{c}\right)^{2}} \\
& \propto-\frac{1}{\sqrt{c}}\left[e^{-\frac{1}{2}\left((1-s) Q_{0}+s Q_{G}+\sqrt{c}\right)^{2}}+e^{-\frac{1}{2}\left((1-s) Q_{0}+s Q_{G}-\sqrt{c}\right)^{2}}\right]
\end{aligned}
$$

From the expression above, note that $\frac{\partial P(\text { Dissent })}{\partial c}$ is always negative; therefore, the probability of dissent decreases with $c$. The higher the cost of dissent, the less likely it is that the DM will dissent.

\subsubsection{Effect of group identity salience on the probability of dissent Next, I} examine whether the probability of dissent increases in $s$.

$$
\begin{aligned}
& \frac{\partial P(\text { Dissent })}{\partial s}=-\phi\left((1-s) Q_{0}+s Q_{G}+\sqrt{c}\right)\left(Q_{G}-Q_{0}\right)+\phi\left((1-s) Q_{0}+s Q_{G}-\sqrt{c}\right)\left(Q_{G}-Q_{0}\right)= \\
& \quad=-\left(Q_{G}-Q_{0}\right) \frac{1}{\sqrt{2 \pi}} e^{-\frac{1}{2}\left((1-s) Q_{0}+s Q_{G}+\sqrt{c}\right)^{2}}+\left(Q_{G}-Q_{0}\right) \frac{1}{\sqrt{2 \pi}} e^{-\frac{1}{2}\left((1-s) Q_{0}+s Q_{G}-\sqrt{c}\right)^{2}}= \\
& \quad=\left(Q_{G}-Q_{0}\right) \frac{1}{\sqrt{2 \pi}}\left[e^{-\frac{1}{2}\left((1-s) Q_{0}+s Q_{G}-\sqrt{c}\right)^{2}}-e^{-\frac{1}{2}\left((1-s) Q_{0}+s Q_{G}+\sqrt{c}\right)^{2}}\right]
\end{aligned}
$$

Rearranging the expression and substituting $Q$ for $(1-s) Q_{0}+s Q_{G}$ yields:

$$
\frac{\partial P(\text { Dissent })}{\partial s} \propto\left(Q_{G}-Q_{0}\right)\left(e^{\frac{1}{2}(Q+\sqrt{c})^{2}}-e^{\frac{1}{2}(Q-\sqrt{c})^{2}}\right)
$$

First, consider the case in which $Q_{G}>0$. I know from the assumptions that if $Q_{G}>0$, then $Q_{0}>0$ as well and that $Q_{G}>Q_{0}$. If $Q_{G}>0$ and $Q_{0}>0$, then $Q=(1-s) Q_{0}+$ $s Q_{G}>0$. Furthermore, if $Q>0$, then $(Q+\sqrt{c})^{2}>(Q-\sqrt{c})^{2}$. Finally, since the exponential function is a monotonic transformation, $e^{\frac{1}{2}(Q+\sqrt{c})^{2}}-e^{\frac{1}{2}(Q-\sqrt{c})^{2}}>0$. Therefore, if $Q_{G}>0$, then $\frac{\partial P(\text { Dissent })}{\partial s}>0$.

Now consider the case in which $Q_{G}<0$. I know from the assumptions that if $Q_{G}<0$, then $Q_{0}<0$ as well and that $Q_{G}<Q_{0}$. If $Q_{G}<0$ and $Q_{0}<0$, then $Q<0$. Furthermore, if $Q<0$, then $(Q+\sqrt{c})^{2}<(Q-\sqrt{c})^{2}$. Finally, again, since the exponential function is a monotonic transformation, $e^{\frac{1}{2}(Q+\sqrt{c})^{2}}-e^{\frac{1}{2}(Q-\sqrt{c})^{2}}<0$. Therefore, if $Q_{G}<0$, then $\frac{\partial P(\text { Dissent })}{\partial s}>0$.

Thus, no matter the sign of $Q$, given my assumptions, $\frac{\partial P(\text { Dissent })}{\partial s}>0$. In other words, 
priming always increases the probability of dissent.

\subsubsection{Effect of priming on the effect of $c$ on the probability of dissent Now,} I examine the kind of dissent that increases with priming. I investigate the dynamics of $\frac{\partial P(\text { Dissent })}{\partial s}$ with respect to $c . \frac{\partial\left(\frac{\partial P(\text { Dissent })}{\partial s}\right)}{\partial c}=$

$$
\frac{\left(Q_{G}-Q_{0}\right)\left(\frac{e^{-\frac{1}{2}\left(-\sqrt{c}+Q_{0}(1-s)+Q_{G} s\right)^{2}}\left(-\sqrt{c}+Q_{0}(1-s)+Q_{G} s\right)}{2 \sqrt{c}}+\frac{e^{-\frac{1}{2}\left(\sqrt{c}+Q_{0}(1-s)+Q_{G} s\right)^{2}}\left(\sqrt{c}+Q_{0}(1-s)+Q_{G} s\right)}{2 \sqrt{c}}\right)}{\sqrt{2 \pi}}
$$

Simplifying the expression and substituting $Q$ for $(1-s) Q_{0}+s Q_{G}$, I obtain:

$$
\frac{\partial\left(\frac{\partial P(\text { Dissent })}{\partial s}\right)}{\partial c}>0 \Longleftrightarrow\left(Q_{G}-Q_{0}\right)\left[e^{-\frac{1}{2}(Q-\sqrt{c})^{2}}(Q-\sqrt{c})+e^{-\frac{1}{2}(Q+\sqrt{c})^{2}}(Q+\sqrt{c})\right]>0
$$

First, consider the case in which $Q_{G}>0$. If $Q_{G}>0$, then I know by the assumptions that $Q_{0}>0, Q_{G}-Q_{0}>0$, and $Q>0$. Thus, $Q>\sqrt{c}$ is a sufficient condition for the effect of priming on the probability that dissent will increase costs. That is, if the prime is large enough relative to the cost of dissent, then high-cost dissents increase more than low-cost dissents.

Now consider the case in which $Q_{G}<0$. If $Q_{G}<0$, then I know by the assumptions that $Q_{0}<0, Q_{G}-Q_{0}<0$, and $Q<0$. But then, $-Q>\sqrt{c}$ is a sufficient condition for the effect of priming on the probability that dissent will increase costs.

In conclusion, regardless of the sign of $Q_{G},|Q|>\sqrt{c}$ is a sufficient condition for priming to increase high-cost dissents more than low-cost dissents.

\subsubsection{Effect of legal precedent on the effect of priming on the probability of} dissent I now model which kinds of cases have costly dissents. I model the strength of legal precedent through the cost of dissent - the cost of dissent not only depends on $c$, but also on the strength of legal precedent $\varepsilon$. I now assume that the DM choice to dissent depends on $\min \left\{\frac{c}{\varepsilon},(Q-\bar{Q})^{2}\right\}$, where $\varepsilon \sim \operatorname{Unif}(0,1)$. If the legal precedent is strong, then $\varepsilon \rightarrow 0$ and hence the net cost of dissent is high; if the legal precedent is weak, then $\varepsilon \rightarrow 1$ and hence the net cost of dissent is low. The parameters $c$ and $\varepsilon$ can also be thought of as capturing two different dimensions of the cost of dissent, with $c$ capturing the time and effort cost of writing a dissent, collegiality costs, and (negatively) the benefit of expressing a policy opinion and potentially influencing the law, while $\varepsilon$ captures legal precedent. Therefore, the DM acts as follows:

$$
\begin{cases}\text { Dissents } & \text { if }(Q-\bar{Q})^{2} \geq \frac{c}{\varepsilon} \\ \text { Does not dissent } & \text { if }(Q-\bar{Q})^{2}<\frac{c}{\varepsilon}\end{cases}
$$

I can calculate the probability of dissenting, which is the probability that $(Q-\bar{Q})^{2} \geq \frac{c}{\varepsilon}$. This 
can be rewritten as:

$$
\begin{aligned}
& P(\text { Dissent })=P\left[(Q-\bar{Q})^{2} \geq \frac{c}{\varepsilon}\right]=P\left[\varepsilon \geq \frac{c}{(Q-\bar{Q})^{2}}\right]=1-P\left[\varepsilon<\frac{c}{(Q-\bar{Q})^{2}}\right]= \\
& =1-\frac{c}{(Q-\bar{Q})^{2}}
\end{aligned}
$$

It can be seen that: $\frac{\partial P(\text { Dissent })}{\partial c}=-\frac{1}{(Q-\bar{Q})^{2}}<0, \frac{\partial P(\text { Dissent })}{\partial s}=2 c \frac{\left(Q_{G}-Q_{0}\right)}{[Q-\bar{Q}]^{3}}>0$, and $\frac{\partial\left(\frac{\partial P(\text { Dissent })}{\partial s}\right)}{\partial c}=$ $2 \frac{\left(Q_{G}-Q_{0}\right)}{[Q-\bar{Q}]^{3}}>0$. In words, dissents generally occur more for cases with weak legal precedent.

The dynamics of $\frac{\partial P(\text { Dissent })}{\partial s}$ with respect to $\varepsilon$ are similar to what was solved earlier. The effect of priming on the probability of dissent increases the lower $\varepsilon$ is, and priming increases dissents more for cases with strong legal precedent. If I consider citation by subsequent dissents as a sign of weak legal precedent, then judges will generally dissent on cases cited more often by subsequent dissents. But before elections, judges will increase their dissent on cases that are less likely to be cited by subsequent dissents (i.e., cases that are less likely to contribute to the development of legal innovations). Another measure of strength of legal precedent is whether the Supreme Court reverses the Courts of Appeals decision. Judges before elections will dissent on cases less likely to be reversed by the Supreme Court.

\subsubsection{Effect of divided panels on the effect of priming on the probability of dis-} sent The model also provides a framework to understand which panels will be more likely to increase dissents during priming. Suppose a judge is Republican. When she is dissenting, the three possible types of panels are DDR, DRR, and RRR. Since $\bar{Q}$ is closer to the judge on a politically unified panel (RRR), I should generally expect fewer dissents on a unified panel. With priming, the judge on a unified panel will move with the other two judges. ${ }^{50}$ This indicates that dissents should increase more for divided panels than for unified panels when there is priming. As for who dissents on a politically divided panel, when the judge is in the majority of a divided panel (DRR), she will be less likely to dissent than when she is in the minority of a divided panel (DDR). This is because she is further away from $\bar{Q}$ as a minority on a divided panel. With priming, she moves further away from $\bar{Q}$ when the other two judges are from the opposing party than when the other two judges are from both parties. Thus, before elections, divided panels will increase their dissents more and minority judges on

\footnotetext{
${ }^{50}$ Derivation is omitted.
} 
divided panels will be particularly likely to increase their dissents.

3.3.6 Type of dissent Suppose that there are two types of reasonings: substantive dissents and procedural quibbles. Reflections by sitting judges indicate that they resent criticism by dissenters, and that dissents make it more difficult for the dissenter to persuade panelists to join his or her majority opinions in subsequent cases (Epstein et al. 2011). The main benefits of dissenting are the influence of the dissenting opinion, the self-expressive character of the judicial opinion, and the enhanced reputation of the judge who writes the dissent. Justice Scalia observed that " $[\mathrm{w}]$ hen history demonstrates that one of the Court's decisions has been a truly horrendous mistake, it is comforting . . . to look back and realize that at least some of the justices saw the danger clearly and gave voice, often eloquent voices, to their concern." In my data, dissents based purely on the merits occur $40 \%$ of the time, while dissents based solely on procedure occur $9 \%$ of the time, which suggests that substantive dissents do have some value. If I assume that substantive dissents are less costly because of the higher benefit a DM receives from a potentially citable reasoning (e.g., by future dissents seeking to change legal precedent), and if I assume that procedural quibbles are more costly because they only corrode judicial collegiality, then I expect, in general, to see more dissents based on substantive issues than on procedural quibbles. But I would also expect dissents based on procedural quibbles to increase more than substantive dissents before elections.

3.4 Remarks To apply the model to the data, the model should be interpreted as evaluating the proportion of dissents taking into account all possible panel compositions. Theoretically, the comparative statics apply prior to the resolution of uncertainty 51 Second, I have assumed that $\bar{Q} \sim N(0,1)$, but ignored the possibility that the realization of $\bar{Q}$ is near $Q$, which would be inconsistent with the assumption that the judge considering dissenting is furthest away from the ideological center of the panel. Simulating three random draws of judges and calculating the probability of dissent as it varies by cost of dissent and priming yields the same comparative statics as found above (plotted in Appendix Figure A). The xaxis represents the cost of dissent, while the y-axis represents the probability of dissent. The color scale represents the degree of priming. The figure shows that the greatest proportion of high-cost dissents occurs with significant priming. The darkest shade of red indicates the greatest proportion of colors along the vertical space when the dissent cost is high; when the dissent cost is low, shades of blue represent a relatively larger share of the dissents. Among low-cost dissents, only a small proportion of these occur with significant priming (i.e., the darkest red constitutes only a small fraction of the vertical distance under the curve when the cost is close to 0 ).

\footnotetext{
${ }^{51}$ The model does not evaluate an individual case of priming of three judges at the extreme $Q_{G}$, but incorporates this instance as one of the possible panel compositions.
} 


\section{Estimation}

4.1 Data My analysis draws from several datasets:

1. Data on cases for 1925-2002 come from the U.S. Courts of Appeals Database Project 52 This database includes information on opinion-specific variables including the identity of judges sitting on each panel for a random sample of roughly $5 \%$ of cases 53

2. Biographical information for the judges in the database was obtained from the MultiUser Data Base on the Attributes of U.S. Appeals Court Judges 54

3. Data on subsequent outcomes in the Supreme Court, if any, come from the Shepardized Courts of Appeals database, which provides a link from the U.S. Courts of Appeals Database to the U.S. Supreme Court.

4. All significant dates for all cases filed in Federal Courts come from the Administrative Office of the U.S. Courts (AOC).

5. Election information comes from the CQ Voting and Elections Collection.55

6. The aggregate number of Presidential campaign advertisements in the 75 largest media markets for the 1996 election and daily Presidential campaign advertisements in all 210 media markets for the 2008 election come from the Wisconsin Ads project.56

7. Judicial ideology scores, a summary measure based on the voting patterns of the appointing President and home state Senators, come from the Judicial Common Space database (Epstein et al. 2007).

8. A shortlist of the 71 Courts of Appeals judges considered for the Supreme Court come from historical sources (Nemacheck 2007).

9. All 230,709 New York Times articles for 1900-2007 mentioning both "Republican" and "Democrat" in the same article come from ProQuest.

10. All newspaper articles mentioning Courts of Appeals decisions or their dissents for 19812013 come from NewsBank.

11. Data on all cases for $1950-2007$ come from OpenJurist 57 and contains dissents, Circuit, and date.

Using these datasets, I construct the variables for dissent, reason for dissent (i.e., procedural

\footnotetext{
${ }^{52}$ Documentation and data available at http://www.cas.sc.edu/poli/juri/appctdata.htm.

${ }^{53}$ The database was constructed in a stratified manner. A set number of cases was collected per Circuit-year. The data collection yielded approximately $5 \%$ of the total sample.

${ }^{54}$ Documentation and data available at http://www.cas.sc.edu/poli/juri/auburndata.htm.

${ }^{55}$ Table 30-1 Divided government, 1860-2006. (2008). In Guide to Congress, 6th ed. (Vol. 2). Washington: CQ Press. Retrieved May 12, 2010, from CQ Press Electronic Library, CQ Voting and Elections Collection, http://library.cqpress.com/elections/g2c6e2-973-36489-1842592. Document ID: g2c6e2-973-36489-1842592.

${ }^{56}$ The results are robust to using the 2004 election data, which is only available for the 100 largest media markets.

${ }^{57}$ http://openjurist.org
} 
or merit) 58 electoral proximity (linear or nonlinear - a full set of indicator variables for each quarter to the upcoming Presidential election), divided (panels having at least one Democrat and one Republican) ${ }^{59}$ legal issue ${ }^{60}$ opinion quality (overall citations and citations by subsequent dissents) ${ }^{61}$ judicial background (age, previous work experience, judicial experience), political environment (incumbent President, electoral vote count), decision valence (liberal = 1 , conservative $=-1$, and mixed or unable to $\operatorname{cod} 6=0) 63$ and treatment of lower court (affirm or reverse, reverse with remand, reverse without remand).

I restrict my analysis to cases decided by panels composed of three judges. My sample contains 18,686 decisions (56,058 votes) for the period 1925 to 2002 and 293,868 decisions for 1950 to 2007. Appendix Table A displays summary statistics. Results from 1925 to 2002 refer to the $5 \%$ sample, while results for 1950 to 2007 refer to the full sample. Overall, $8 \%$ of opinions from 1925 to 2002 have dissents. My data contains only published decisions. Prior to the 1970s, all decisions were published (Cleveland 2010), and my results are robust when I restrict the data to the pre-1970 time period (Table 11, Column 1). Some analyses requiring biographical information on judges use a reduced sample 64 I also present an analysis of dissents by time (elections, wartime, and winning margin in the Electoral College).

From 1950 to 2007, I obtain information on dates (97.5\%), circuits (94\%), and whether there was a dissenting opinion from OpenJurist. Not all dissents have dissenting opinions. $6.2 \%$ of opinions from 1950 to 2007 have dissents with dissenting opinions. My analyses of the OpenJurist data are limited, so my estimation specification varies slightly across outcome

\footnotetext{
${ }^{58}$ The Courts of Appeals Database codes whether the dissent addresses a procedural issue or addresses a merits issue.

${ }^{59}$ The database assigns each judge to one of the following parties: republican, democrat, liberal, conservatives and independents. I group liberal judges with Democratic judges, conservative judges with Republican judges and independent judges with the party of the appointing President.

${ }^{60}$ I use the following 1-digit classification: criminal, civil rights, constitutional (i.e., First Amendment, due process and privacy cases), labor relations, economic activity and regulation, and miscellaneous. I also use finer 2-digit categories of legal issues for robustness checks.

${ }^{61}$ I winsorize this variable at the $1 \%$ level, that is, I censor all observations outside of $1 \%$ to $1 \%$. Citation data come from Lexis's Shephards service. Newer cases have less time to accumulate citations, but controlling for year fixed effects addresses this censoring. Data is not available to distinguish whether the dissent or the majority opinion is being cited.

${ }^{62} \mathrm{My}$ results are robust to dropping the votes that are unable to be coded.

${ }^{63}$ The Courts of Appeals Database Project states that for most, but not all issue categories, these will correspond to notions of "liberal" and "conservative" that are commonly used in the public law literature. For example, decisions supporting the position of the defendant in a criminal procedure case, the plaintiff who asserts a violation of her First Amendment rights, and the Secretary of Labor who sues a corporation for violation of child labor regulations are all coded as "liberal."

${ }^{64}$ Missing data include elevation to the Supreme Court and previous service as Assistant U.S. Attorney or U.S. Attorney. The regressions that use this data have a reduction in sample size of $10 \%$. In addition, I exclude the votes by judges sitting on cases when they have less than 0 years of experience or greater than 35 years of experience, as these experience data are likely with error. These regressions have a $13 \%$ reduction in sample size.
} 
variables. Control variables that are missing from the OpenJurist data do not appear in the tables and I verify that the results in the $5 \%$ sample are similar when the controls unavailable in the OpenJurist data are removed from the $5 \%$ specification. The campaign ad data is missing in non-election years. Some analyses are grouped into three quarters before the election rather than one because the treatment effect is observed for all three quarters.

I link OpenJurist to the administrative data on case calendaring for 1971-2006. I achieve a high match of $75 \%$ (164,591 out of 218,683 cases) by successively attempting to match using different docket numbers, where the two-digit portions of the docket number are successively assigned to years preceding the publication date 65

4.2 Baseline Specification I begin with the basic specification. Consider the following specification for latent ideology $Q$, where electoral Proximity perturbs $s: 66_{6}^{66}$

$$
\left|Q_{c i t}\right|=\alpha_{1} \text { Proximity }_{t}+\alpha_{2} \mathbf{Z}_{c i t}+\omega_{c i t}
$$

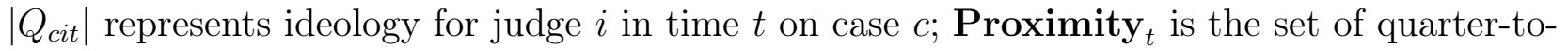
election fixed effects: ${ }^{67} \mathbf{Z}_{\text {cit }}$ contains dummy indicators for case characteristics, such as Circuit and year of the decision, season, ${ }^{68}$ the panel composition (whether it was politically divided) ${ }^{69}$ and legal issue (criminal, civil rights, constitutional, labor relations, and economic activity); and $\omega_{\text {cit }}$ is the error term.

Ideology $Q$ is latent, and as it becomes more extreme, the more likely I observe dissent. This motivates the following probit (reported in Appendix Table B) or linear probability (reported

\footnotetext{
${ }^{65}$ This matching method does not appear to result in bias, since the electoral cycle estimates are similar when analyzing only the matched sample. Table 9 Column 1 presents the analysis for the entire OpenJurist data and Table 9 Column 10 presents the analysis for the matched OpenJurist data. I also attempted to merge with the Appeals Court database, but I am only able to match 38\%. A large fraction of opinions did not record the two-digit portion of the docket number (the docket number is a two-digit year followed by a five-digit number), and the Appeals Court database assigned the two-digit year of publication. This match disproportionately reflects cases docketed in the same year as the publication date, which renders a sample bias towards cases that resolve quickly.

${ }^{66}$ For notational ease, I suppress the transpose on coefficients, which are actually vectors of coefficients.

${ }^{67}$ I compare to quarter 16, i.e., the quarter immediately following an election, which is the omitted quarter, so the interpretation is akin to a regression discontinuity design. I also compare the quarter-before-an-election to all other quarters, compare the three-quarters-before-an-election to all other quarters, and report models that employ a linear proximity to election. The disadvantage of the more parsimonious regressions are that the non-linearities are not as clearly delineated.

${ }^{68}$ Seasons are defined as winter (December-February), spring (March-May), summer (June-August), and fall (September-November). Appendix Table B shows that results are robust to alternative definitions of seasons, e.g., winter (January-March), spring (April-June), summer (July-September), and fall (October-December).

${ }^{69}$ Appendix Table B shows that results are robust to a full set of dummies for DDD, DDR, DRR, and RRR.
} 
in all other tables) specification:

$$
Y_{c i t}=\beta_{1} \text { Proximity }_{t}+\beta_{2}^{\prime} \mathbf{Z}_{c i t}+\eta_{c i t}
$$

My outcome of interest $Y_{\text {cit }}$ is an indicator variable equal to 1 if a dissent was filed on case $c$. I cluster standard errors at the quarter-year level ${ }^{70}$ Appendix Table B shows that the results are robust to different levels of clustering, for example at the Circuit level. Figure 4 uses randomization inference, where I rerun the basic specification with each quarter randomly assigned to a different quarter-to-election. Figure 4A is reproduced from Berdejo and Chen (2016) and shows that the true t-statistic of 4.01 lies far to the right of all the other simulated t-statistics.

To compare with the existing literature on electoral cycles, I estimate a specification that replaces Proximity $_{t}$ with a linear measure of time to election (Appendix Table C). I examine the presence of dissents at the case level and judges' dissent votes at the judge level. The latter allows me to exploit variation across states where the judges reside ${ }^{71}$ In the vote-level analysis, I also include judge fixed effects $\sqrt{7^{2}}$ even though they are not necessary for identification because cases are randomly assigned ${ }^{73}$ In some specifications, I replace Proximity Pith $_{t}$ the monthly increases in campaign advertisements in different states, since different states are important at different points in the Presidential election cycle. I use changes in campaign advertisements rather than levels to address the high degree of persistence in a serial measurement. ${ }^{74}$ This specification exploits additional variation across states and over time within

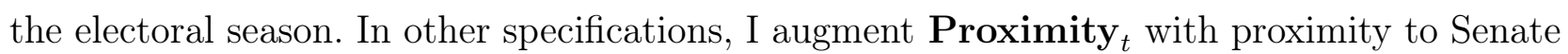
and gubernatorial (State Governor) elections, which also exploits variation across states and over time.

\subsection{Additional Specifications Berdejo and Chen (2016) conducted analysis with an-} other measure of ideology — voting valence - which can measure legal precedent and therefore legal outcomes 75 Voting valence and dissents are separate phenomena. For example, a panel with three Democrats may vote conservatively when its session is not held prior to an election

\footnotetext{
${ }^{70}$ Analyses of data collapsed to the quarter-year level do not cluster standard errors.

${ }^{71}$ Results are robust to state fixed effects.

${ }^{72}$ Analyses that have very few years of data exclude judge fixed effects.

${ }^{73}$ For the same reason, fixed effects for each unique combination of three judges are not necessary in the case-level analysis. The robustness to judge fixed effects and the fact that the results are more salient among judges with 1-2 years of experience mitigates the concern that the tiny number of judges that retire around the election are driving the results.

${ }^{74}$ Taking first-differences is standard in panel data analysis since the insights of Arellano-Bond.

${ }^{75}$ The liberal or conservative valence of each vote was hand-coded by other researchers collecting the 19252002 sample.
} 
because of a prevailing precedent; the panel may choose to vote liberally when the case is prior to an election; and it may make a unanimous decision in both situations. In this paper, I present a visualization of the results: the slope between predicted ideology and vote valence becomes steeper before the election.76

I assess heterogeneous treatment effects in various sub-samples (by Circuit, by appointing President, by legal issue, by state's electoral importance, by birth cohort, and by experience) ${ }^{77}$ Analyses are presented at the case level when examining the influence of environmental factors common to all judges on the panel, and at the vote level when examining the influence of judgespecific factors. If separate sub-samples are presented for ease of interpretation, the critical tests are also presented in interaction models. Identification comes from comparing judicial behavior just before elections (September and October) with just after elections (November), within legal case categories, within the set of divided or non-divided panels, within a Circuit, and within a year.

I use alternative dates $t$ for the case representing every available significant event in a case's history to assess when the mental decision to dissent may have occurred. I also conduct randomization inference (randomizing cases to other quarters) and present plots of whether case, litigant, or judge characteristics vary during the election, and compare all the t-statistics from the other regressions with the true t-statistic of dissent regression.78

Additional outcomes characterize the extent and nature of these electoral cycles. I replace $Y_{\text {cit }}$ with counts of news articles mentioning Republican and Democrat in the same article

\footnotetext{
${ }^{76}$ I reproduce the regression analyses for the reviewer. Valence $_{\text {cit }}$ represents voting valence where 1 indicates liberal; -1, conservative; and 0 , mixed. Priming social categories, such as party affiliation, shifts $Q^{*}$ to be closer to $Q_{G}$, and will cause voting to be more aligned along partisan lines. The specification is:
}

$$
\text { Valence }_{\text {cit }}=\gamma_{1} \text { Proximity }_{t}+\gamma_{2} \text { Proximity }_{t} * \text { Democrat }_{i}+\gamma_{3} \text { Democrat }_{i}+\gamma_{4} \mathbf{Z}_{c i t}+\nu_{c i t}
$$

Berdejo and Chen (2016) also run regressions restricting the sample to panels with three Democrats or three Republicans, which tests whether proximity to a Presidential election affects the establishment of precedent

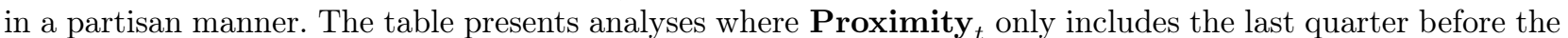
election. Figure 3A reproduces an analysis with the full set of quarters-to-election in Proximity (Berdejo and Chen 2016). The difference between the quarter-before-the-election and the quarter-after-the-election is the same as the difference between the quarter-before-the-election and all other quarters, suggesting that the judges are not significantly time-shifting their decisions on cases.

${ }^{77}$ Berdejo and Chen (2016) only analyzed heterogeneous effects by experience and by divided panel. These analyses are reproduced here for the reviewer.

${ }^{78} \mathrm{I}$ also reproduce for the reviewer, specifications with a prime for consensus - wartime - rather than dissensus. Dates come from the International Crisis Behavior Project. Michael Brecher \& Jonathan Wilkenfeld, International Crisis Behavior Project, 1918-2001 (ICPSR Study No. 9286, 2004), at http://www.icpsr.umich.edu. I consider the following wars: World War II: $12 / 7 / 41-8 / 14 / 45$; Korea: 6/27/50-7/27/53; Vietnam: 2/7/65-1/27/73; Gulf: 1/16/91-4/11/91; Afghanistan: 10/7/01-3/14/02. Berdejo and Chen (2016) interacted wartime with factors where I might expect larger effects such as whether the judge was inexperienced or sat in a divided panel. 
and counts of newsarticles that mention Courts of Appeals decisions and their dissents. I also replace $Y_{\text {cit }}$ with reason for dissent (procedure or merit based) and how the case treats the lower court decisions (affirmations, reversals, and remands).79 A remand indicates that the lower court has to re-evaluate the facts of the case (perhaps with a new trial) to be sure that the outcome conforms to the law set out by the Circuit Court. Sometimes Courts of Appeals will reverse a lower court decision but not remand; this requires the Circuit Court panel to be more specific about the outcome of the case, as it has not only decided on the law but also evaluated the facts and deemed it unnecessary for the lower court to do so, in effect determining the final outcome for the original plaintiff and defendant in the case. Reversals without remand might be interpreted as a measure of effort.

I further characterize the cases by examining how they are subsequently handled by the Supreme Court (whether an appeal was made, whether the Supreme Court decided to accept the appeal and hear the case, and whether the Supreme Court reversed), and how future judges treat the case (citation counts and citations by subsequent dissents):

$$
Y_{c t}=\zeta_{1} \text { LastQuarter }_{t}+\zeta_{2} \text { LastQuarter }_{t} * \text { Dissent }_{c t}+\zeta_{3} \text { Dissent }_{c t}+\zeta_{4}^{\prime} \mathbf{Z}_{c t}+\kappa_{c t}
$$

\section{Electoral Cycles in Judicial Behavior}

5.1 Dissents Dissents are most frequent in the quarters preceding a Presidential election. Figure 1A presents group means indicating a low of $6 \%$ to a high of $11 \%$ in the quarter before the election ${ }^{80}$ Table 1 shows that the increase before an election is robust and sharpens with the inclusion of fixed effects for panel composition, year, and Circuit (Column 1) as well as fixed effects for legal issue and season (Column 2). ${ }^{81}$ Columns 3-4 present the 1950-2007 sample. In the first set of results previously reported in Berdejo and Chen (2016), the rate of dissent is elevated in each of the three quarters before an election and is highest in the quarter immediately preceding an election. The effect size in the final quarter is equivalent to roughly a 100\% increase over the baseline average dissent rate in Columns 1-2. To benchmark the findings, panels with Republicans and Democrats are 1.5 percentage points more likely to have a dissent, but panels in the quarter before an election are 6.4 percentage points more likely to have a dissent. In the full sample, a noticeable increase also appears in the 9th quarter before a Presidential election (Columns 3-4); this time period is during the midterm elections, when U.S. House and some U.S. Senate seats are up for election. The $5 \%$ sample may be too

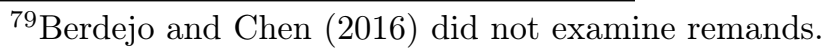

${ }^{80}$ All other figures are visualizations of regression coefficients with standard errors.

${ }^{81}$ The results are also robust to fixed effects for Circuit-year. Figure 1A and Table 1 Columns 1-2 are reproduced from Berdejo and Chen (2016) for the reviewer.
} 
small to observe significant midterm effects in dissents. However, when I distinguish by judge's state of residence, I find that U.S. Senate elections significantly increase dissents, as discussed in Section 6.1. Moreover, as Berdejo and Chen (2016) shows, midterm elections increase the correlation between the party of appointment and voting valence (i.e., whether the vote has a conservative or liberal ideology) even for panels with all three judges appointed by the same party. These midterm effects may be detectable in the $5 \%$ sample since judges may more strongly correlate their vote ideology with their party of appointment even when they do not dissent.

Dissents are elevated for ten months leading up to a Presidential election. Figures $1 \mathrm{~B}$ and $1 \mathrm{C}$ show that the electoral cycle remains statistically significant when broken down to the monthly level throughout the primary season. Before elections, the news cycle is amplified along partisan lines (Figure 2A shows that the number of New York Times articles mentioning both "Republican" and "Democrat" in the same article increases in the quarter before Presidential and - to a lesser extent-midterm elections and Figure 2B shows the same pattern at the monthly level - in particular, it shows that the number of articles is elevated up to ten months leading up to a Presidential election). Ten months before the Presidential election is roughly when the Presidential primaries begin in earnest, when each party chooses the candidate to compete in the general election and when candidates begin to target the median voter within their party.

Table 1 shows that the increase in dissent is roughly six times larger in the $5 \%$ sample. To investigate why, I calculate the proportion of published cases by Circuit-year in my full sample that is contained in the $5 \%$ Appeals Court Database. I use this fraction, which varies by Circuit and year, as sampling weights. The Appeals Court Database selects 15 cases per Circuit-year before 1960 and 30 cases per Circuit-year after 1960. When I rerun my analyses using these weights, the magnitude of the electoral cycle remains the same (Appendix Table B, Column 2) 82

Controlling for season does not change the results, and no seasonal pattern appears in the monthly figures. Accordingly, Appendix Table B (Column 3) reports that the results are robust to shifting seasonality controls by one month (January through March, etc.). The results are also robust to including dummy indicators for each type of panel composition (DDD, DDR, RRD, RRR) (Column 4) and using a probit specification (Column 5), where notably, the

\footnotetext{
${ }^{82}$ I speculate that the larger effects in the Appeals Court Database is due to the fact that the Appeals Court Database records dissents even if there are no opinions explaining the reasoning behind the dissent, and these types of dissents that are less reflective may be more likely to increase before Presidential elections. Alternatively, there could be measurement error in the way the $100 \%$ sample is coded, measurement error in the $5 \%$ sample, or error in randomization. However, randomization error in selection of cases probably does not explain the difference since the elevation in dissents begins in exactly the same month in Figures $1 \mathrm{~B}$ and $1 \mathrm{C}$.
} 
ordinary least squares coefficients are similar in magnitude to the marginal effects of the probit specification. The results are robust to clustering standard errors at the Circuit level (Column 6) and controlling for the presence of a concurrence (Column 7). Concurrences also display electoral cycles (Column 8); the effect size is equivalent to $50 \%$ of the baseline in the two quarters preceding the election. Appendix Table $\mathrm{C}$ shows that my results are robust to using a linear measure of the number of quarters to an election and to dropping one Circuit at a time. To ensure that the documented effects are not spurious, I rerun my basic specification with each quarter randomly assigned to a different "quarter-to-election" (a natural bootstrap with 200 draws); the $95 \%$ interval for t-statistics is between -2.62 and +2.62 . Figure $4 \mathrm{~A}$ shows that the true t-statistic of 4.01 lies far to the right of all the other simulated t-statistics. Several other simulated t-statistics are close to the true t-statistic, but this is to be expected, since the second and third quarters before an election also display significant increases in dissents.

To interpret magnitudes, the electoral cycles in dissent for these unelected judges with life tenure are larger and more statistically significant than electoral cycles for judges running for re-election. A recent study documents that within a sample of 276,119 decisions by Washington state judges, criminal sentencing lengths increase by $10 \%$ and deviations from criminal sentencing guidelines increase by $50 \%$ in the two quarters before a judicial election (Berdejó and Yuchtman 2013). Using the same specification, among my sample of 18,686 cases, the ratio of coefficients to standard errors is twice as large as in the Washington state sample. While these effects among unelected judges may seem large compared to the effects for elected judges, partisanship may be heightened in a group decision-making setting. A sizable share of dissents also appears attributable to electoral proximity, and this share is larger than the share of prison sentence lengths that has been attributed to electoral proximity. Using a linear measure of proximity to election, an estimated 5.9\% of total prison time for sentenced criminals is attributed to electoral proximity (Huber and Gordon 2004, Gordon and Huber 2007). In a linear model, an estimated $23 \% 83$ of all dissents is attributed to electoral proximity. ${ }^{84}$

\subsection{Voting Valence Voting valence measures a behavior that is different from dissents.} For example, if legal precedent dictates a liberal decision, a unified Republican panel should make a liberal vote. In the months leading up to a Presidential election, however, such a panel

\footnotetext{
${ }^{83}$ Each quarter-to-an-election reduces the dissent rate by $0.24 \%$ (Appendix Table C, Column 1). Since the average case is 7.5 quarters before the next election, multiplying 7.5 by $0.24 \%$ and dividing by the average dissent rate of $8 \%$ results in $23 \%$.

${ }^{84}$ The electoral cycles in Courts of Appeals decisions are also larger than political business cycles and robust to controlling for these cycles. The literature suggests that political business cycles are actually weak or nonexistent (Drazen 2001, Alesina et al. 1997; Alt and Chrystal 1983; McCallum 1978). I consider GDP, GDP growth, GNP, GNP growth, unemployment, and unemployment growth. Since the data is available by year and quarter, not quarter-before-an-election, my calculations are somewhat approximate (e.g., economic data one quarter before the Presidential election is a weighted average that puts one-third weight on economic data from the last quarter of the year and two-thirds weight on data from the third quarter).
} 
may instead cast a conservative vote. While there would be no dissent, an alignment between the decision and the judges' party of appointment could occur. Berdejo and Chen (2016) observed that the ideological difference between Democratic and Republican appointees doubles in magnitude in the quarter before an election. ${ }^{85}$ The positive coefficient in the first row of Table 2 shows that Democratic appointees typically cast more liberal votes than Republican appointees. The interpretation of the coefficient on political party in Column 4 is that Democratic appointees are 3.5 percentage points more likely than Republican appointees to cast a liberal vote than a neutral or conservative vote, but this difference doubles before an election. Column 1 shows that these estimates are robust to maintaining only a parsimonious set of controls (party of appointment, last quarter before the election, and their interaction), and Column 2 shows that the results are similar from a saturated model (all quarter-to-election

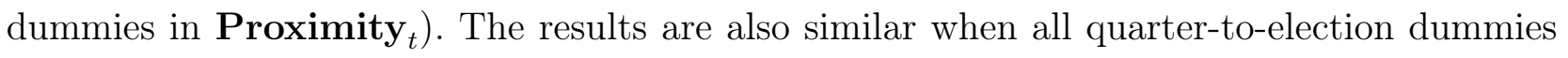
are interacted with the party of appointment (interaction coefficients presented in Figure $3 \mathrm{~A}$ ). This means that the ideological effect is similar whether comparing to the quarter after an election or to all other quarters.

Figure 3A shows that the partial correlation before the election is a little over 0.15 , which is roughly twice the average partial correlation and consistent with the results reported in Table 2A Columns 1-2. Like Figure 1C, Figure 3A reveals that midterm elections increase ideological polarization. The magnitude of the correlation between the party of appointment and voting valence increases by $100 \%$. The results are robust to ordered probit estimates for Columns 1-2 and probit estimates for Columns 3-4. The results are also robust to including judge fixed effects, though Table 2 excludes them for ease of interpretation of the coefficient on party of appointment. Comparing across columns, the point estimates in Columns 3 and 4 add up to the point estimates in Column 2, which suggests that judges switch their vote valence from conservative to liberal (and vice versa) rather than to or from a neutral or hard-to-code valence.

Figure 3B summarizes the role of ideology in a different manner. The flatter line represents the average voting valence by ideology score quintile when it is not the last quarter before a Presidential election, while the steeper line indicates the average voting valence by score quintile during the last quarter before an election. Judges to the left of the median score vote more liberally, while judges to the right of the median vote more conservatively. The most conservative quintile may be libertarian, which makes coding voting valence difficult (difficultto-code votes are coded as 0 ). These judges also become more conservative in the last quarter before a Presidential election. The vertical shift for judges in quintiles 2 and 3 represents a one-decile shift in more extreme ideology score while judges in quintiles 1,4 , and 5 shift by

\footnotetext{
${ }^{85}$ Results are reproduced for the reviewer.
} 
one-quintile in more extreme ideology score ${ }^{86}$ The one-decile shift is similar to that found by Hollibaugh Jr. (2011), who observes that the extent to which state supreme court judges in competitive partisan elections exhibit polarizing behavior in election years is equivalent to a shift of 8\%-10\% in ideology score. My magnitudes are similar and slightly larger, on average.

5.3 Legal Outcomes These electoral cycles affect legal precedent in both Circuit and District Courts. In Circuit Courts, Table 2, Panel B reports that decisions issued by unified panels (RRR or DDD) are more likely to be partisan in the months leading up to a Presidential election. Because case types should be evenly distributed in terms of panel composition and across the electoral cycle, one might expect there to be no correlation between the panel's party of appointment and the case outcome. Precedent dictating a liberal outcome should be just as likely to appear before Democratic panels as Republican panels. In the quarter before a Presidential election, however, unified panels are $125 \%$ more likely to issue partisan opinions. Like in Panel A, the fact that summing the point estimates on the interaction terms in Columns 3 and 4 yields the point estimate on the interaction term in Column 2 again suggests that judges switch to a conservative/liberal vote valence rather than to or from a neutral valence 87

The magnitudes are equivalent to the proportion of cases that judges estimate to be legally indeterminate. Columns 3 and 4 show that panels appointed by Democrats are 10 percentage points more likely to make liberal precedent than those appointed by Republicans in the last quarter before an election. Only $5-15 \%$ of cases are legally indeterminate according to judges' estimates (Edwards and Livermore 2008). On average, the party of appointment shifts the vote valence of the same number of cases as those that are deemed legally indeterminate. It is possible that vote valence may even shift in cases with little legal ambiguity. Interestingly, this pattern does not appear for decisions issued by divided panels; that is, RRD and DDR panels are not significantly more likely to issue decisions that reflect the party of appointment of the majority of the panel. The presence of a minority judge appears to be sufficient to prevent at least this kind of ideological effect on the setting of legal precedent.

Valence of precedent is one way that judges' decisions affect the development of law; the direct impact on the District Court decisions is another. In the even-numbered columns, Table 3 shows that Courts of Appeals judges are $10 \%$ less likely to affirm ${ }^{88}$ and $20 \%$ more likely to reverse lower court decisions in the quarter before an election. These results are statistically robust to specifications with different sets of controls, though the magnitudes vary. Notably, judges' decisions appear to be increasing in the type of reversal that requires

\footnotetext{
${ }^{86}$ To obtain the horizontal shift, I compare the vertical shift against the slope represented in quintiles 1-4.

${ }^{87}$ Table 2 and Table 3 Columns 2 and 4 are reproduced from Berdejo and Chen (2016) for the reviewer.

${ }^{88} 5.8$ percentage points out of the baseline of $56.8 \%$ translates to about $10 \%$.
} 
less work: reversals with remand increase by $25 \%$ before Presidential elections, while those without remand do not. Reversals without remand require Courts of Appeals judges to be specific about the outcome of the case - such that the District Court no longer needs to adjudicate it. The majority of reversals have remands, which means the lower court has to decide the case again. A loose analogy would be a referee report that writes the final article for the author (6.5\% of cases) as opposed to one that advises changes, but the author still needs to revise the opinion to follow the guidelines ( $20 \%$ of cases); the former requires more work than the latter.

\subsection{Type of Case Table 4 shows that dissents increase in a variety of legal categories ${ }^{89}$} Criminal cases and economic activity cases show more accentuated electoral cycles. When I break the sample into finer case categories, electoral cycles are greatest for federal criminal cases, commercial cases (e.g., contract breach), and property cases (e.g., eminent domain)..$^{90}$ Notably, legal areas - such as civil rights and due process - that are typically politically divisive (i.e., dissents are 4-10\% more likely in politically divided panels) do not increase in dissents before elections, whereas legal areas - like economic activity - which typically do not divide along political lines, do display electoral cycles.91 Seventy percent of campaign ads mention economic policy, while only $0.26 \%$ of ads mention civil rights or civil liberties. In addition, only economic activity cases display statistically significant changes in the quarter before the election regarding affirming, reversing, and remanding to the lower court. Thus, the consistency across behavioral measures aligns for the case category sharing the topics of campaign ads.

5.5 Check for Omitted Variables I examine the extent to which observable case and judge characteristics, caseload, and publication tendency vary over the election cycle. Figure 4B displays the t-statistics for significant changes in the quarter before Presidential elections for over 106 case and litigant characteristics coded in the database. I find no increase or decrease before Presidential elections on substantive legal issues. ${ }^{92}$ I also find no difference before elections in litigant type or strategy, including how many appellants or respondents were persons, businesses, public interest groups, or government actors, and so on. Along four procedural issues - issues in the "other" category - I find some evidence of an increase before a Presidential election. Accordingly, I include these issues as controls and find that the results

\footnotetext{
${ }^{89}$ The listed groupings are the 1-digit case category provided in the $5 \%$ sample.

${ }^{90}$ The $5 \%$ sample provides 2-digit legal case categories. I consider each 2-digit sub-category within the 1-digit category of criminal cases and economic activity.

${ }^{91}$ Criminal cases are 2.5 percentage points more likely to dissent with divided panels and also increase in dissents before elections.

${ }^{92}$ Legal issues include whether there was an issue of constitutionality; whether the court engaged in statutory interpretation; whether the issue involved state or local law, an executive order or administrative regulation, summary judgment, alternative dispute resolution, conflict of laws, international law, or agency discretion. Results from Berdejo and Chen (2016) are reproduced for the reviewer.
} 
are robust.

Figures $4 \mathrm{C}$ and $4 \mathrm{D}$ conduct the same randomization check for over 50 characteristics coded for the opinion writer and for the two other panelists. In all of these tests, the t-statistic of the dissent is far to the right of the other t-statistics. These results are consistent with related work finding that judges are randomly assigned to cases in each Circuit Court and suggests that the authors of opinions do not systematically change before an election 93

Appendix Table D shows that the type, caseload, and composition of the three-judge panels do not vary over the electoral cycle. The proportion of panels with judges from both parties is evenly distributed across the political cycle (Column 1). The number of cases in each of five broad legal categories does not systematically change in the quarter before Presidential elections (Columns 2-6). When I count up the monthly number of cases in each Circuit in the AOC, I also observe no electoral cycle in caseload (Column 7) 94

Appendix Table E, Column 5 shows that the proportion of cases published (all cases are decided but only some of them are published) does not significantly increase in the quarter before a Presidential election. This table comes from Berdejó (2012), who constructs and conducts extensive analysis of a database linking the universe of Ninth Circuit cases and the AOC beginning in 1990. The table also shows that there is no systematic difference in time spent between docket and judgment (Columns 6-8) or between hearing and judgment before an election (Columns 9-11). The monthly number of cases filed is also not systematically different before elections (Column 4).

In summary, my results suggest that the electoral cycles observed are unlikely to be due to judges having more or less time on their hands or differences in unobservable case types. The large variation in the length of time required to resolve a case seen in Appendix Table E also suggests that it would be very difficult for lower court appellants to time their filing (or for District Court judges to time their decision) so that Circuit decisions occur in a particular month.

\section{Priming}

6.1 Political Debate Some regions of the country are more likely to be saturated with political debate before Presidential elections. This can be seen in heightened levels of campaign ads in electorally pivotal states (contrast Figures 5A and 5B). These states' media markets are an attractive target for campaigns because swing states count heavily in the Presidential election, in which the winner of a plurality of a state's votes wins all of that state's electoral

\footnotetext{
${ }^{93}$ The decision of who authors an opinion is typically made several months before publication around the time of oral argument if there is an oral argument.

${ }^{94}$ The large standard errors in this Column is attributable to the tremendous variation in the monthly number of cases recorded in the AOC.
} 
votes. I begin this analysis by presenting simple splits of the data and then use more granular variation across states, across elections, and within elections.

Investigating the possibility that a judge's local environment drives electoral cycles was motivated by the observation that electoral cycles are larger in Circuits with electorally pivotal states and in Washington, D.C. For example, electoral cycles are more pronounced in the Sixth Circuit, which includes the historically electorally pivotal states of Ohio and Michigan-large states that have a heavy influence on the election outcome (Appendix Table C, Column 4). In fact, the average increase in dissents before a Presidential election is three times larger when a judge resides in the eight states ranked highest in electoral vote count (California, Texas, New York, Florida, Illinois, Pennsylvania, Ohio, and Michigan) ${ }^{95}$ and the District of Columbia (Table 6). Judges' increase in dissents in the quarter before a Presidential election is 2.9 percentage points compared to 0.8 percentage points for judges residing in other regions of the country. In another split of the data, the average increase in dissents before a Presidential election is 3-4 times larger when they reside in states likely to be electorally pivota ${ }^{96}$ and the District of Columbia; in the 1996 election, these states had almost 2,000 more campaign advertisements and 900 more negative campaign advertisements per media market. ${ }^{97}$ States in the top quartile of campaign ads display electoral cycles twice as large as other states.98

Rather than splitting the sample according to states that on average experience more political debate than others, I would like to know in which elections these states experience political debate. To do this, I interact the closeness of a state's popular vote count with its electoral vote count. I anticipate the environment to be more political in tight Presidential races, and I expect states with high electoral vote counts to be the target of more campaign ads. To make the regression easier to interpret, I construct a measure of election competitiveness, where positive values indicate a closer Presidential race ${ }^{99}$ Next, I construct a state-level measure of the impact of Presidential elections on dissents - the average dissent rate in the three quarters before the election. I construct a separate measure for each state and each election, and I use the number of votes as regression weights. Table 7 presents an analysis of the impact on the average dissent rate, conditioning on Circuit and election fixed effects and double-clustering standard errors at the election and state levels. I find that dissents are more

\footnotetext{
${ }^{95}$ I rank states according to electoral vote counts during the recent time period when polarization has been greatest.

${ }^{96}$ These states are Michigan, Ohio, Pennsylvania, Florida, and California, which since the 1970s have voted for different parties and been more political before elections.

${ }^{97}$ This difference is statistically significant at the $1 \%$ level.

${ }^{98}$ The results hold with or without judge fixed effects.

${ }^{99}$ I calculate the tightness of a state's popular vote by taking the negative of the absolute difference in the fraction of votes received by the Republican candidate and the Democratic candidate for the Presidential election, so this number ranges from 0 to 1 .
} 
elevated for judges residing in states with high electoral vote counts when their states have close Presidential races 100

To interpret the magnitude of 0.0024 in Table 7 , Column 1, going from a popular vote tightness of $5 \%$ to $0 \%$ (statistical tie) for a large state with 30 electoral votes would result in an increase of 0.4 percentage points in the dissent rate above the baseline of $2.4 \%$, roughly a $20 \%$ increase. The interaction term is statistically significant at the $5 \%$ level. Notably, it is the political environment of the dissenting judge, not the environment of the author of the majority opinion or the third panel member, that is significantly associated with dissent (contrast Column 1 with Columns 2 and 3). The absence of significant correlations in Columns 2 and 3 suggests that the dissenting judges' local environment is driving the electoral cycles.

To further investigate the importance of the local environment, I analyze U.S. Senate and gubernatorial elections. Senators have six-year terms, and only one-third of states have Senate elections at a time. Using this variation, I can separately distinguish the effects of U.S. Senate elections in Appendix Table 1. The effect of Senate elections is equivalent to half the effect of Presidential elections. In Column 4, which includes both elections, the coefficients become more similar. Note that this comparison omits the importance of the second and third quarters before an election that appears for the Presidential election but not the midterm elections in Table 1, Columns 3-4. In the full set of coefficients, the dummy for the 9th quarter-to-election is insignificant, which suggests a negligible role of U.S. House elections relative to U.S. Senate elections in explaining the midterm effect. The larger effect of U.S. Senate elections relative to House elections is consistent with the much larger amount of money spent on U.S. Senate elections. ${ }^{101}$ Elections for state governor are held every four years (only nine states hold them at the same time as Presidential elections). No effect is found before state governor elections. One reason for this may be that spending for a U.S. Senate election is roughly $50 \%$ more than spending for a gubernatorial election. ${ }^{102}$

6.2 Timing Elevated dissents appear for many months prior to an election in Figures $1 \mathrm{~B}$ and $1 \mathrm{C}$ throughout the primary season. Primaries have always played an important role in Presidential elections. Before the modern era, party leaders would select candidates for the Presidential election. The alternative would have been a general election with many candidates, which could result in unintentionally electing someone who would not otherwise win. Primaries ameliorated this problem by narrowing the field to a few candidates. During the primaries, candidates compete against other candidates from the same party to be the nominee. Since the

\footnotetext{
${ }^{100}$ Results are robust to alternative specifications.

${ }^{101}$ https://www.opensecrets.org/overview/topraces.php

${ }^{102}$ According to a report by Center for Public Integrity Analysis, spending in 36 Governors' races was almost the same as the spending in 36 Senator races (http://time.com/3558262/governors-elections-spending/). However, there are roughly 12 Governor races per year and roughly 34 Senator races per two years.
} 
primary season involves choosing a candidate to represent a particular party, candidates target more extreme wings of their parties. The median voter within a party is more extreme than the median voter in the general election. Accordingly, candidates are more extreme during the primaries but move towards the middle after winning the primary (Brady et al. 2007). The Presidential primaries thus entail salient ideological differences even between voters for the same party (Goldberg 2016) ${ }^{103}$ Moreover, different states hold primary elections at different times in the season, and momentum is very important. The primary season ends around the third month before the election, and parties generally coalesce around the candidate who will represent them in the general election. The nominating conventions can be viewed as a rally and call for party unity.

Many states also use a proportional system to allocate delegates during the primaries, whereas all states use a plurality system to allocate delegates for the general election. The plurality system in the general election is well known to make swing states more important. The shift in how delegates are allocated, along with the importance of momentum during the primaries and the elevated focus on activists within the party, can heighten the relative importance of electorally non-pivotal states, which decreases precipitously after the nominating conventions ${ }^{104}$ I can verify this change in states' relative importance by observing that campaign advertisements only double from their pre-nominating convention peak for non-pivotal states; they increase fivefold in pivotal states (Figures $5 \mathrm{~A}$ and $5 \mathrm{~B}$ ). Corresponding to these differences in local levels of political debate, dissents begin declining three months before Presidential elections in electorally non-pivotal states but remain elevated in pivotal states (Figures 6A and 6B) ${ }^{105}$

I expect changes in judicial behavior to coincide closely to changes in the political environment. Priming effects have only been documented one week after the stimulus (Tulving et al. 1982; Ostergaard 1994; Hassin et al. 2007). Yet few studies evaluate many experimental stimuli over a long period, so the exact timing of the response and decay is not known from laboratory studies. Table 8 exploits variation in the timing and magnitude of campaign advertisements in judges' states of residence. It shows that judges' dissent rates coincide with increases in campaign advertisements in the state of their duty station. The importance of different states at different points in time during the 2008 election cycle predicts the monthly stimulus in

\footnotetext{
${ }^{103}$ The primaries may bring out ideological perfectionists who perceive concave costs to voting for candidates they disagree with politically or morally (Osborne 1995, Chen et al. 2015a).

${ }^{104}$ One explanation for why Barack Obama won the Democratic nomination over Hillary Clinton in 2008 is that he focused more on the smaller states while she focused only on the big states during the primary season. She won states like New York, California, Texas, Pennsylvania, and Florida, while he won many of the small states in the Mountain West and South. In particular, his efforts rendered large vote margins in small caucuses.

${ }^{105}$ Since there are more judges in non-pivotal states than in pivotal states, there is an overall decline.
} 
different states for prior elections. Note that I only have daily campaign advertisement data for the 2008 election, so I assign the monthly increase in campaign advertisements for some month before November 2008 to the same month before the November in other elections. The identification assumption is similar to the assumption used in a large economics literature that employs historical instrumental variables to cross-sectionally identify the causal effects of institutional conditions over many years. In my case, the identification assumption is that the timing of different states' primaries in a particular month in the 2008 season is uncorrelated with non-election factors that influence the dissent rate of a judge in that state and month in previous elections. I am effectively estimating the reduced form of a two-stage least squares specification, where the first stage is whether the timing and degree to which different states' primaries elevate that state's importance in different months before the election are similar across elections (the calendar months in which states vote over the primary season is fairly stable across elections). To interpret the magnitudes, an increase of 10,000 campaign advertisements in the prior month increases the dissent rate by 0.5 percentage points by the judge in that state (Column 1). The effect is significant at the $5 \%$ level; it is robust, and increases, when adding lags and leads. Similar effects are found with the inclusion of fixed effects for Circuit, year, and judge (Columns 4-5) ${ }^{106}$

6.3 Summary Justice In order for the local temporal environment of the dissenting judge to explain the timing of elevated dissents before an election, it must be the case that dissents are issued around the same time as the "treatment event." Administrative data on every important milestone of a Federal Court case's development suggests that the exact time at which a judge makes the mental decision to dissent may be shortly before publishing an opinion. I merge the Appeals Court database with the Administrative Office of the U.S. Courts database to obtain docketing date, the date of filing in District Courts, the date the notice of appeal was filed, the date the original notice of the brief was issued, the date of the last brief filing, the date the appeal was submitted on the merits, and the date the appeal was orally argued (this occurs, on average, two or three months before the publication date). I substitute the publication date with dates for any of seven earlier milestones of the case. If electoral cycles correspond to these "placebo" dates, such as the date of filing, this could suggest that the effect of elections occurs on the filing date (e.g., litigants file more controversial cases before elections). If electoral cycles appear for the date of the oral argument, this could suggest that the effect of elections occurs when the case is heard rather than when it is published.

I find no electoral cycles for those alternative dates (Table 9). Column 1 repeats the main specification but using the full sample, while Column 10 repeats the analysis but restricts to

\footnotetext{
${ }^{106}$ The inclusion of quarter-to-election fixed effects reduces the statistical significance, but the point estimates in Column 6 are similar to the point estimates in the other columns.
} 
the data that successfully merges into the AOC database to ensure that the main inferences are stable after the merge. Columns 2 through 9 use alternative dates in the AOC data. This null finding suggests that judges make the mental decision to dissent very near the publication date rather than near the time of the oral arguments.

Thus, the conventional view that judges convene right after a hearing to decide how they will vote, and whether someone will write a dissent, seems incomplete. In at least some cases, judges may decide at the last minute to dissent (or not), and this last-minute decision could be less likely to occur before an election. I take this as suggestive evidence that the decision about whether to dissent may occur quite late in the opinion-writing process. The fact that concurrences also display electoral cycles corroborates the view that these decisions are made very late, since they occur after the first draft of the majority opinion has been circulated.

If decisions are made very late, do the reasonings reflect more hasty decisions? Table 5 shows that before elections, judges dissent more on issues related to procedure than merit. On average, $9 \%$ of dissents mention procedural (but not merit) reasons for the dissent. In the quarter immediately before an election, this motivation increases by 10 percentage points, a doubling of the baseline, when compared to all other quarters. However, the database only codes the reasoning for dissent between 1997-2002. For the entire 1925-2002 time period, I find that only four case characteristics significantly varied with the electoral cycle: (1) whether there were "other issues" related to juries, (2) whether some "other evidence" besides confession and evidence obtained through search and seizure was inadmissible, (3) whether the attorneys' fees favored the appellant, and (4) whether there was some "other issue" of civil law. About $1-6 \%$ of the cases mention these issues. What is notable about all four of these issues is that they are highly discretionary (e.g., attorneys' fees are only to be awarded to the appellant in exceptional circumstances (Rolax v. Atlantic C. L. R. Co. 186 F2d 473)). This is consistent with judges, consciously or subconsciously, looking for easier, less direct reasons to dissent before elections. If judges do appear to be dissenting based on procedural issues, in particular on miscellaneous procedural issues, these decisions could happen at the last minute.

\section{Identity}

7.1 Latent Partisan Identities Campaign messages can activate latent partisan identities (Ansolabehere and Iyengar 1997), so if judges have partisan identities, priming may influence their perception of cases brought before them. To investigate this hypothesis, I show that a judge's ideology score plays a role in behavioral changes before elections. Rows 1-4 of Figure $7 \mathrm{~A}$ report group means. ${ }^{107}$ A large proportion of the increase in dissents comes from

\footnotetext{
${ }^{107}$ The first four rows are presented as case-level dissents in Berdejo and Chen (2016) and as judge-level dissents here.
} 
ideologically divided panels. For unified panels, the dissent vote rate is $1.9 \%$ (increasing to $2.2 \%$ before Presidential elections), while for divided panels the dissent vote rate is $2.4 \%$ (increasing to $3.9 \%$ before Presidential elections). Among divided panels, a significant proportion of these increases come from minority judges ( $\mathrm{D}$ on DRR panels or $\mathrm{R}$ on RDD panels), who almost double their rate of dissent (Rows 6 and 8), while majority judges increase their dissent rate by $50 \%$ (Rows 5 and 7 ). 108

The increase in dissent by one of the two majority judges may seem counter-intuitive. However, I observe that the increase in dissent is largely due to the majority judge with the more extreme ideology score (ranked first or third when the ideology scores are sorted from left to right) (Rows 1-4 of Figure 7B). Finally, Rows 5 and 7 show that when the minority judges share the same ideology score as a judge in the political majority, this minority judge triples the dissent rate in the quarter before a Presidential election from a non-election dissent rate that is lower than average. Notably, in the quarter before a Presidential election, they dissent at the same rate as those with a different ideology score (Row 6). These results suggest that the increase in dissents does not simply reflect a shift in mood, which would affect all judges.

7.2 Type of Election Partisan identities are more likely to be activated in close Presidential elections. Table 10 Panel A shows that close elections - defined as the winning party achieving less than $55 \%$ of the Electoral College vote-increase the rate of dissent during the contested period before an election by $200 \%$ (Column 1). Landslide elections - when the winning party achieves more than $95 \%$ of the Electoral College vote - reduce the increase in the rate of dissent before an election by $80 \%$ (Column 2). Wartime elections are unifying; they reduce the dissent rate by 0.6 percentage points (Column 3). This analysis is limited by the handful of landslide and wartime elections. In Panel B, I use the universe of cases from 1950 to 2007 and construct circuit-by-election electoral dissent spikes by taking the difference between the dissent rate in the three quarters before an election and the dissent rate in the three quarters after an election. As the Electoral College percent drops from 100 to 50, the dissent spike increases by 1.0 percentage points, roughly 1.5 times the average dissent spike, which is 0.7 percentage points. This finding is consistent with the finding that dissents are elevated in states with many electoral votes when the Presidential election is close in that state (Table 7).

7.3 Political Environment Many studies document that politics in the United States has become more polarized (McCarty et al. 2006, Bernhard et al. 2012, Gentzkow et al. 2015). Cross (2003) finds evidence that the Reagan and George W. Bush judicial appointees have

\footnotetext{
${ }^{108}$ Analyses of the vote valence also confirm that when judges dissent, their vote is politically liberal if appointed by Democrat and conservative if appointed by Republican.
} 
been the most ideological of any judicial appointees since the late 1940s. Consistent with their findings, Appendix Table F shows that Reagan, George W. Bush, and Clinton appointees are the most likely to display electoral cycles. The increase in the dissent rate three quarters before a Presidential election has been growing sharply: close to 0 and statistically insignificant for every appointee before Reagan; then increasing to $2 \%, 5 \%$, and $5 \%$ for the last three sets of appointees; and statistically significant at the 1\%, 1\%, and $10 \%$ levels, respectively.

Figure 8 displays the moving average correlation between last quarter and judicial behavior. In Figure 8A, each year on the $\mathrm{x}$-axis represents the center point for four elections. Electoral cycles in dissents were quite small during the 1940s, and increase around 1960. After 1975, fourelection moving averages of the electoral cycle become statistically significant. Accordingly, I divide the cases into two groups, those decided on or prior to December 31, 1975, and those decided afterwards. The electoral cycle before 1975 is quite strong and statistically significant, but it is roughly $100 \%$ larger in the recent time period (Table 11). This finding is robust to controls for a judge's birth cohort. For example, if I control for whether the vote was cast by a judge born after the 1940s (roughly $15 \%$ of the sample), the result suggests that judges' susceptibility to political priming is not due to cohort-specific experience. Rather, all judges, regardless of the year of their, become more primeable in the recent time period (Column 2).

Figure $8 \mathrm{~B}$ presents further evidence to support the polarization interpretation of these electoral cycles. Changes in dissent cycles over time coincide with changes in partisan voting cycles 109 Regression analyses including controls indicate that the influence of party of appointment on voting valence is $90 \%$ larger since 1975 (Column 3) ${ }^{110}$ and robust to controls for birth cohort (Column 4) 111 Figure $8 \mathrm{C}$ replicates the increase in dissent cycles over time in the full sample. These results indicate that the judiciary is more polarized now than even at the very beginning of the dataset, as early as 1934, when President Roosevelt attempted to fill the judiciary with judges who would vote for his New Deal programs. Chen (2016) presents additional evidence of growing polarization in the evolution of the judiciary.

\subsection{Previous Experience I now turn to the role of past experience to further investi-} gate whether the characteristics that make individuals more susceptible to priming in the lab are found in the field. Experimental research has found that inexperience magnifies priming effects (Krosnick and Kinder 1990). Table 12 re-estimates my basic specification for subsamples of judges grouped by the number of years they have served as Circuit judges. Overall, judges are 1.7 percentage points more likely to cast a dissenting vote before a Presidential election (Row 1). For judges with 1 or 2 years of experience, the magnitude of this effect is a

\footnotetext{
${ }^{109}$ Each year on the $\mathrm{x}$-axis represents the mid-point in a 10-year moving average correlation.

${ }^{110}$ The results hold with or without judge fixed effects.

${ }^{111}$ Younger judges are also more polarized, as indicated by the larger coefficient on the interaction with birth cohort than on the interaction with the post-1975 dummy.
} 
considerably larger 3.4 percentage points. ${ }^{112}$ The point estimates are positive and sometimes statistically significant for other experience groups, e.g., 7-8 years of experience. The fact that inexperienced judges are more likely to dissent before a Presidential election is consistent with judges taking awhile to develop the strong professional, conscious commitments that would otherwise control the influence of unconscious bias (Rachlinski et al. 2009). 113

Certain types of experience can strengthen the priming mechanism. Lab research suggests that activation will only spread if an associative link has been formed, and the stronger the association the wider and faster the activation will spread (Bargh and Chartrand 2000, Kimball 2005). A natural candidate to use to examine the associative link is former federal prosecutors, since this role involves advocating on behalf of the government in Federal Courts. Prosecutors have tremendous amounts of power in the courtroom and beyond: they can choose whether to press charges, and how harshly or how leniently to pursue cases; when federal laws issue guidelines, there is no power of enforcement except through prosecutors, and they act under very little regulation. The fact that they are politically appointed makes their roles more political, as they may be under pressure from elected officials to prioritize certain types of criminal enforcement (Lantigua-Williams 2016). U.S Attorneys are the top-ranked tier of prosecutors; they are appointed by the President and confirmed by the Senate, and they play a large role in setting the law enforcement priorities for their jurisdiction. Significant political motivation has been documented in the behavior of federal prosecutors (Nyhan and Rehavi 2015). They can choose to enforce different aspects of federal law (or not); they can also choose to pursue litigation in specific types of criminal categories - health care fraud, obscenity, immigration cases - the choice to enforce and litigate is a political choice (Perry Jr. 1998). Federal prosecutors have displayed behavior reflecting party politics in federal public corruption prosecutions Gordon 2009), and they often run for higher office (Engstrom 1971) ${ }^{114}$

The role of Assistant U.S. Attorneys has also become increasingly political. During the study period, judges came of age at a time when even Assistant U.S. Attorneys would leave with a change in Presidential administration, and $23 \%$ of U.S. Attorneys eventually became Federal judges (Lochner 2002). Table 13 shows that judges who were previous U.S. Attorneys or Assistant U.S. Attorneys are more likely to display electoral cycles. This effect is statis-

\footnotetext{
${ }^{112}$ The results hold with or without judge fixed effects. Table 12 except the last two rows are reproduced from Berdejo and Chen (2016) for the reviewer.

${ }^{113}$ The inference is not simply due to sample size. Judges with exactly 1 or exactly 2 years of experience also significantly increase their dissents before elections. However, while these effects are larger for those with less experience, they are not significantly larger. Judges with more experience also display significant increases before the election.

${ }^{114}$ For a well-known contemporary example, Rudy Giuliani was a U.S. Attorney for the Southern District of New York before becoming Mayor of New York City and ran for U.S. President in 2008.
} 
tically significant at the $5 \%$ level with the inclusion of judge fixed effects (Column 10). ${ }^{115}$ Parsimonious specifications that exclude all controls and keep only previous federal prosecution experience, last quarter, and their interaction reveal the same relationship in the probit specification. Notably, this is the only experience that remains statistically significant when other controls are included. It is stronger, for example, than the influence of divided panels and being a minority judge on a divided panel. It is possible that individuals with other political experience are also primed more than other individuals, but either they are few in number or their behavior does not vary significantly from other judges before the election.

7.5 Wartime If elections prime partisan identities, what about wartime, which can prime national identity? Figure 9 shows that dissents decrease during wars, the official dates of which are indicated by the vertical lines. In regressions, I break out the wartime results by war to match the visualization, and confirm that the results are not driven by an outlier war ${ }^{116}$ This result is robust to regression controls and sample (Table 14). The decrease is somewhat stronger during the first half of a war, which is what one might expect if wars eventually become more politically divisive. Notably, the decrease in dissent rates during wartime is almost entirely due to attributed to divided panels (Column 2) and inexperience (Column 4) ${ }^{117}$ The coefficient on the non-interacted term, war, is insignificant, while the coefficients on the interaction terms are large and negative. Since $70 \%$ of panels are divided, the average effect of wartime is also negative. ${ }^{118}$ Moreover, divided panels, which are usually 2 percentage points more likely to dissent, are 0.6 percentage points less likely to dissent during war. In sum, judges who are less experienced and sitting on divided panels are both more likely to dissent before Presidential elections and more likely to not dissent during wartime.

During wartime, judges are also more likely to affirm (and less likely to reverse) lower court decisions (Columns 5-6); these effects are statistically significant at the $1 \%$ level. Notably, the influence of war is 2 to 3 times the influence of a divided panel on affirmation and reversals. The effect of wartime is about half the size of the effect of electoral proximity in absolute magnitude. My results are robust to using the full OpenJurist sample (Column 7) and to randomization inference, where I randomly assign the dates of the case to another date (Figure $9)$. I also conduct randomization checks of judicial and case characteristics ${ }^{119}$

\footnotetext{
${ }^{115}$ Column 9 indicates that the results are weaker without judge fixed effects.

${ }^{116}$ Figure 9 is reproduced from Berdejo and Chen (2016) for the reviewer. Only the aggregate results for the $5 \%$ sample are reported in Berdejo and Chen (2016). The effects do seem to differ across different wars and why that occurs is an open question.

${ }^{117}$ I display results using 10 years of experience as the cut-off, but the finding is robust to other experience thresholds.

${ }^{118}$ I can see this by observing: $0.7 *(-0.026+0.01) * 0.3(0.01)<0$.

${ }^{119}$ Some characteristics are statistically significant. Accordingly, I check and confirm the wartime results are robust to controlling for these characteristics. Berdejo and Chen (2016) reported Table 14 Columns 2, 3, 5, and 6 (reproduced for the reviewer), but not robustness checks or disaggregation by the different war.
} 


\section{Development of Law}

I have detailed the impact of electoral cycles on the development of law in the U.S. Courts of Appeals and District Courts (in the vote valence of unified panels and the reversal of lower court decisions). I now turn to the impact in the U.S. Supreme Court and the subsequent citation patterns. Table 5 examines how dissents before Presidential elections are subsequently treated by the courts. Note that the correlations I report can reflect either selection effects (judges choose to dissent on different types of cases) or treatment effects (the election itself affects the subsequent treatment by courts). I first examine citations by subsequent dissents, which suggest legal ambiguity or legal innovation when dissenting opinions seek to follow a new precedent ${ }^{120}$ Cases with dissents are cited more often in subsequent opinions and dissents. Opinions with dissents written in the quarter preceding an election, however, are cited less often by subsequent dissents than similar cases decided in other quarters ${ }^{121}$ This reduction is equivalent to $70 \%$ of the typical association between dissents and citations by subsequent dissents. These results are consistent with judges dissenting on less controversial cases before elections. 122

Panel B reports how cases with dissents are subsequently treated by the U.S. Supreme Court. Unlike Courts of Appeals, which must hear all appeals from District Courts, the Supreme Court can choose whether to take the case. Only 2-3\% of cases are heard in the Supreme Court, but cases with dissents are two to three times more likely to be heard. This increase is the same regardless of whether the dissent occurs before an election. Dissents before elections thus appear to crowd the court docket, which can have a long-run impact. Crowding the court docket can be welfare-decreasing, as it has been documented to decrease the attention judges are able to spend on cases, and change their decisions on unrelated cases (Huang 2011) 23

Does the Supreme Court recognize that cases with dissents before elections may be different, potentially less controversial, and use more discretionary reasons for the dissent? The motivation for this test is analogous to one in experimental economics, according to which if a player recognizes the bias in a second mover and accounts for it (e.g., by issuing a different ultimatum game offer), then the presence of the bias is supported. Columns 3 and 4 suggest that the Supreme Court partially corrects for the behavioral anomalies due to elections. I link the 607 appealed (out of 18,686) Courts of Appeals cases to their outcomes in the Supreme

\footnotetext{
${ }^{120}$ Similar results are found with log citation counts.

${ }^{121}$ Year fixed effects ensure that the results are not simply due to censoring, for example, when newer dissents have had less time to accumulate citations.

${ }^{122}$ The citation data does not distinguish between citation to the majority opinion or the citation to the dissent.

${ }^{123}$ I also find no significant differences in the rate at which cases are reheard en banc (i.e., by the entire court), so electoral cycles in dissents may crowd the Circuit docket as well.
} 
Court. The Supreme Court reverses $71 \%$ of its cases, and this reversal rate is generally the same for cases with a dissent, but cases with dissents before elections are significantly less likely to be reversed: It reverses only $30 \%$ of cases with dissents before elections (Column $3)$. These results are consistent with Circuit Court judges dissenting on cases with stronger legal precedent before elections, since the Supreme Court is more likely to affirm the majority opinion when there is strong legal precedent. If I assume that the doubling of the dissent rate means that half of these dissents receive the typical $71 \%$ reversal rate and the other half face almost $0 \%$ reversal, the average would be roughly the $30 \%$ reversal that I observe in the raw data. Under this calculation, the Supreme Court seems to recognize which cases have potentially spurious dissents. However, the presence of a dissent still affects court crowding, and Courts of Appeals reversals of District Court decisions that do not have dissents do not seem to be easily overturned.

I also investigate whether the Supreme Court reverses the reversals made by Courts of Appeals before elections, and whether the Supreme Court corrects for and reverses cases decided by unified panels that issue partisan precedent before an election (Column 4). No significant effects are found. The sample size is particularly small for the analysis of how precedents issued by unified panels are treated. Only 183 decisions issued by unified panels from 1925-2002 in the 5\% dataset were heard in the Supreme Court, which necessitated the removal of year fixed effects in Column 4. More parsimonious specifications with fewer controls yield similar insignificant results. Together, these results suggest that the Supreme Court may be only partially correcting for the behavioral effects of Presidential elections on Courts of Appeals decisions.

\section{$9 \quad$ Alternative Explanations}

Electoral cycles are typically explained by re-election concerns, but Courts of Appeals judges are appointed for life. I next consider career concerns, reputational capital (including legacy concerns and collegiality norms), and get-out-the-vote campaigns. Table 13 shows that judges who are elevated to the Supreme Court, on the shortlist as a potential Supreme Court candidate, or about to retire after the election are not more likely to dissent before elections. Moreover, there is no correlation between dissenting before an election and the candidate from one's party winning the Presidential election.

The higher office that Courts of Appeals judges may primarily aspire to is the U.S. Supreme Court. In my 5\% sample, not a single judge elevated to the Supreme Court chose to dissent before an election. Using a shortlist of 71 Courts of Appeals judges considered for the Supreme Court (Nemacheck 2007), there is also no partial correlation between dissenting before an election and being a potential nominee. It is also not theoretically clear whether dissenting 
is a good strategy to get promoted to the Supreme Court: it could also signal an inability to persuade colleagues and forge a majority coalition on the Supreme Court.

Perhaps judges have electoral incentives to get out the vote despite professional rules that forbid any type of political involvement. Getting out the vote for the President is, however, unlikely to explain these electoral cycles. Political candidates from the dissenting judges' party in the Presidential and Senate elections are no more likely to win. Also, if judges are trying to get out the vote, dissents would not peak in the third month before the Presidential election. Moreover, as Presidential primaries involve competition within the same party to be the nominee for the general election, dissents during the Presidential primary season do not obviously encourage voters to vote for a specific candidate. Theoretically, it is also unclear that casting a partisan vote will be relevant, since undecided voters may backlash to partisan behavior and may not notice the dissents. Even if partisan votes are relevant, since case decisions are promulgated at the Circuit - not state - level, judges in all states would have an interest in getting out the vote.

Perhaps judges seek to influence precedent when they or their colleagues retire. But judges who are about to retire or resign after an election are not significantly more likely to dissent. Perhaps collegiality norms breakdown during the election, but a shift in collegiality norms and the retirement of colleagues should uniformly affect all judges. Perhaps judges gain reputational capital for dissenting before an election. However, elections of the most physically proximate politician - the state governor - do not affect the dissent rate. Also, newspapers are no more likely to report on Courts of Appeals decisions or their dissents before Presidential elections (Appendix Table H). ${ }^{124}$ Notably, judges appear to dissent for highly discretionary, procedural reasons; and various citation measures for an opinion's impact or quality suggest that dissents attributable to electoral cycles do not strongly contribute to the development of law, which is inconsistent with judges seeking to build a reputation.

A final explanation is not an alternative behavioral explanation, but instead an important behavioral mechanism that would have different policy implications. Do judges shift their attention to cases that require dissent, and away from other cases, before an election? Such a shift could still be due to priming. I can determine whether judges temporally relocate their dissents by first examining the dissent rate after landslide elections, which decreases even though it did not increase before the election. Appendix Table G presents a formal test of displacement using all of the data. I analyze aggregate dissent rates and their relationship to the competitiveness of the Presidential election. I estimate the dissent spike - the difference

\footnotetext{
${ }^{124}$ Appendix Table $\mathrm{H}$ Columns 1-3 use a database of newspapers covering each Circuit and is simply the count of newspaper articles satisfying a word search. When I collapse the $5 \%$ sample by quarter-to-election and Circuit for 192 observations and remove controls in order to run the analogous specification, the dissent is still significantly elevated for each of the three quarters before the Presidential election.
} 
in the dissent rate in the three quarters before the election with the dissent rate in the three quarters after the election - for each Circuit and each election, and I examine its correlation with the percent of the Electoral College votes that went to the winner ${ }^{125}$ If dissents are displaced, I should see a positive correlation between the increase in the dissent rate before the election and the size of the decrease in the dissent rate after the election. Instead, I see a negative correlation. Appendix Table G reports that the dissent increase in the three months before an election is negatively correlated with the dissent decrease in the three months after. A negative correlation suggests that polarizing elections elevate dissents even after an election is over. Appendix Table $\mathrm{G}$ shows that the results are robust to using different definitions of the election cycle that form the baseline for the dissent increase/decrease around the election. Second, displacing controversial cases to a later time does not apply to the wartime results; wars can last for several years, and court guidelines limit the ability to delay cases for that long. Finally, delaying a case is largely a joint decision. It is conceivable that a judge could unilaterally delay the decision on a case - for instance, by being slower to respond to drafts but it is much harder for a judge to speed up the decision and harder still for him or her to speed up a decision with dissents, as the other two judges would need to review the dissent and decide how to incorporate a response into the majority opinion (and the dissenting judge needs time to write the dissent). Note that there were no significant differences before an election in numbers of decisions, proportion of published cases, or time between stages of the case, as reported in Section 5.5. Finally, I note that I cannot determine if the political environment is affecting people around the judge, such as family members or clerks, who can have indirect effects on the judge.

\section{Conclusion}

The U.S. Courts of Appeals decide the vast majority of cases that constitute the law in the U.S. common law system. Berdejo and Chen (2016) showed that Presidential elections affect the rate at which Courts of Appeals judges dissent, affirm, and reverse District Court decisions, and vote and set precedent along partisan lines. The current paper explains why. Across states, I document that dissents increase more for judges sitting in electorally pivotal states, which are exposed to more campaign advertisements. The channel is through the dissenting judge rather than the other two judges on the panel. Dissents do not vary significantly with the electoral conditions of the states of the other two judges on the panel. Dissents track increases in campaign advertisements in different states over time and the closeness of the state's popular vote when that state has more electoral votes across elections. Across stimuli,

\footnotetext{
${ }^{125}$ In construction of all aggregate dissent rates, I winsorize at the $1 \%$ level. The results are similar when I do not winsorize.
} 
U.S. Senate elections, the timing of which varies across states, further increase dissents. Across individuals, previous associative links magnify the electoral cycle. Over time, the polarization around elections have become larger. The behavioral changes are also larger in close elections, non-existent in landslide elections, and reversed in wartime elections.

Dissents are elevated for ten months before Presidential elections, which accords with the heightened salience of partisanship during the Presidential primaries. Using administrative data on case progression, I find that dissents seem to occur just before the publication of decisions. I also find electoral cycles in concurrences, which typically occur after the first draft of the opinion has been circulated. I find that dissents remain elevated in swing states that are pivotal for the general election but decline precipitously for non-swing states, which are relatively more important for the primary elections. I find that dissents increase most for cases regarding economic activity, which comprise the majority of the topics of campaign ads. I present a model of priming that renders an increase in dissents on marginal rather than inframarginal cases, and find that dissents are more likely to use procedural rather than substantive arguments, and are more likely to occur on cases citing discretionary miscellaneous issues.

If electoral cycles undermine the legitimacy of the court and rule of law by challenging the notion of an unbiased federal judiciary, then the consequences may be greater in terms of the direct economic impacts of the court decisions and changes in legal compliance. A normative evaluation might need to consider the entire situation: for example, what is the optimal amount of dissent and political partisanship? If it is deemed too high, it might be interesting to consider a policy such as debiasing via awareness, nudges via reminders, or formal mechanisms such as deferring cases until a non-election period.

Courts of Appeals judges are appointed for life and are forbidden from any semblance of impropriety or political involvement. The behavioral changes around elections I document are large and materially relevant, and comparable to previously documented electoral cycles of elected judges running for re-election. My results suggest that partisan decision-making in courts is not simply about differences in philosophy. A significant portion of partisan decisionmaking appears to be biased per se. If Courts of Appeals judges have strong commitments to be unbiased yet are affected by Presidential elections, then highly trained professionals may be primeable in other contexts as well. If priming of group identity affects Courts of Appeals judges, my results may indicate a causal link between group identity and ideology in a naturally occurring high-stakes setting. 


\section{References}

Akerlof, George A., and Rachel E. Kranton, 2000, Economics and Identity, The Quarterly Journal of Economics $115,715-753$.

Alesina, Alberto, Nouriel Roubini, and Gerald D. Cohen, 1997, Political Business Cycles and the Macroeconomy (The MIT Press).

Alt, James E., and K. Alec Chrystal, 1983, Political Economics, volume 2 of California Series on Social Choice and Political Economy (University of California Press).

Ansolabehere, Stephen, and Shanto Iyengar, 1997, Going Negative (Simon \& Schuster).

Ash, Elliott, Daniel L. Chen, and Suresh Naidu, 2016, The Effect of Conservative Legal Thought on Economic Jurisprudence, Technical report.

Atran, Scott, Robert Axelrod, and Richard Davis, 2007, Sacred Barriers to Conflict Resolution, Science 317, $1039-1040$.

Babcock, Linda, George Loewenstein, Samuel Issacharoff, and Colin Camerer, 1995, Biased Judgments of Fairness in Bargaining, The American Economic Review 85, 1337-1343.

Baker, Scott, and Claudio Mezzetti, 2012, A Theory of Rational Jurisprudence, The Journal of Political Economy 120, 513-551.

Bargh, John A., and Tanya L. Chartrand, 2000, Studying the Mind in the Middle: A Practical Guide to Priming and Automaticity Research, in Harry T. Reis, and Charles M. Judd, eds., Handbook of Research Methods in Social and Personality Psychology, chapter 10, 253-285 (Cambridge University Press, New York).

Bargh, John A., Paula Raymond, John B. Pryor, and Fritz Strack, 1995, The Attractiveness of the Underling: An Automatic Power Association and its Consequences for Sexual Harassment and Aggression, Journal of Personality and Social Pyschology 68, 768-781.

Barry, Nora, Laura Buchanan, Evelina Bakhturina, and Daniel L. Chen, 2016, Events Unrelated to Crime Predict Criminal Sentence Length, Technical report.

Belloni, Alexandre, Victor Chernozhukov, and Christian Hansen, 2011, Estimation of Treatment Effects with High-Dimensional Controls, CeMMAP working papers CWP42/11, Centre for Microdata Methods and Practice, Institute for Fiscal Studies.

Bénabou, Roland, 2012, Groupthink: Collective Delusions in Organizations and Markets, The Review of Economic Studies 0, 1-34.

Bénabou, Roland, and Jean Tirole, 2012, Laws and Norms, Discussion Paper series 6290, Institute for the Study of Labor (IZA), Bonn, Germany.

Benjamin, Daniel J., James J. Choi, and Geoffrey W. Fisher, 2013, Religious Identity and Economic Behavior, Review of Economics and Statistics (Revised and Resubmitted).

Benjamin, Daniel J., James J. Choi, and Joshua A. Strickland, 2010, Social Identity and Preferences, The American Economic Review 100, 1913-1928.

Berdejó, Carlos, 2012, It's the Journey, Not the Destination: Judicial Preferences and Decision-Making in the Ninth Circuit, University of Louisville Law Review 51.

Berdejo, Carlos, and Daniel L. Chen, 2016, Electoral Cycles Among U.S. Courts of Appeals Judges, Technical report.

Berdejó, Carlos, and Noam M. Yuchtman, 2013, Crime, Punishment and Politics: An Analysis of Political Cycles in Criminal Sentencing, The Review of Economics and Statistics 95, 741-756.

Bernhard, William, Timothy P. Nokken, and Brian R. Sala, 2012, Strategic Shifting: Reelection Seeking and Ideological Adjustment in the US Senate, 1952-98.

Bernheim, B. Douglas, and Antonio Rangel, 2004, Addiction and Cue-Triggered Decision Processes, The American Economic Review 94, 1558-1590.

Bordalo, Pedro, Nicola Gennaioli, and Andrei Shleifer, 2012a, Salience in experimental tests of the endowment effect, The American Economic Review 102, 47-52.

Bordalo, Pedro, Nicola Gennaioli, and Andrei Shleifer, 2012b, Salience Theory of Choice Under Risk, The Quarterly journal of economics 127, 1243-1285.

Bordalo, Pedro, Nicola Gennaioli, and Andrei Shleifer, 2013a, Salience and asset prices, The American Economic Review 103, 623-628.

Bordalo, Pedro, Nicola Gennaioli, and Andrei Shleifer, 2013b, Salience and Consumer Choice, Journal of Political Economy 121.

Bordalo, Pedro, Nicola Gennaioli, and Andrei Shleifer, 2015, Salience Theory of Judicial Decisions, The Journal 
of Legal Studies 44, S7-S33.

Boyd, Christina, Lee Epstein, and Andrew D. Martin, 2010, Untangling the Causal Effects of Sex on Judging, American Journal of Political Science 54, 389-411.

Brady, David W., Hahrie Han, and Jeremy C. Pope, 2007, Primary Elections and Candidate Ideology: Out of Step with the Primary Electorate?, Legislative Studies Quarterly 32, 79-105.

Cameron, Charles M., 1993, New Avenues for Modeling Judicial Politics, in Conference on the Political Economy of Public Law, W. Allen Wallis Institute of Political Economy, University of Rochester, Rochester, NY.

Card, David, and Gordon B. Dahl, 2011, Family Violence and Football: The Effect of Unexpected Emotional Cues on Violent Behavior, The Quarterly Journal of Economics 126, 103-143.

Chen, Daniel, Yosh Halberstam, and Alan C. L. Yu, 2016a, Covering: Mutable Characteristics and Perceptions of (Masculine) Voice in the U.S. Supreme Court, Technical report.

Chen, Daniel, Yosh Halberstam, and Alan C. L. Yu, 2016b, Perceived Masculinity Predicts United States Supreme Court Outcomes, Technical report.

Chen, Daniel, and J.J. Prescott, 2016, Implicit Egoism in Sentencing Decisions: First Letter Name Effects with Randomly Assigned Defendants, Technical report.

Chen, Daniel L., 2004, Gender Violence and the Price of Virginity: Theory and Evidence of Incomplete Marriage Contracts, Working paper, University of Chicago, Mimeo.

Chen, Daniel L., 2006, Islamic Resurgence and Social Violence During the Indonesian Financial Crisis, in Mark Gradstein, and Kai A. Konrad, eds., Institutions and Norms in Economic Development, chapter 8, 179-199 (MIT Press).

Chen, Daniel L., 2010, Club Goods and Group Identity: Evidence from Islamic Resurgence during the Indonesian Financial Crisis, The Journal of Political Economy 118, 300-354.

Chen, Daniel L., 2011, Markets and Morality: How Does Competition Affect Moral Judgment?, Working paper, Duke Law School.

Chen, Daniel L., 2013, The Deterrent Effect of the Death Penalty? Evidence from British Commutations During World War I, Working paper, ETH Zurich.

Chen, Daniel L., 2014, Can Markets Overcome Repugnance? Muslim Trade Reponse to Anti-Muhammad Cartoons, Working paper, ETH Zurich, Mimeo.

Chen, Daniel L., 2016, Evolution of the Judiciary: Political Cycles in Judicial Exits from the U.S. Courts of Appeals, Technical report.

Chen, Daniel L., Xing Cui, Lanyu Shang, and Jing Zhang, 2016c, What Matters: Agreement Between U.S. Courts of Appeals Judges, Technical report.

Chen, Daniel L., Matt Dunn, Rafael Garcia Cano Da Costa, Ben Jakubowki, and Levent Sagun, 2016d, Early Predictability of Asylum Court Decisions, Technical report.

Chen, Daniel L., and Jess Eagel, 2016, Can Machine Learning Help Predict the Outcome of Asylum Adjudications?, Technical report.

Chen, Daniel L., Jens Frankenreiter, and Susan Yeh, 2014a, Measuring the Effects of Legal Precedent in U.S. Federal Courts, Working paper, ETH Zurich.

Chen, Daniel L., Damian Kozbur, and Alan Yu, 2016e, Mimicry: Phonetic Accommodation Predicts U.S. Supreme Court Votes, Working paper, ETH Zurich.

Chen, Daniel L., Kristen Kwan, Maria Maass, , and Luisa Ortiz, 2016f, Law and Norms: Using Machine Learning to Predict Attitudes Towards Women and Abortion, Technical report.

Chen, Daniel L., Vardges Levonyan, and Susan Yeh, 2014b, Do Policies Affect Preferences? Evidence from Random Variation in Abortion Jurisprudence, Working paper, ETH Zurich.

Chen, Daniel L., and Jo Thori Lind, 2014, The Political Economy of Beliefs: Why Fiscal and Social Conservatives and Liberals Come Hand-in-Hand, Working paper.

Chen, Daniel L., Moti Michaeli, and Daniel Spiro, 2015a, Ideological Perfectionism on Judicial Panels, Working paper, ETH Zurich.

Chen, Daniel L., Tobias J. Moskowitz, and Kelly Shue, 2015b, Decision-Making Under the Gambler's Fallacy: Evidence from Asylum Judges, Loan Officers, and Baseball Umpires, Working paper, ETH Zurich.

Chen, Daniel L., and Martin Schonger, 2013, Social Preferences or Sacred Values? Theory and Evidence of Deontological Motivations, Working paper, ETH Zurich, Mimeo.

Chen, Daniel L., and Martin Schonger, 2015, A Theory of Experiments: Invariance of Equilibrium to the 
Strategy Method of Elicitation and Implications for Social Preferences, Working paper, ETH Zurich.

Chen, Daniel L., and Jasmin Sethi, 2011, Insiders and Outsiders: Does Forbidding Sexual Harassment Exacerbate Gender Inequality?, Working paper, University of Chicago.

Chen, Daniel L., and Holger Spamann, 2014, This Morning's Breakfast, Last Night's Game: Detecting Extraneous Factors in Judging, Working paper, ETH Zurich.

Chen, Daniel L., and Susan Yeh, 2014a, The Construction of Morals, Journal of Economic Behavior and Organization 104, 84-105.

Chen, Daniel L., and Susan Yeh, 2014b, Growth Under the Shadow of Expropriation? The Economic Impacts of Eminent Domain, Working paper, ETH Zurich and George Mason University.

Chen, Daniel L., and Susan Yeh, 2014c, How Do Rights Revolutions Occur? Free Speech and the First Amendment, Working paper, ETH Zurich.

Chen, Yan, and Sherry Xin Li, 2009, Group Identity and Social Preferences, The American Economic Review 99, 431-457.

Cleveland, David R., 2010, Local Rules in the Wake of Federal Rule of Appellate Procedure 32.1, The Journal of Appellate Practice and Process 11, 19-73.

Cohn, Alain, Michel André Maréchal, and Thomas Noll, 2015, Bad boys: How criminal identity salience affects rule violation, The Review of Economic Studies 82, 1289-1308.

Cross, Frank B., 2003, Decisionmaking in the U.S. Circuit Courts of Appeals, California Law Review 91, $1457-1515$.

DellaVigna, Stefano, and Ethan Kaplan, 2007, The Fox News Effect: Media Bias and Voting, The Quarterly Journal of Economics 122, 1187-1234.

Dohmen, Thomas, and Jan Sauermann, 2015, Referee bias, Journal of Economic Surveys .

Drazen, Allan, 2001, The Political Business Cycle After 25 Years, in NBER Macroeconomics Annual 2000, Volume 15, 75-138 (National Bureau of Economic Research).

Druckman, James N., 2004, Priming the Vote: Campaign Effects in a U.S. Senate Election, Political Psychology $25,577-594$.

Duclos, Jean-Yves, Joan Esteban, and Debraj Ray, 2004, Polarization: Concepts, Measurement, Estimation, Econometrica 72, 1737-1772.

Edmans, Alex, Diego Garcia, and Øyvind Norli, 2007, Sports Sentiment and Stock Returns, The Journal of Finance 62, 1967-1998.

Edwards, Harry T., and Michael A. Livermore, 2008, Pitfalls of Empirical Studies That Attempt to Understand the Factors Affecting Appellate Decisionmaking, Duke Law Journal 58, 1895-1989.

Englich, Birte, Thomas Mussweiler, and Fritz Strack, 2005, The Last Word in Court: A Hidden Disadvantage for the Defense, Law and Human Behavior 29, 705-722.

Englich, Birte, and Kirsten Soder, 2009, Moody Experts - How Mood and Expertise Influence Judgmental Anchoring, Judgment and Decision Making 4, 41-50.

Engstrom, Richard L., 1971, Political Ambitions and the Prosecutorial Office, The Journal of Politics 33, 190-194.

Epstein, Lee, William M. Landes, and Richard A. Posner, 2011, Why (and When) Judges Dissent: A Theoretical and Empirical Analysis, Journal of Legal Analysis 3, 101-137.

Epstein, Lee, William M Landes, and Richard A Posner, 2013, The Behavior of Federal Judges: A Theoretical and Empirical Study of Rational Choice (Harvard University Press).

Epstein, Lee, Andrew D. Martin, Jeffrey A. Segal, and Chad Westerland, 2007, The Judicial Common Space, Journal of Law, Economics, and Organization 23, 303-325.

Eren, Ozkan, and Naci Mocan, 2016, Emotional Judges and Unlucky Juveniles, Working paper.

Esteban, Joan-María, and Debraj Ray, 1994, On the Measurement of Polarization, Econometrica 62, 819-851.

Falk, Armin, and Jean Tirole, 2016, Narratives, Imperatives and Moral Reasoning .

Falk, Emily B., Elliot T. Berkman, and Matthew D. Lieberman, 2012, From Neural Responses to Population Behavior: Neural Focus Group Predicts Population-Level Media Effects, Psychological Science 23, 439-445.

Fehr, Ernst, and Klaus M. Schmidt, 1999, A Theory of Fairness, Competition, and Cooperation, The Quarterly Journal of Economics 114, 817-868.

Fong, Christina M., and Erzo F. P. Luttmer, 2009, What Determines Giving to Hurricane Katrina Victims? Experimental Evidence on Racial Group Loyalty, American Economic Journal: Applied Economics 1, 64-87.

Friedman, Milton, and Leonard J. Savage, 1948, The Utility Analysis of Choices Involving Risk, The Journal 
of Political Economy 56, 279-304.

Garicano, Luis, Ignacio Palacios-Huerta, and Canice Prendergast, 2005, Favoritism under social pressure, Review of Economics and Statistics 87, 208-216.

Gennaioli, Nicola, and Andrei Shleifer, 2007, The Evolution of Common Law, The Journal of Political Economy $115,43-68$.

Gentzkow, Matthew, Jesse M Shapiro, and Matt Taddy, 2015, Measuring Polarization in High-dimensional Data: Method and Application to Congressional Speech .

Gentzkow, Matthew Aaron, and Jesse M. Shapiro, 2010, What Drives Media Slant? Evidence From U.S. Daily Newspapers, Econometrica 78, 35-71.

Goldberg, Michelle, 2016, The Democratic Primary Ruined My Friendship!, Slate, April 18, 2016.

Golub, Benjamin, and Matthew O. Jackson, 2012, How Homophily Affects the Speed of Learning and BestResponse Dynamics, The Quarterly Journal of Economics 127, 1287-1338.

Gordon, Sanford C., 2009, Assessing Partisan Bias in Federal Public Corruption Prosecutions, The American Political Science Review 103, 534-554.

Gordon, Sanford C., and Gregory A. Huber, 2007, The Effect of Electoral Competitiveness on Incumbent Behavior, Quarterly Journal of Political Science 2, 107-138.

Groseclose, Tim, and Jeffrey Milyo, 2005, A Measure of Media Bias, The Quarterly Journal of Economics 120, $1191-1237$.

Guthrie, Chris, Jeffrey J. Rachlinski, and Andrew J. Wistrich, 2007, Blinking on the Bench: How Judges Decide Cases, Cornell Law Review 93, 1-44.

Hall, Matthew, 2010, Randomness Reconsidered: Modeling Random Judicial Assignment in the U.S. Courts of Appeals, Journal of Empirical Legal Studies 7, 574-589.

Hart, William, Roderick D Blanchard, and Janis Walter, 2006, Litigation and trial practice (Cengage Learning).

Hassin, Ran R., Melissa J. Ferguson, Daniella Shidlovski, and Tamar Gross, 2007, Subliminal Exposure to National Flags Affects Political Thought and Behavior, Proceedings of the National Academy of Sciences of the United States of America 104, 19757-19761.

Hollibaugh Jr., Gary E., 2011, Selection, Election, and Retention: State Supreme Courts and the Electoral Connection, Working paper, University of Rochester.

Huang, Bert I., 2011, Deference Drift? Evidence from a Surge in Federal Appeals, Harvard Law Review 124, $1121-1126$.

Huber, Gregory A., and Sanford C. Gordon, 2004, Accountability and Coercion: Is Justice Blind When It Runs for Office?, American Journal of Political Science 48, 247-263.

Kahneman, Daniel, 2011, Thinking, Fast and Slow (Farrar, Straus and Giroux).

Kimball, David C., 2005, Priming Partisan Evaluations of Congress, Legislative Studies Quarterly 30, 63-84.

Kornhauser, Lewis A., 1999, Judicial Organization and Administration, in Chris William Sanchirico, ed., Encyclopedia of Law and Economics, volume 5, chapter 11, 27-44.

Krishnakumar, Anita S, 2000, On the evolution of the canonical dissent, Rutgers Law Review 52, 781.

Krosnick, Jon A., and Donald R. Kinder, 1990, Altering the Foundations of Support for the President Through Priming, The American Political Science Review 84, 497-512.

Laibson, David, 2001, A Cue-Theory of Consumption, The Quarterly Journal of Economics 116, 81-119.

Lantigua-Williams, Juleyka, 2016, Are Prosecutors the Key to Justice Reform?, The Atlantic, May 18, 2016.

Lenz, Gabriel S., 2009, Learning and Opinion Change, Not Priming: Reconsidering the Priming Hypothesis, American Journal of Political Science 53, 821-837.

List, John A., 2003, Does Market Experience Eliminate Market Anomalies?, The Quarterly Journal of Economics $118,41-71$.

Lochner, Todd, 2002, Strategic Behavior and Prosecutorial Agenda Setting in United States Attorneys' Offices: The Role of U.S. Attorneys and Their Assistants, The Justice System Journal 23, 271-294.

McCallum, Bennett T., 1978, The Political Business Cycle: An Empirical Test, Southern Economic Journal $44,504-515$.

McCarty, Nolan M., Keith T. Poole, and Howard Rosenthal, 2006, Polarized America: The Dance of Ideology and Unequal Riches, Walras-Pareto lectures (The MIT Press).

Mobius, Markus M, Muriel Niederle, Paul Niehaus, and Tanya S Rosenblat, 2011, Managing self-confidence: Theory and experimental evidence, Technical report, National Bureau of Economic Research.

Montalvo, José G., and Marta Reynal-Querol, 2005, Ethnic Polarization, Potential Conflict, and Civil Wars, 
The American Economic Review 95, 796-816.

Morris, James P., Nancy K. Squires, Charles S. Taber, and Milton Lodge, 2003, Activation of Political Attitudes: A Psychophysiological Examination of the Hot Cognition Hypothesis, Political Psychology 24, 727745 .

Mullainathan, Sendhil, and Andrei Shleifer, 2005, The Market for News, The American Economic Review 95, 1031-1053.

Mussweiler, Thomas, and Birte Englich, 2005, Subliminal Anchoring: Judgmental Consequences and Underlying Mechanisms, Organizational Behavior and Human Decision Processes 98, 133-143.

Mussweiler, Thomas, and Fritz Strack, 2000, The Use of Category and Exemplar Knowledge in the Solution of Anchoring Tasks., Journal of Personality and Social Psychology 78, 1038-1052.

Nemacheck, Christine L., 2007, Strategic Selection: Presidential Nomination of Supreme Court Justices from Herbert Hoover through George W. Bush, Constitutionalism and Democracy (University of Virginia Press, Charlottesville).

Nyhan, B, and M Rehavi, 2015, Tipping the Scales? Testing for Political Motives in Prosecution, Technical report, Vancouver School of Economics.

Osborne, Martin J., 1995, Spatial models of political competition under plurality rule: a survey of some explanations of the number of candidates and the positions they take, The Canadian Journal of Economics $28,261-301$.

Ostergaard, Arne L., 1994, Dissociations between Word Priming Effects in Normal Subjects and Patients with Memory Disorders: Multiple Memory Systems or Retrieval?, The Quarterly Journal of Experimental Psychology 47, 331-364.

Perry Jr., H. W., 1998, United States Attorneys: Whom Shall They Serve?, Law and Contemporary Problems 61, 129-148.

Pope, Devin G, Joseph Price, and Justin Wolfers, 2013, Awareness reduces racial bias, Technical report, National Bureau of Economic Research.

Posner, Richard A., 1973, An Economic Approach to Legal Procedure and Judicial Administration, The Journal of Legal Studies 2, 399-458.

Rachlinski, Jeffrey J., Sheri Lynn Johnson, Andrew J. Wistrich, and Chris Guthrie, 2009, Does Unconscious Bias Affect Trial Judges?, Notre Dame Law Review 84, 1195-1246.

Saunders Jr., Edward M., 1993, Stock Prices and Wall Street Weather, The American Economic Review 83, $1337-1345$.

Shayo, Moses, and Asaf Zussman, 2011, Judicial Ingroup Bias in the Shadow of Terrorism, The Quarterly Journal of Economics 126, 1447-1484.

Simonsohn, Uri, 2010, Weather to Go to College, The Economic Journal 120, 270-280.

Skotnicki, Mike, 2012, A Peek Inside the Chambers: How the Eleventh Circuit Court of Appeals Decides Cases, April 9, 2012.

Spencer, Steven, Claude Steele, and Diane M. Quinn, 1999, Stereotype Threat and Women's Math Performance, Journal of Experimental Social Psychology 35, 4-28.

Srull, Thomas K., and Robert S. Wyer, 1979, The Role of Category Accessibility in the Intrerpretation of Information about Persons: Some Determinants and Implications, Journal of Personality and Social Psychology 37, 1660-1672.

Sunstein, Cass, and Richard Thaler, 2008, Nudge: Improving Decisions about Health, Wealth, and Happiness (Yale University Press).

Sunstein, Cass R., David Schkade, Lisa M. Ellman, and Andres Sawicki, 2006, Are Judges Political?: An Empirical Analysis of the Federal Judiciary (Brookings Institution Press).

Tulving, Endel, Daniel L. Schacter, and Heather A. Stark, 1982, Priming Effects in Word-Fragment Completion are Independent of Recognition Memory., Journal of Experimental Psychology: Learning, Memory, and Cognition 8, 336-342. 


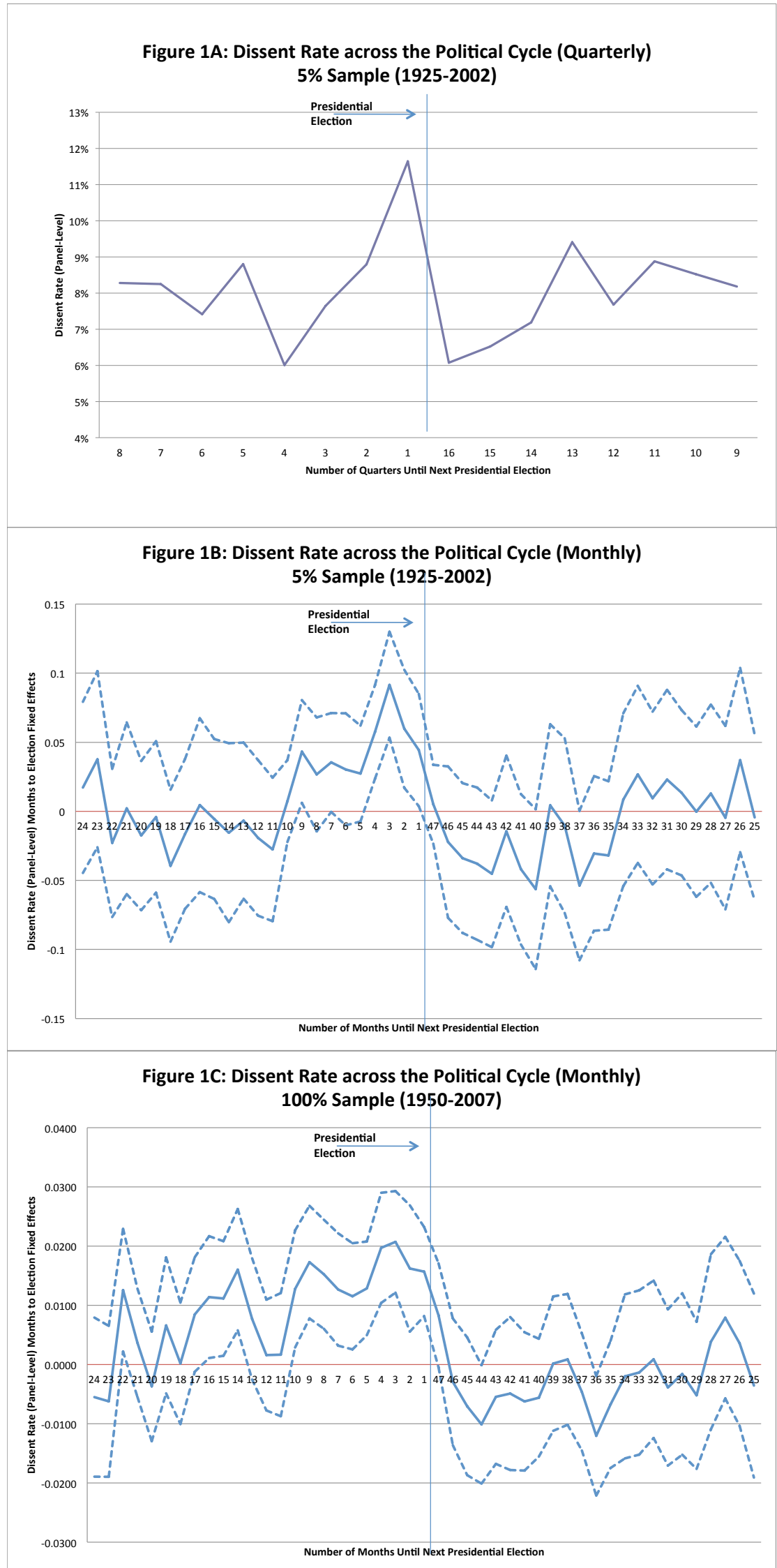

Notes: Figures $1 \mathrm{~A}$ and $1 \mathrm{~B}$ display dissents with or without dissenting opinions Figure $1 \mathrm{C}$ displays dissents with dissenting opinions 


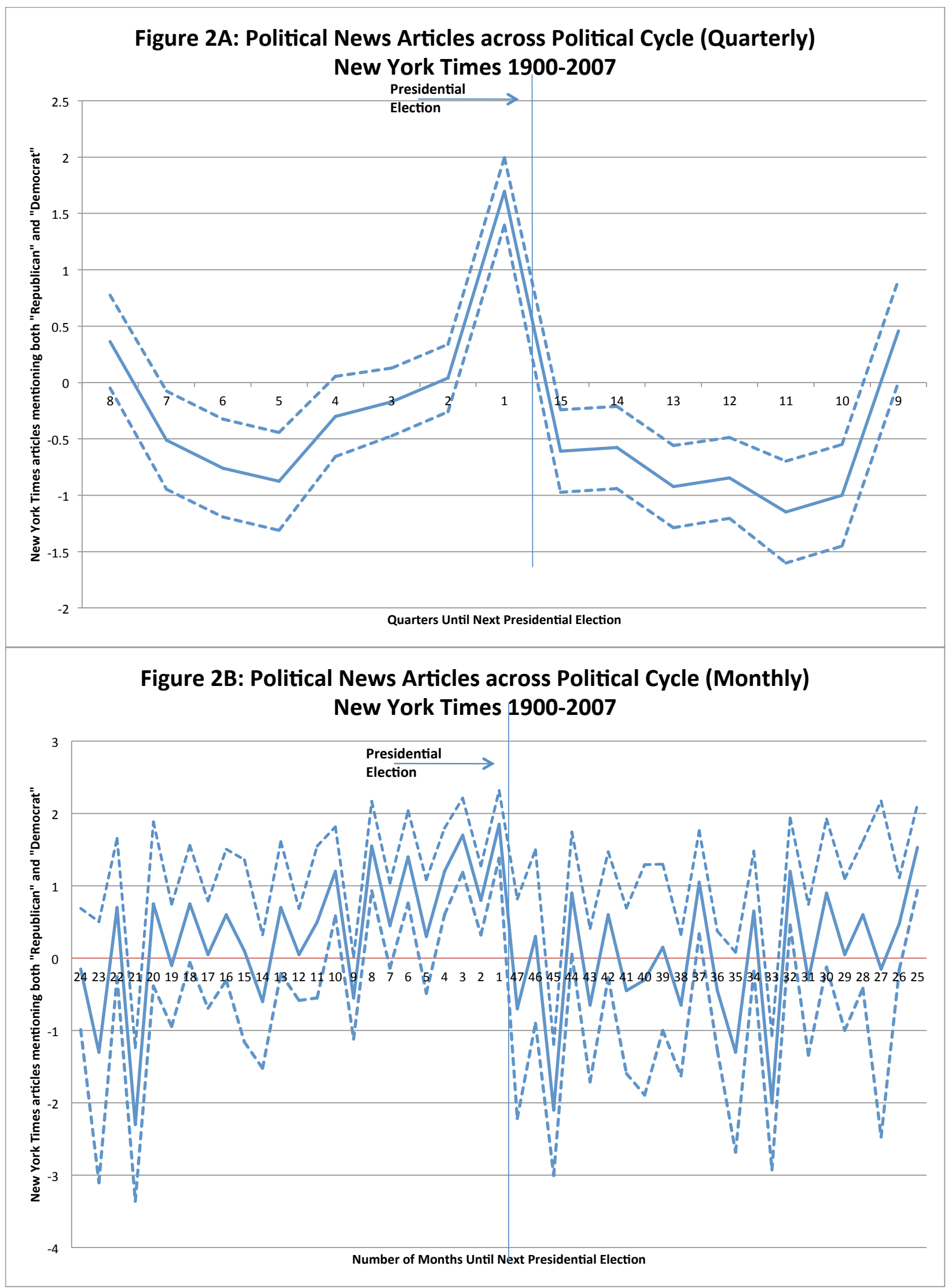


Figure 3A: Influence of Party of Appointment on Voting Valence across Political Cycle (Quarterly)

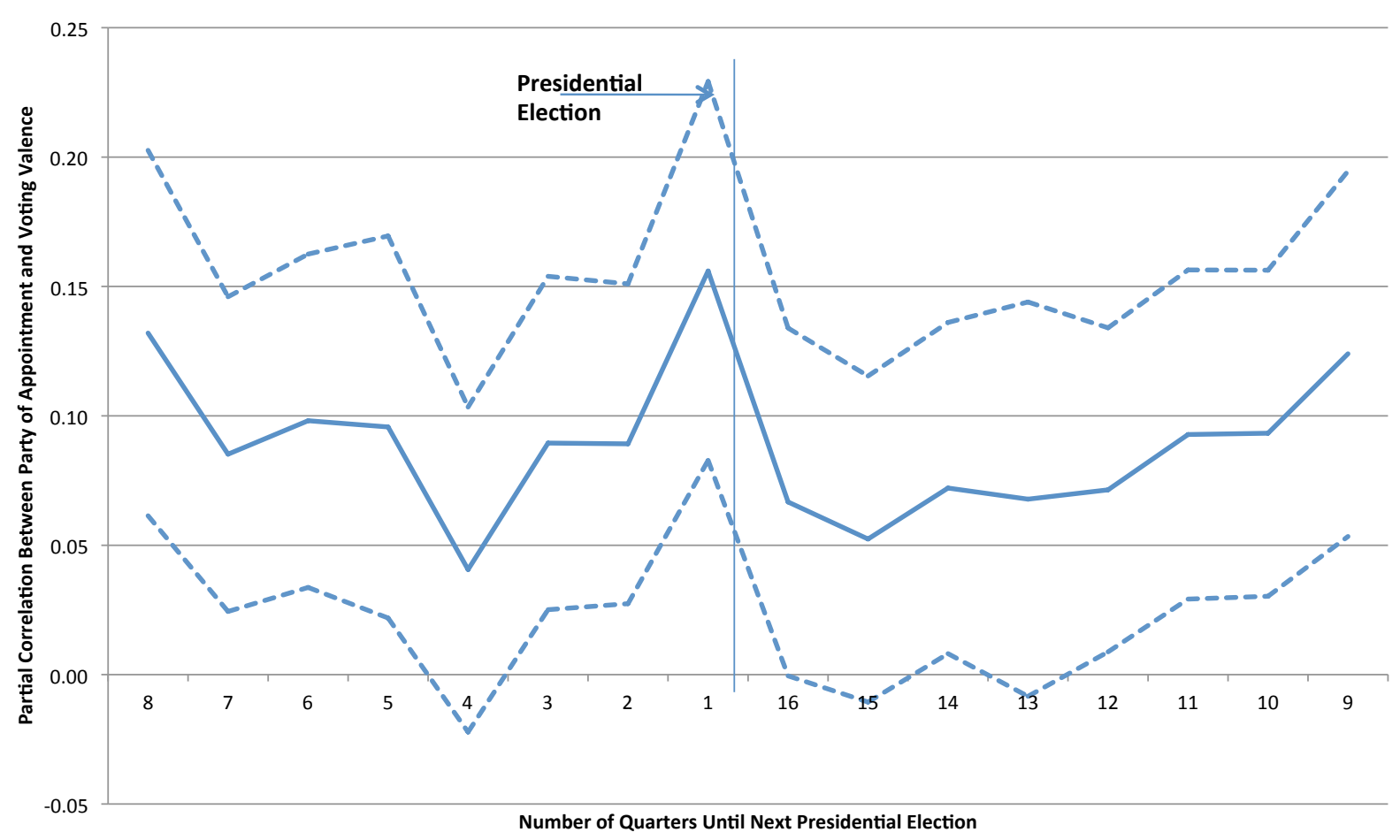

Figure 3B: Electoral Cycles in Voting Valence by Ideology Score

$\longrightarrow$ Not Last Quarter $\quad-$ Last Quarter

Ideology Score Quintile

Quintile 1

Quintile 2

Quintile 3

Quintile 4

Quintile 5

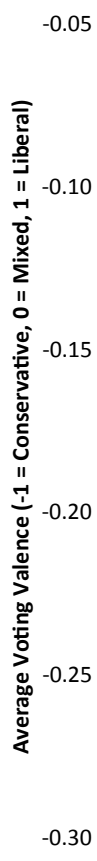




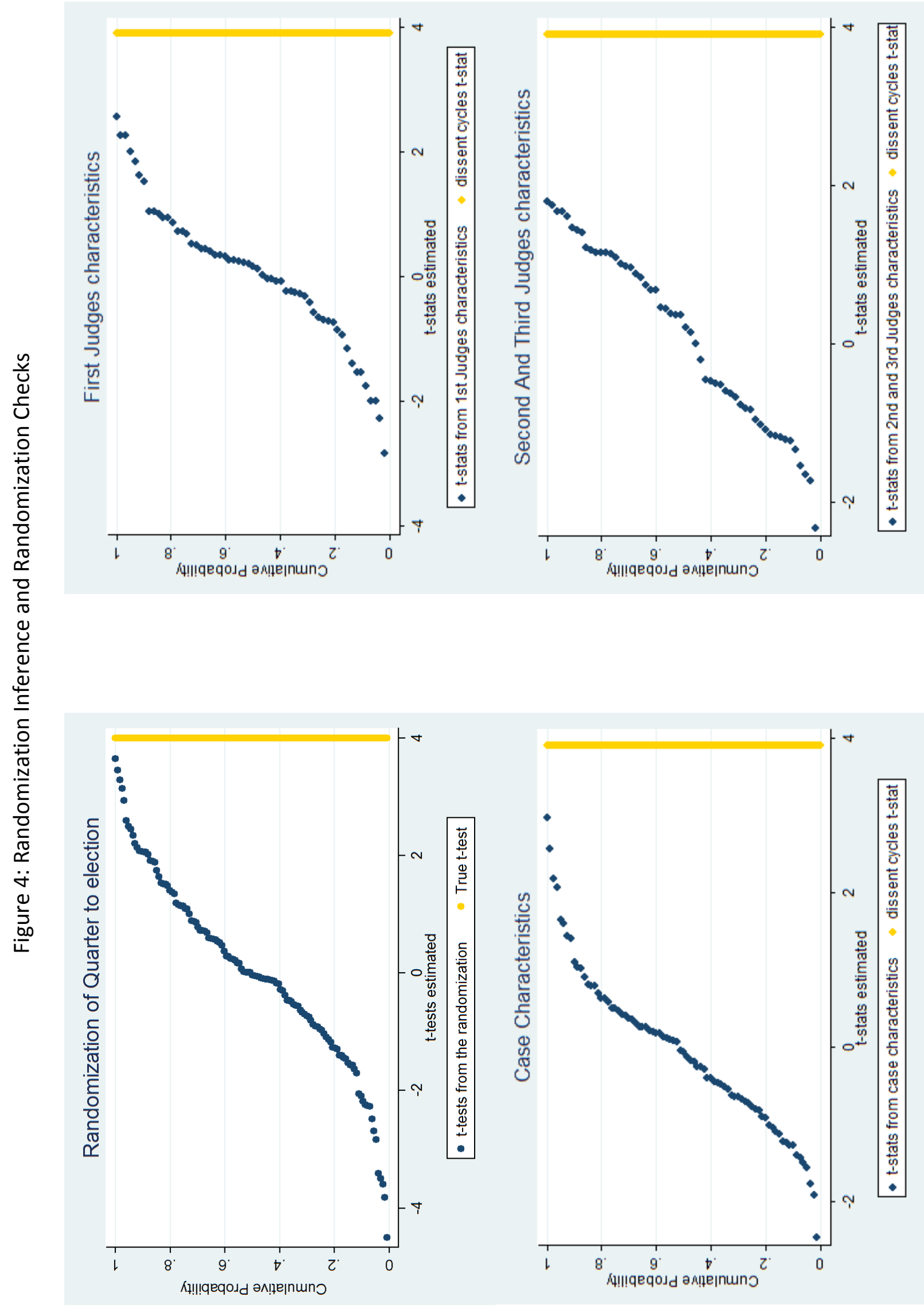


Figure 5: Campaign Advertisements across Political Cycle (Weekly)

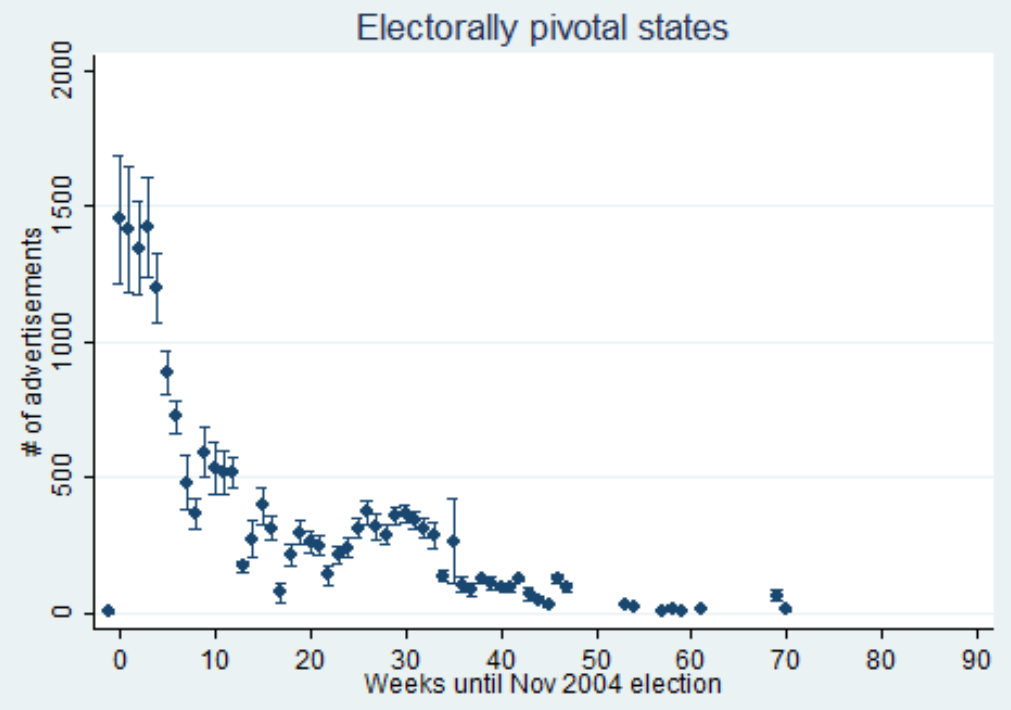

Figure 5A

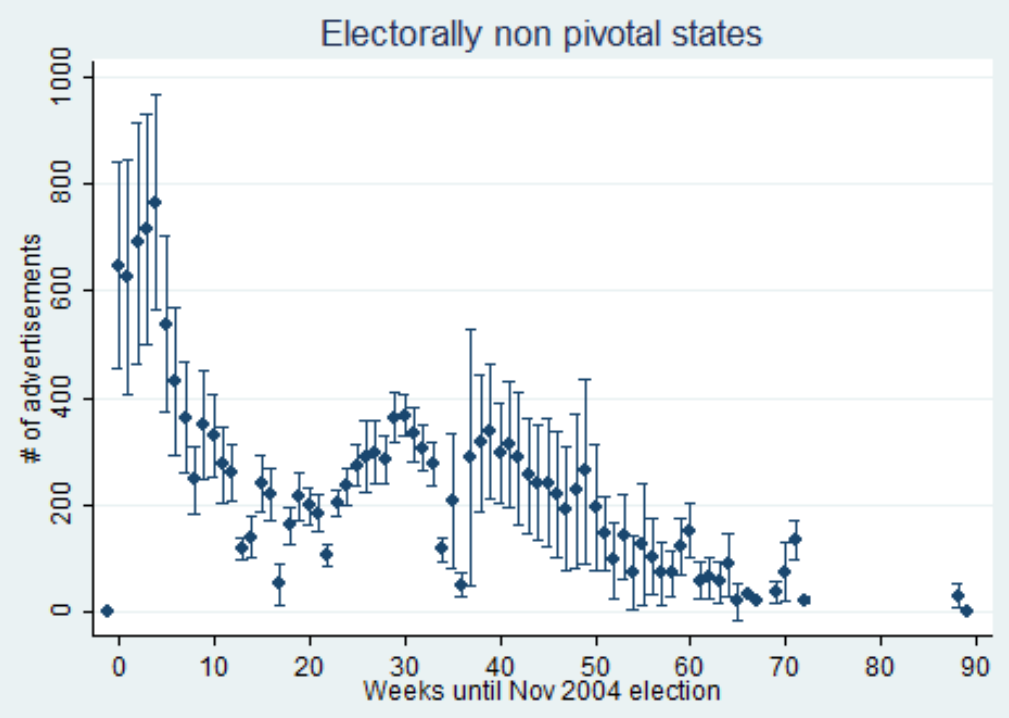

Figure 5B

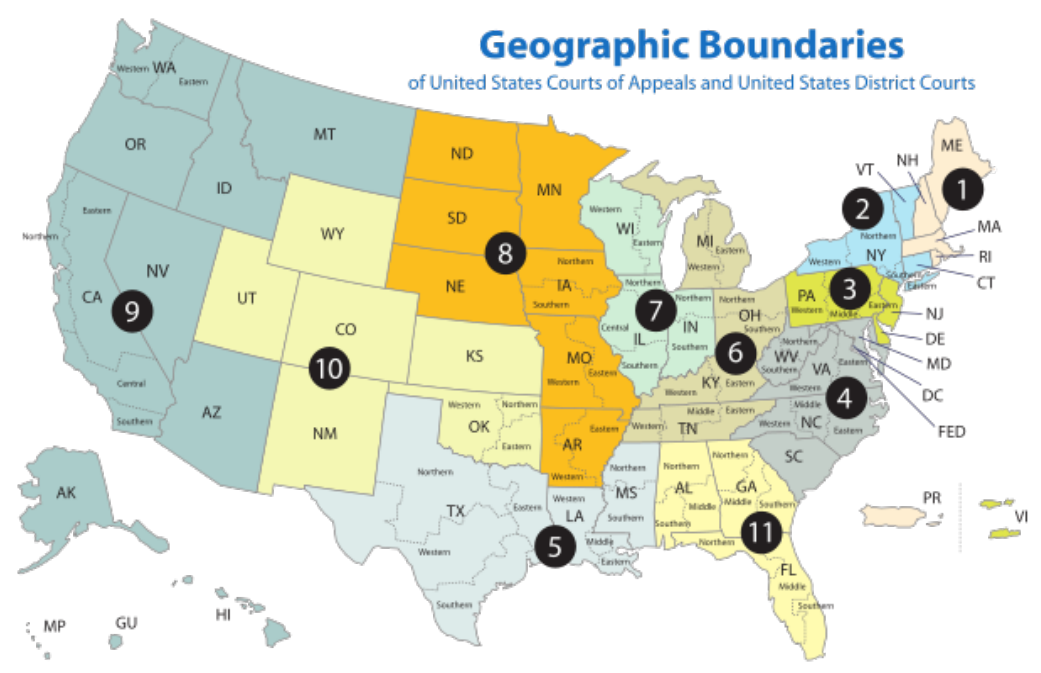

Figure 5C 


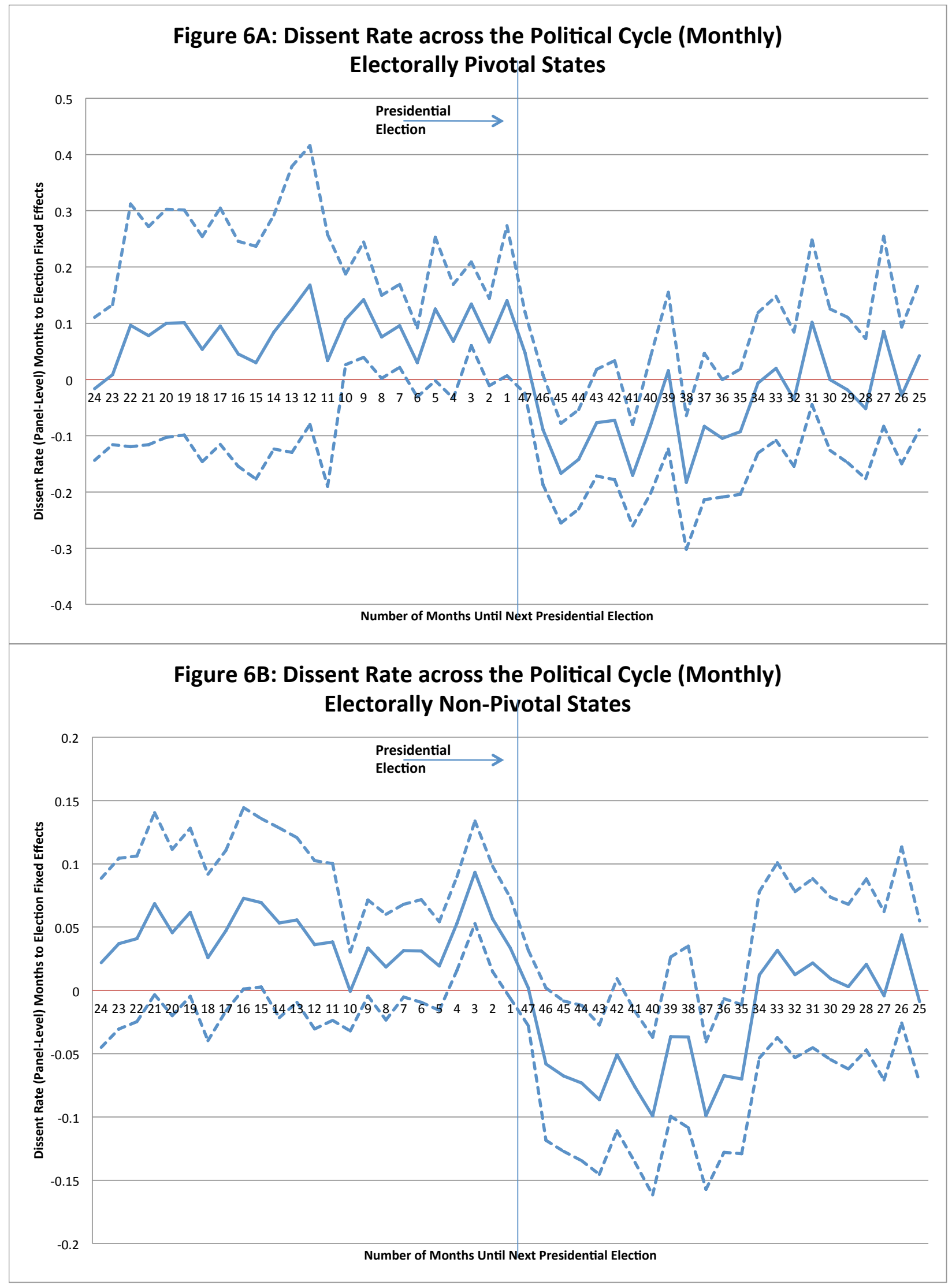




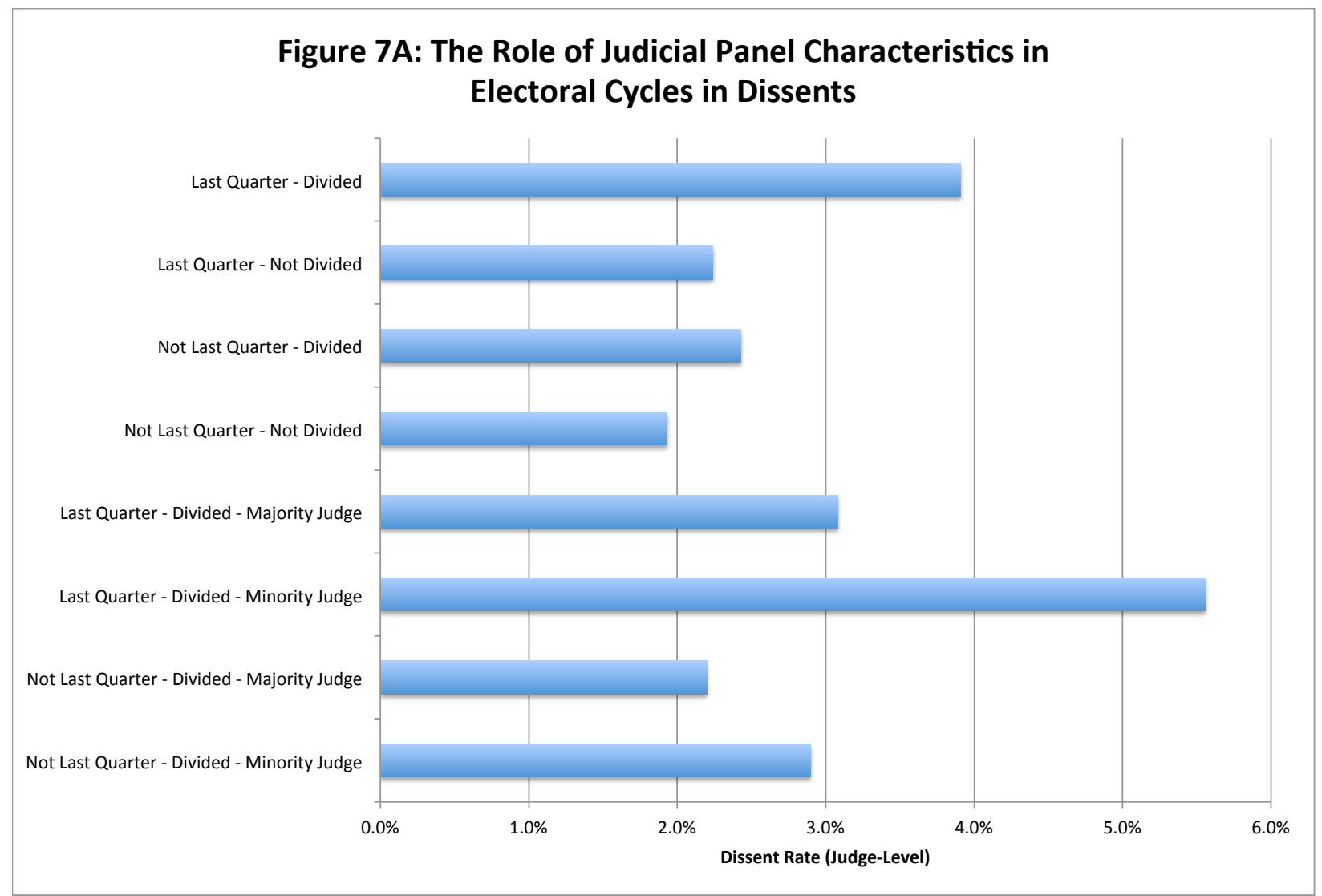

Figure 7B: The Role of Judicial Ideology Score in Electoral Cycles in Dissents

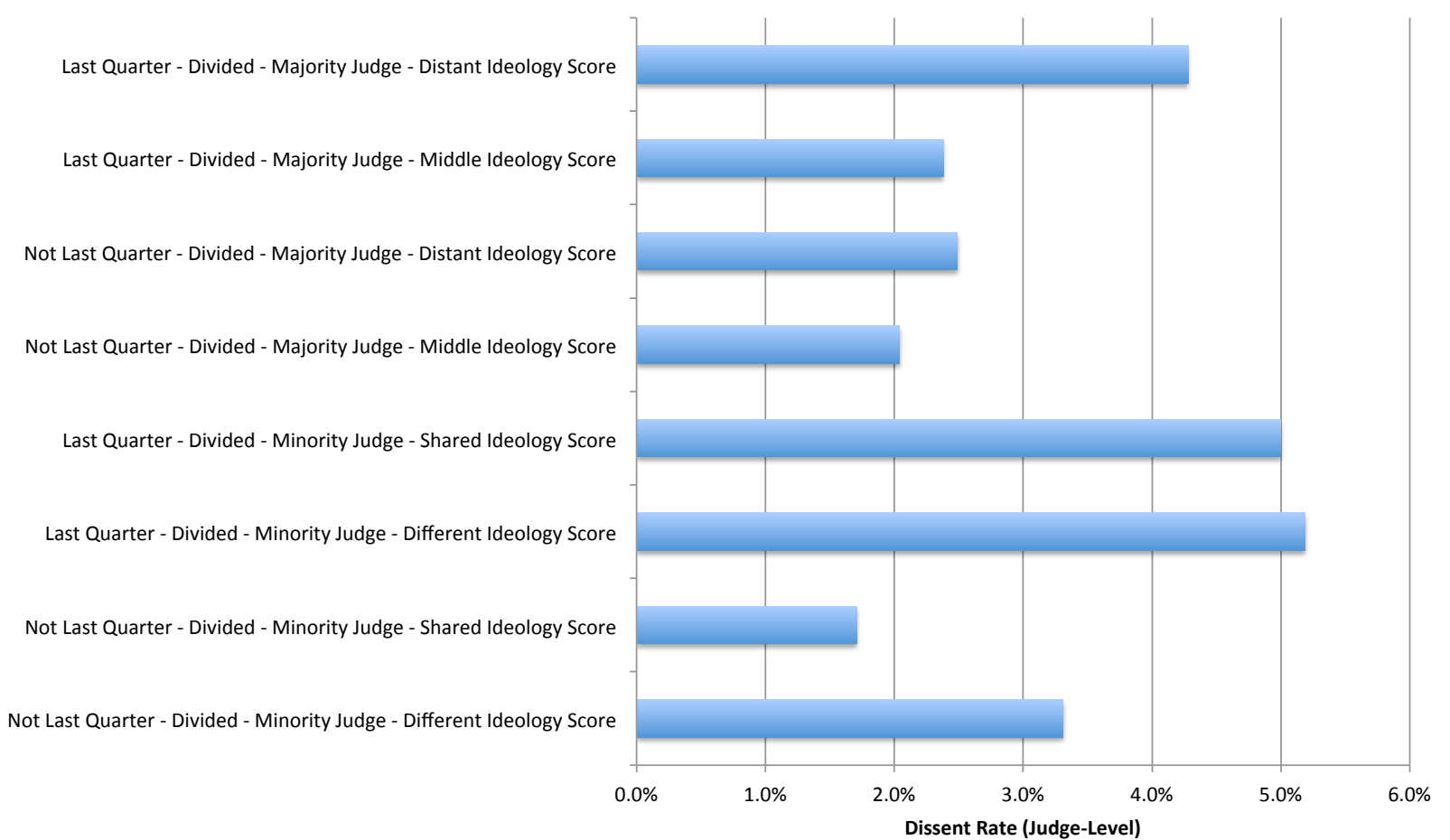

Notes: Politically Divided Panels are RRD or DDR; Non-Divided Panels are DDD or RRR.

Majority Judge is $R$ in RRD panels and $D$ in DDR panels; Minority Judge is $D$ in RRD and R in DDR panels. 


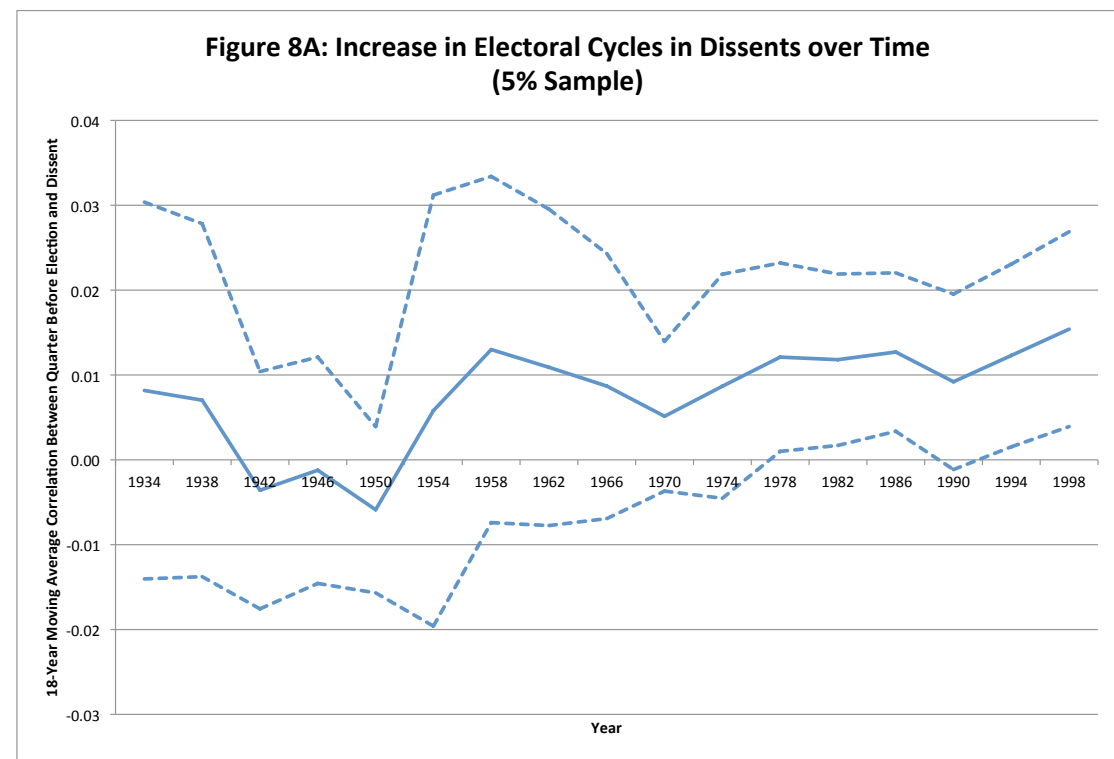

Figure 8B: Influence of Party of Appointment on Voting Valence Over Time (5\% Sample)

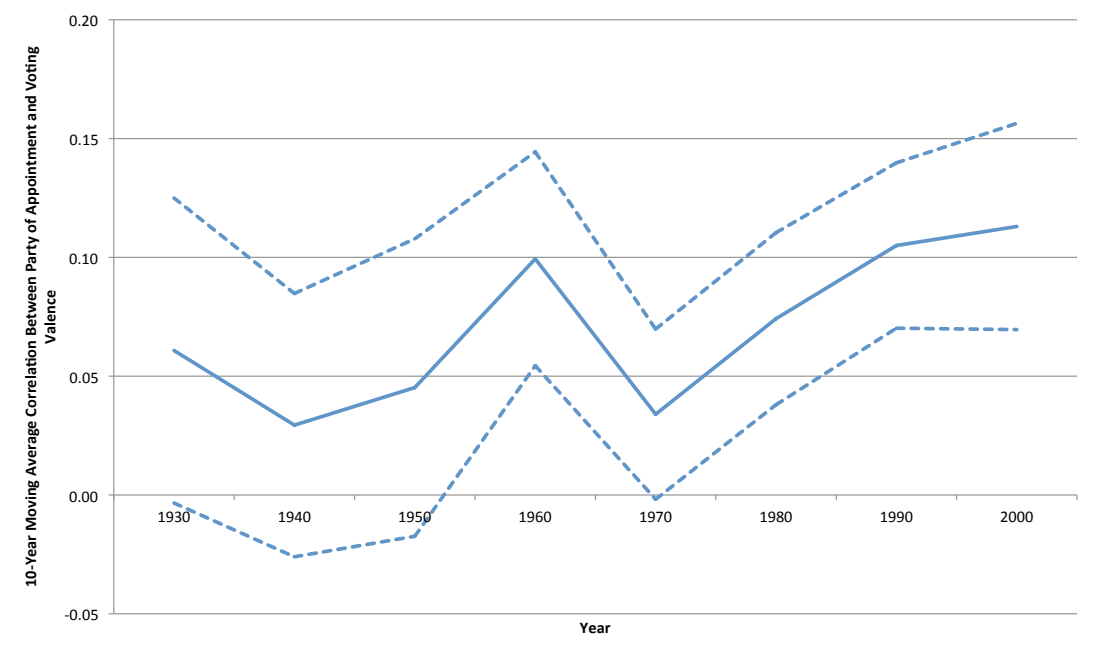

Figure 8C: Increase in Electoral Cycles in Dissents over Time (100\% Sample)

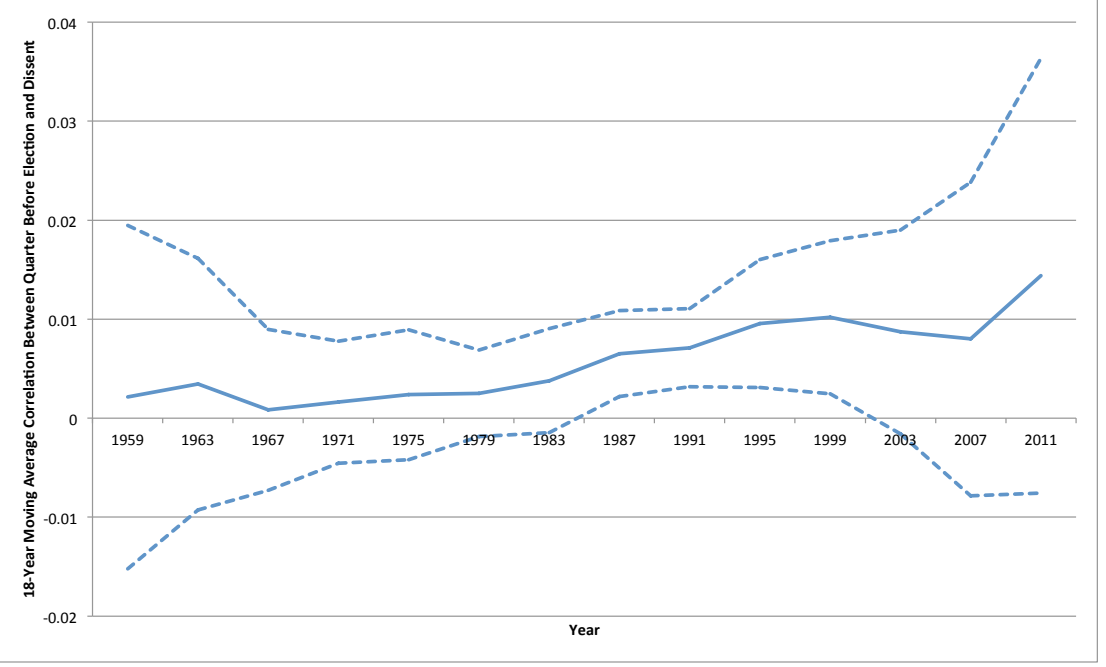



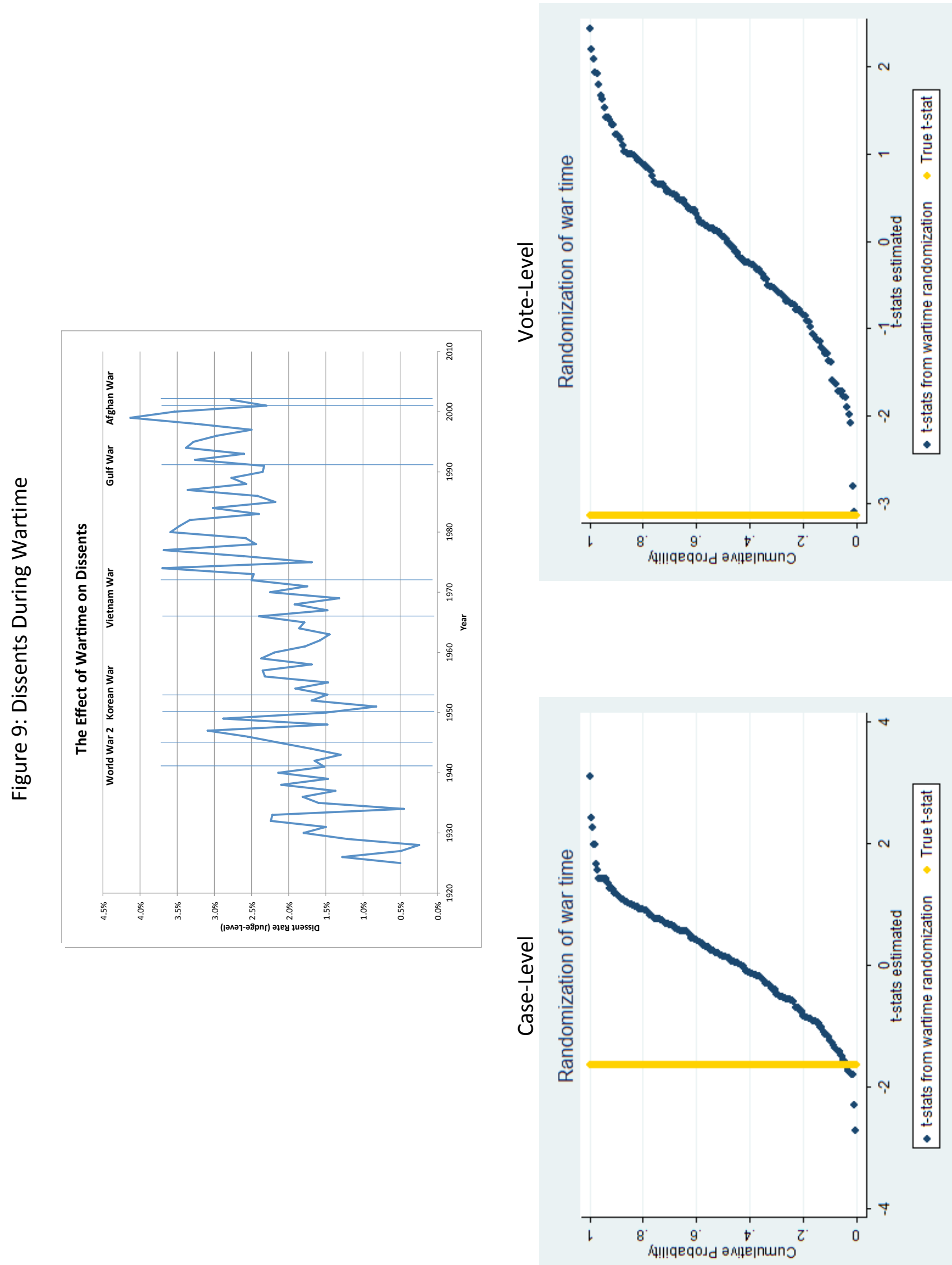
Table 1: Electoral Cycles in Dissents (2-1 Decision)

\begin{tabular}{|c|c|c|c|c|}
\hline & (1) & $(2)$ & $(3)$ & (4) \\
\hline & \multicolumn{2}{|c|}{$5 \%$ Sample (1925-2002) } & \multicolumn{2}{|c|}{$100 \%$ Sample (1950-2007) } \\
\hline Mean of dep. var. & \multicolumn{2}{|c|}{0.079} & \multicolumn{2}{|c|}{0.060} \\
\hline \multirow[t]{2}{*}{ Divided (DRR or RDD) } & $0.0157^{* * *}$ & $0.0154^{* * *}$ & & \\
\hline & $(0.00452)$ & $(0.00450)$ & & \\
\hline \multirow[t]{2}{*}{ Quartertoelect $=1$} & $0.0637^{* * *}$ & $0.0680^{* * *}$ & $0.0113^{* * *}$ & $0.00847^{* *}$ \\
\hline & $(0.0123)$ & $(0.0135)$ & $(0.00323)$ & $(0.00337)$ \\
\hline \multirow{2}{*}{ Quartertoelect $=2$} & $0.0347^{* * *}$ & $0.0341 * *$ & $0.00785^{* * *}$ & 0.00474 \\
\hline & $(0.0121)$ & $(0.0145)$ & $(0.00292)$ & $(0.00318)$ \\
\hline \multirow[t]{2}{*}{ Quartertoelect $=3$} & $0.0325^{* * *}$ & $0.0343^{* *}$ & $0.00782^{* *}$ & 0.00445 \\
\hline & $(0.0123)$ & $(0.0133)$ & $(0.00318)$ & $(0.00331)$ \\
\hline \multirow[t]{2}{*}{ Quartertoelect $=4$} & 0.00581 & 0.00582 & 0.00153 & 0.00158 \\
\hline & $(0.0111)$ & $(0.0111)$ & $(0.00399)$ & $(0.00368)$ \\
\hline \multirow[t]{2}{*}{ Quartertoelect $=5$} & 0.0209 & 0.0251 & 0.00747 & 0.00454 \\
\hline & $(0.0152)$ & $(0.0159)$ & $(0.00465)$ & $(0.00450)$ \\
\hline \multirow[t]{2}{*}{ Quartertoelect $=6$} & 0.0120 & 0.0115 & 0.00496 & 0.00185 \\
\hline & $(0.0141)$ & $(0.0153)$ & $(0.00460)$ & $(0.00455)$ \\
\hline \multirow[t]{2}{*}{ Quartertoelect $=7$} & 0.0226 & 0.0238 & 0.0000166 & -0.00330 \\
\hline & $(0.0141)$ & $(0.0153)$ & $(0.00470)$ & $(0.00448)$ \\
\hline \multirow[t]{2}{*}{ Quartertoelect $=8$} & 0.00772 & 0.00870 & 0.00519 & 0.00528 \\
\hline & $(0.0141)$ & $(0.0142)$ & $(0.00446)$ & $(0.00415)$ \\
\hline \multirow[t]{2}{*}{ Quartertoelect $=9$} & -0.0115 & -0.00718 & $0.0120^{* *}$ & $0.00891^{*}$ \\
\hline & $(0.0155)$ & $(0.0157)$ & $(0.00500)$ & $(0.00490)$ \\
\hline \multirow[t]{2}{*}{ Quartertoelect $=10$} & -0.0114 & -0.0110 & 0.00647 & 0.00326 \\
\hline & $(0.0160)$ & $(0.0168)$ & $(0.00482)$ & $(0.00490)$ \\
\hline \multirow[t]{2}{*}{ Quartertoelect $=11$} & 0.000311 & 0.00269 & 0.00706 & 0.00364 \\
\hline & $(0.0162)$ & $(0.0167)$ & $(0.00499)$ & $(0.00497)$ \\
\hline \multirow[t]{2}{*}{ Quartertoelect $=12$} & -0.0102 & -0.00929 & -0.00102 & -0.00117 \\
\hline & $(0.0128)$ & $(0.0129)$ & $(0.00382)$ & $(0.00351)$ \\
\hline \multirow[t]{2}{*}{ Quartertoelect $=13$} & 0.00115 & 0.00451 & 0.00450 & 0.00141 \\
\hline & $(0.0148)$ & $(0.0151)$ & $(0.00385)$ & $(0.00374)$ \\
\hline \multirow[t]{2}{*}{ Quartertoelect $=14$} & -0.0157 & -0.0159 & 0.000920 & -0.00234 \\
\hline & $(0.0134)$ & $(0.0147)$ & $(0.00382)$ & $(0.00391)$ \\
\hline \multirow[t]{2}{*}{ Quartertoelect $=15$} & -0.0176 & -0.0154 & -0.000372 & -0.00386 \\
\hline & $(0.0117)$ & $(0.0121)$ & $(0.00391)$ & $(0.00377)$ \\
\hline Year FE & Yes & Yes & Yes & Yes \\
\hline Circuit FE & Yes & Yes & Yes & Yes \\
\hline Season FE & No & Yes & No & Yes \\
\hline Legal Issue FE & No & Yes & No & No \\
\hline Observations & 18686 & 18686 & 263388 & 263388 \\
\hline R-squared & 0.019 & 0.021 & 0.012 & 0.013 \\
\hline
\end{tabular}


Table 2: Electoral Cycles in the Correlation between Party of Appointment and Judges' Votes

\begin{tabular}{|c|c|c|c|c|}
\hline \multirow[t]{2}{*}{ Panel $A$} & $(1)$ & $(2)$ & $(3)$ & $(4)$ \\
\hline & \multicolumn{4}{|c|}{ Liberal Vote (5\% Sample, 1925-2002) } \\
\hline Code & \multicolumn{2}{|c|}{$+1 / 0 /-1$} & +1 vs. $0 /-1$ & $+1 / 0$ vs. -1 \\
\hline Mean of dep. var. & \multicolumn{2}{|c|}{-0.157} & 0.340 & 0.503 \\
\hline \multirow[t]{2}{*}{ Judge appointed by Democrat } & $0.0849^{* * *}$ & $0.0708^{* * *}$ & $0.0348^{* * *}$ & $0.0359^{* * *}$ \\
\hline & $(0.00910)$ & $(0.00821)$ & $(0.00416)$ & $(0.00462)$ \\
\hline \multirow{2}{*}{$\begin{array}{l}\text { Judge appointed by Democrat } \\
\text { * Last Quarter }\end{array}$} & $0.0684^{* *}$ & $0.0712^{*}$ & $0.0394^{*}$ & $0.0319 *$ \\
\hline & $(0.0335)$ & $(0.0365)$ & $(0.0211)$ & $(0.0177)$ \\
\hline Year FE & No & Yes & Yes & Yes \\
\hline Circuit FE & No & Yes & Yes & Yes \\
\hline Season FE & No & Yes & Yes & Yes \\
\hline Legal Issue FE & No & Yes & Yes & Yes \\
\hline Divided (RDD or DRR) FE & No & Yes & Yes & Yes \\
\hline Quarter-to-Election FE & No & Yes & Yes & Yes \\
\hline Observations & 56058 & 56058 & 56058 & 56058 \\
\hline R-squared & 0.002 & 0.087 & & \\
\hline \multirow[t]{2}{*}{ Panel B } & \multicolumn{4}{|c|}{ Liberal Precedent (5\% Sample, 1925-2002) } \\
\hline & \multicolumn{4}{|c|}{ Politically unified panels (DDD or RRR) } \\
\hline \multirow{3}{*}{$\begin{array}{l}\text { Mean of dep. var. } \\
\text { Panel appointed by Democrat }\end{array}$} & & & 0.344 & 0.517 \\
\hline & $0.168^{* * *}$ & $0.164^{* * *}$ & $0.0753^{* * *}$ & $0.0883^{* * *}$ \\
\hline & $(0.0257)$ & $(0.0302)$ & $(0.0165)$ & $(0.0160)$ \\
\hline \multirow{2}{*}{$\begin{array}{l}\text { Panel appointed by Democrat } \\
\text { * Last Quarter }\end{array}$} & $0.217^{*}$ & $0.207^{*}$ & 0.0828 & $0.124^{*}$ \\
\hline & $(0.124)$ & $(0.125)$ & $(0.0683)$ & $(0.0633)$ \\
\hline Year FE & No & Yes & Yes & Yes \\
\hline Circuit FE & No & Yes & Yes & Yes \\
\hline Season FE & No & Yes & Yes & Yes \\
\hline Legal Issue FE & No & Yes & Yes & Yes \\
\hline Divided (RDD or DRR) FE & No & Yes & Yes & Yes \\
\hline Quarter-to-Election FE & No & Yes & Yes & Yes \\
\hline Observations & 5659 & 5659 & 5659 & 5659 \\
\hline R-squared & 0.011 & 0.101 & & \\
\hline
\end{tabular}

Notes: Robust OLS standard errors clustered at the quarter-year level in parentheses ${ }^{*} \mathrm{p}<0.10$; ** $\mathrm{p}<0.05$; *** $\mathrm{p}<0.01)$. Panel A: Vote-level regression. The outcome variable is Liberal Vote, which is coded as 1 for liberal, 0 for mixed or not applicable, and -1 for conservative. Panel B: Case-level regression. The outcome variable is Liberal Precedent. 


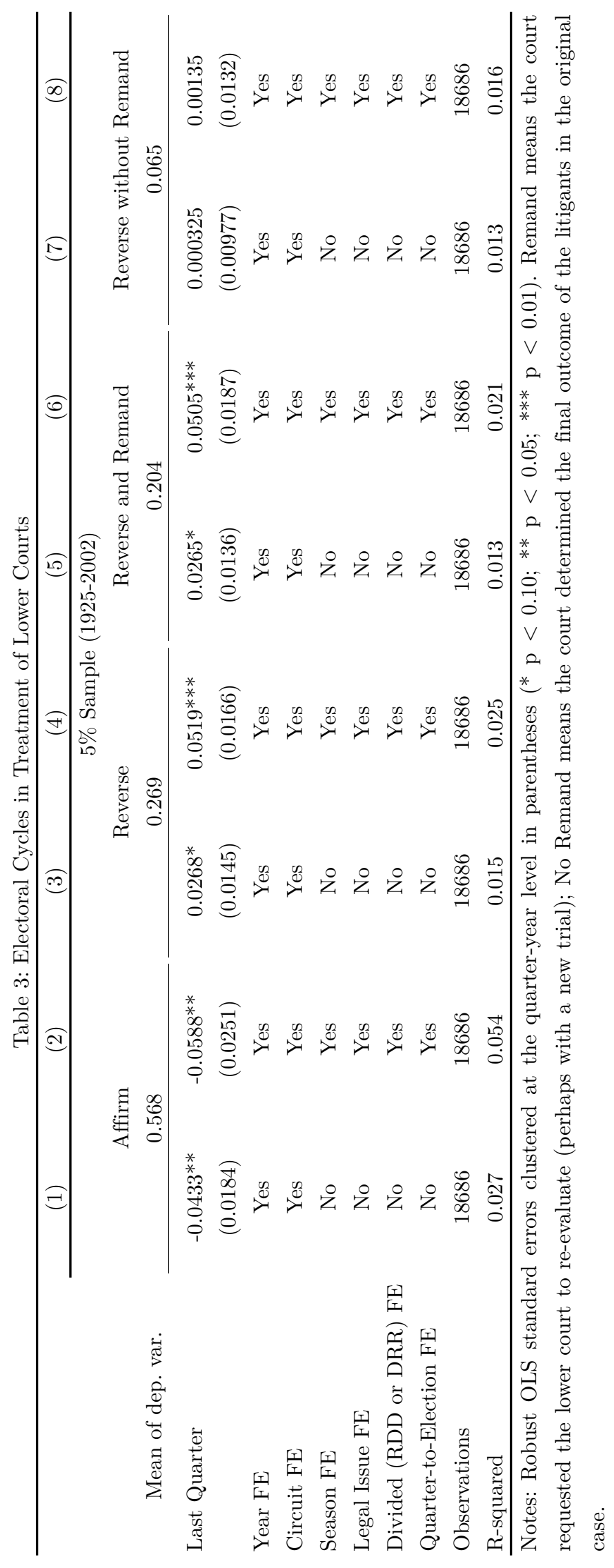




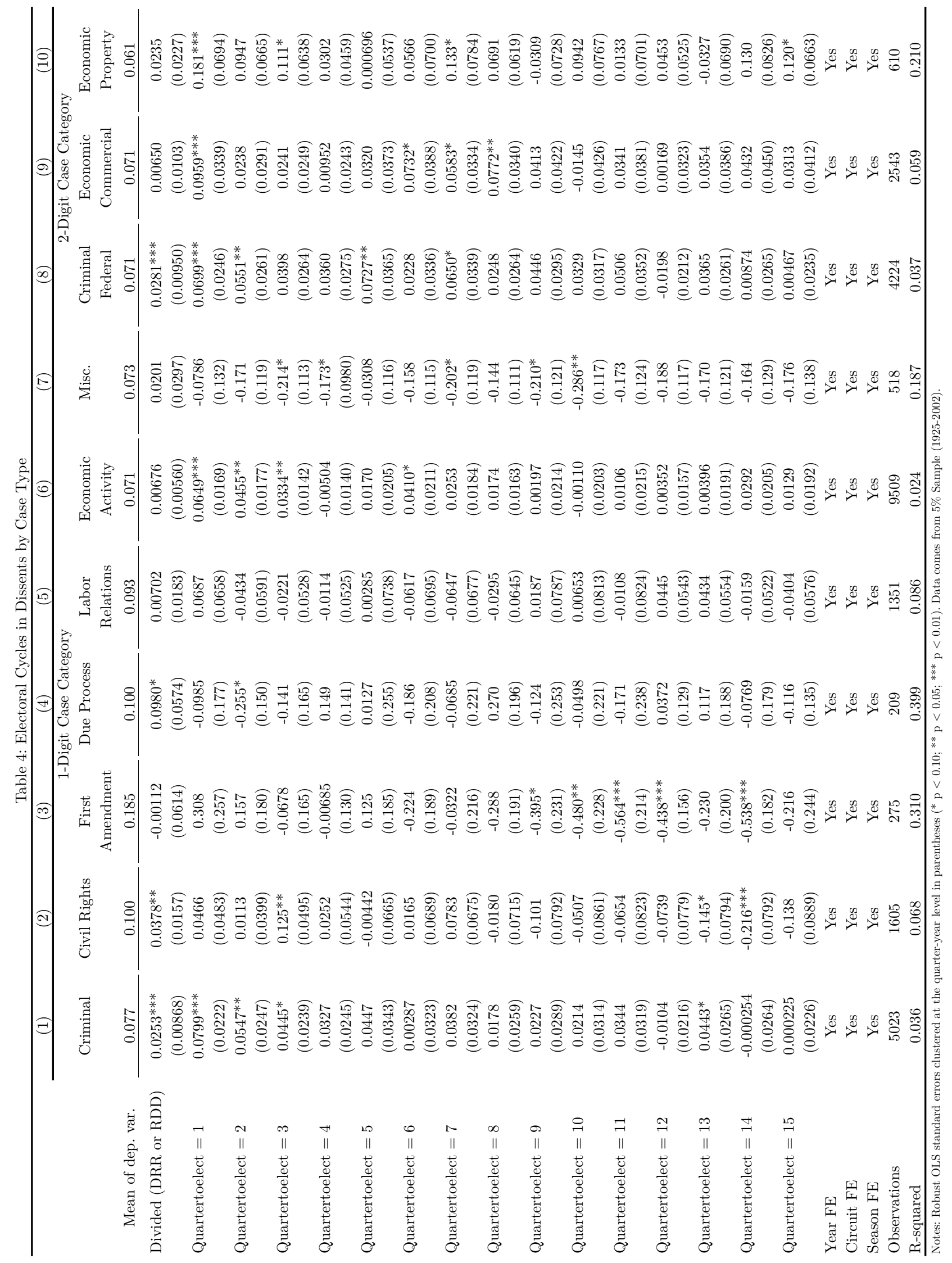


Table 5: Characteristics of Opinions before Presidential Elections

\begin{tabular}{|c|c|c|c|c|}
\hline \multirow[t]{2}{*}{ Panel A: Quality } & (1) & $(2)$ & $(3)$ & $(4)$ \\
\hline & \multicolumn{4}{|c|}{$5 \%$ Sample (1925-2002) } \\
\hline Mean of dep. var. & $\begin{array}{l}\text { Citations by } \\
\text { Subsequent } \\
\text { Opinions } \\
6.142 \\
\end{array}$ & $\begin{array}{c}\text { Citations by } \\
\text { Subsequent Dissents } \\
0.549 \\
\end{array}$ & \multicolumn{2}{|c|}{$\begin{array}{l}\text { Dissent for Non-Merit, Procedural } \\
\text { Grounds } \\
0.093\end{array}$} \\
\hline Last Quarter & $\begin{array}{c}0.575 \\
(0.519)\end{array}$ & $\begin{array}{l}-0.0201 \\
(0.0435)\end{array}$ & $\begin{array}{l}0.0785^{* *} \\
(0.0289)\end{array}$ & $\begin{array}{l}0.100 * * \\
(0.0469)\end{array}$ \\
\hline Dissent & $\begin{array}{c}2.090^{* * *} \\
(0.254)\end{array}$ & $\begin{array}{l}0.415^{* * *} \\
(0.0362)\end{array}$ & & \\
\hline Last Quarter * Dissent & $\begin{array}{l}-0.211 \\
(1.210)\end{array}$ & $\begin{array}{c}-0.281^{* *} \\
(0.113)\end{array}$ & & \\
\hline Year FE & Yes & Yes & No & Yes \\
\hline Circuit FE & Yes & Yes & No & Yes \\
\hline Season FE & Yes & Yes & No & Yes \\
\hline Legal Issue FE & Yes & Yes & No & Yes \\
\hline Divided (RDD or DRR) FE & Yes & Yes & No & Yes \\
\hline Quarter-to-Election FE & Yes & Yes & No & Yes \\
\hline Observations & 18684 & 18684 & 227 & 227 \\
\hline R-squared & 0.164 & 0.076 & 0.038 & 0.204 \\
\hline Panel B: Treatment by & & $5 \%$ Sample & 925-2002) & \\
\hline Supreme Court & $\begin{array}{l}\text { Appeal Made to } \\
\text { Supreme Court }\end{array}$ & $\begin{array}{l}\text { Supreme Court } \\
\text { Takes Case }\end{array}$ & $\begin{array}{l}\text { Supreme Court } \\
\text { Reverses }\end{array}$ & $\begin{array}{l}\text { Supreme Court } \\
\text { Reverses }\end{array}$ \\
\hline Mean of dep. var. & 0.252 & 0.029 & 0.712 & 0.705 \\
\hline Last Quarter & $\begin{array}{c}0.0176 \\
(0.0217)\end{array}$ & $\begin{array}{c}0.00655 \\
(0.00905)\end{array}$ & $\begin{array}{l}-0.206 \\
(0.146)\end{array}$ & $\begin{array}{l}-0.151 \\
(0.336)\end{array}$ \\
\hline Dissent & $\begin{array}{l}0.139^{* * *} \\
(0.0131)\end{array}$ & $\begin{array}{l}0.0446^{* * *} \\
(0.00729)\end{array}$ & $\begin{array}{c}0.0102 \\
(0.0642)\end{array}$ & \\
\hline Last Quarter * Dissent & $\begin{array}{c}0.0131 \\
(0.0434)\end{array}$ & $\begin{array}{l}0.00961 \\
(0.0324)\end{array}$ & $\begin{array}{l}-0.340^{*} \\
(0.194)\end{array}$ & \\
\hline Partisan Precedent & & & & $\begin{array}{l}-0.0157 \\
(0.0838)\end{array}$ \\
\hline $\begin{array}{l}\text { Last Quarter * Partisan } \\
\text { Precedent }\end{array}$ & & & & $\begin{array}{l}0.0345 \\
(0.316)\end{array}$ \\
\hline Year FE & Yes & Yes & Yes & No \\
\hline Circuit FE & Yes & Yes & Yes & Yes \\
\hline Season FE & Yes & Yes & Yes & Yes \\
\hline Legal Issue FE & Yes & Yes & Yes & Yes \\
\hline Divided (RDD or DRR) FE & Yes & Yes & Yes & Yes \\
\hline Quarter-to-Election FE & Yes & Yes & Yes & Yes \\
\hline Observations & 18686 & 18686 & 549 & 183 \\
\hline R-squared & 0.040 & 0.019 & 0.217 & 0.129 \\
\hline
\end{tabular}

Notes: Robust OLS standard errors clustered at the quarter-year level in parentheses $\left({ }^{*} \mathrm{p}<0.10 ;{ }^{* *} \mathrm{p}<0.05 ;{ }^{* * *} \mathrm{p}<0.01\right)$. Panel

A: The outcome variables are the total number of times the case has been cited in subsequent opinions winsorized at the $1 \%$ level (Column 1), the total number of time the case has been cited in subsequent dissents winsorized at the $1 \%$ level (Column 2), and a dummy variable equal to 1 if the dissenting opinion focused on procedural rather than merit issues (Columns 3-4). Panel B: The outcome variables are whether the appellate case was subsequently appealed to the Supreme Court (Column 1), whether the Supreme Court actually took the case (Column 2), and whether the Supreme Court reversed any part of the case (Columns 3-4). The sample in Column 4 is restricted to politically unified panels (DDD or RRR). Partisan Precedent is 1 if the panel was appointed by Democrats and made a liberal decision or if the panel was appointed by Republicans and made a conservative 


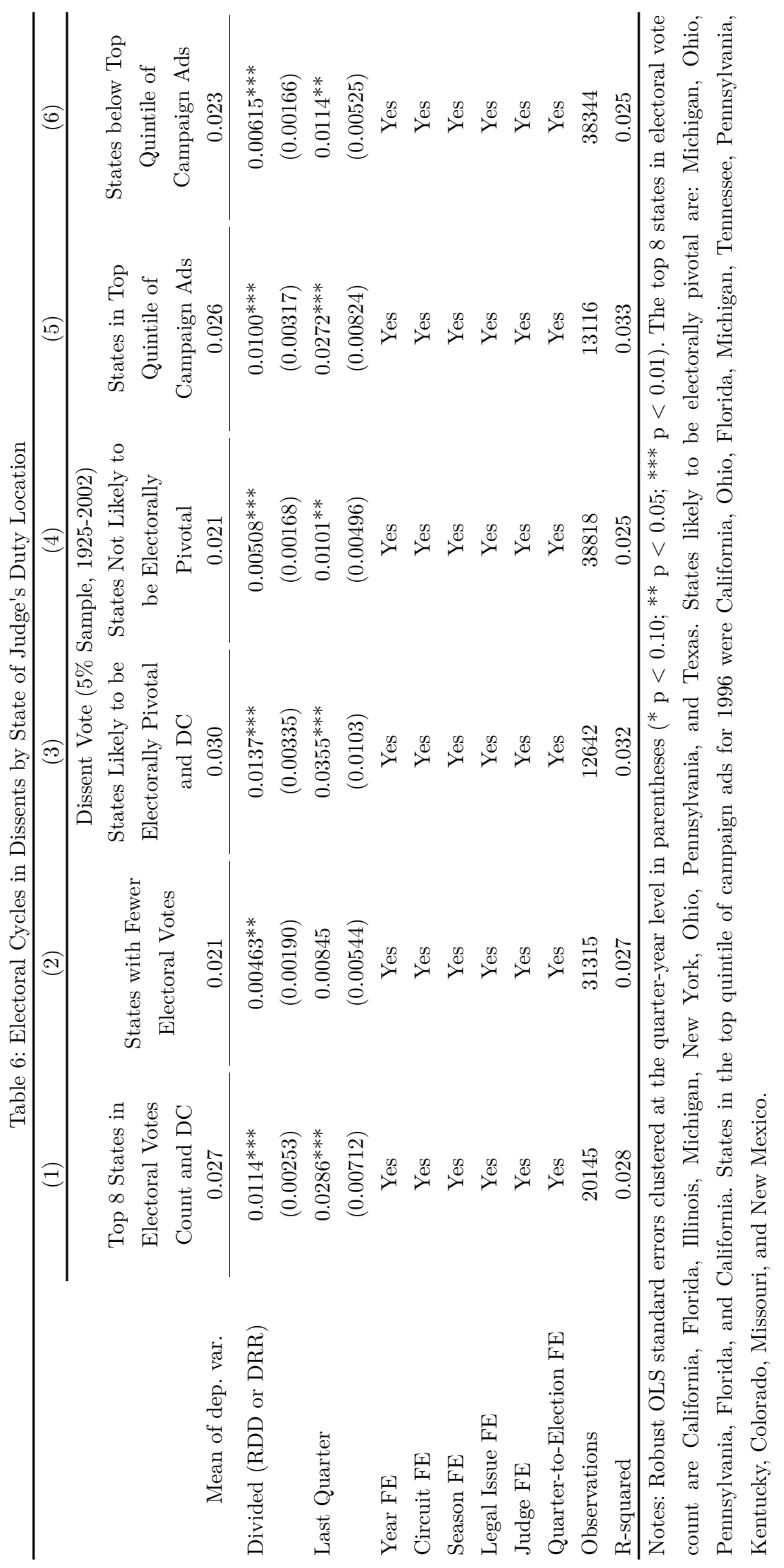




\begin{tabular}{|c|c|c|c|}
\hline & $(1)$ & $(2)$ & $(3)$ \\
\hline & \multicolumn{3}{|c|}{$\begin{array}{l}\text { Dissent Rate in the Three Quarters Before Election } \\
\qquad 5 \% \text { Sample (1925-2002) }\end{array}$} \\
\hline Mean of dep. var. & 0.023 & 0.027 & 0.033 \\
\hline \multicolumn{4}{|l|}{ State of Dissenting Judge } \\
\hline Electoral Vote Count & $\begin{array}{l}-0.00193^{*} \\
(0.00100)\end{array}$ & & \\
\hline Popular Vote Tightness & $\begin{array}{l}-0.0335 \\
(0.0305)\end{array}$ & & \\
\hline $\begin{array}{l}\text { Electoral Vote Count } \\
\text { * Popular Vote Tightness }\end{array}$ & $\begin{array}{r}0.00239^{* *} \\
(0.00115)\end{array}$ & & \\
\hline \multicolumn{4}{|l|}{ State of Majority Author } \\
\hline Electoral Vote Count & & $\begin{array}{l}-0.00194^{*} \\
(0.00114)\end{array}$ & \\
\hline Popular Vote Tightness & & $\begin{array}{l}-0.00950 \\
(0.0261)\end{array}$ & \\
\hline $\begin{array}{l}\text { Electoral Vote Count } \\
\text { * Popular Vote Tightness }\end{array}$ & & $\begin{array}{c}0.00200 \\
(0.00134)\end{array}$ & \\
\hline \multicolumn{4}{|l|}{ State of Third Panel Member } \\
\hline Electoral Vote Count & & & $\begin{array}{r}-0.000994 \\
(0.00223)\end{array}$ \\
\hline Popular Vote Tightness & & & $\begin{array}{l}-0.0202 \\
(0.0270)\end{array}$ \\
\hline $\begin{array}{l}\text { Electoral Vote Count } \\
\text { * Popular Vote Tightness }\end{array}$ & & & $\begin{array}{l}0.000859 \\
(0.00237)\end{array}$ \\
\hline Election FE & Yes & Yes & Yes \\
\hline Circuit FE & Yes & Yes & Yes \\
\hline Observations & 804 & 804 & 804 \\
\hline R-squared & 0.075 & 0.087 & 0.083 \\
\hline
\end{tabular}

Notes: Robust OLS standard errors double-clustered at the election and state level in parentheses $\left(^{*} \mathrm{p}<0.10 ; * *\right.$ $\mathrm{p}<0.05$; $\left.^{* *} \mathrm{p}<0.01\right)$. Each election-state is a separate observation. Dissent rate in the three quarters before the election is winsorized at the $1 \%$ level. Dissent rate is the proportion of cases where the judge dissents (Column 1), authors the majority opinion and someone else dissents (Column 2), and sits on a case with a dissent, but was neither the author nor dissenter (Column 3). Regressions are weighted by the number of judgments used to compute the average dissent rate. Electoral vote count is the number of electoral college votes for a given state where a judge resides in a given election, which ranges from 3 to 55 . Popular vote tightness is 1 minus the absolute value of the difference in the popular vote fraction won by Republicans vs. won by Democrats. Values that are more positive indicate a tighter election. The mean popular vote tightness is 0.82 . 


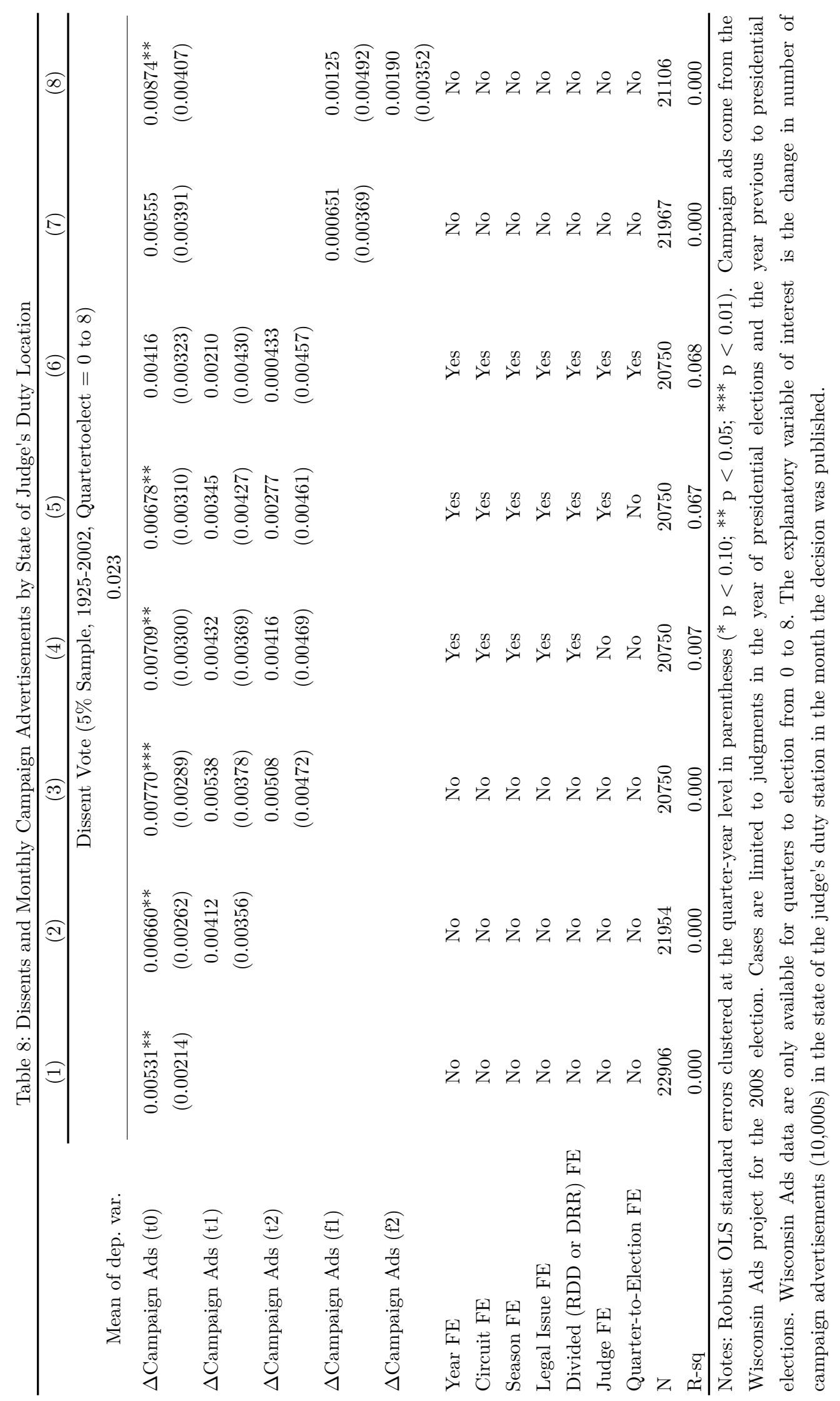




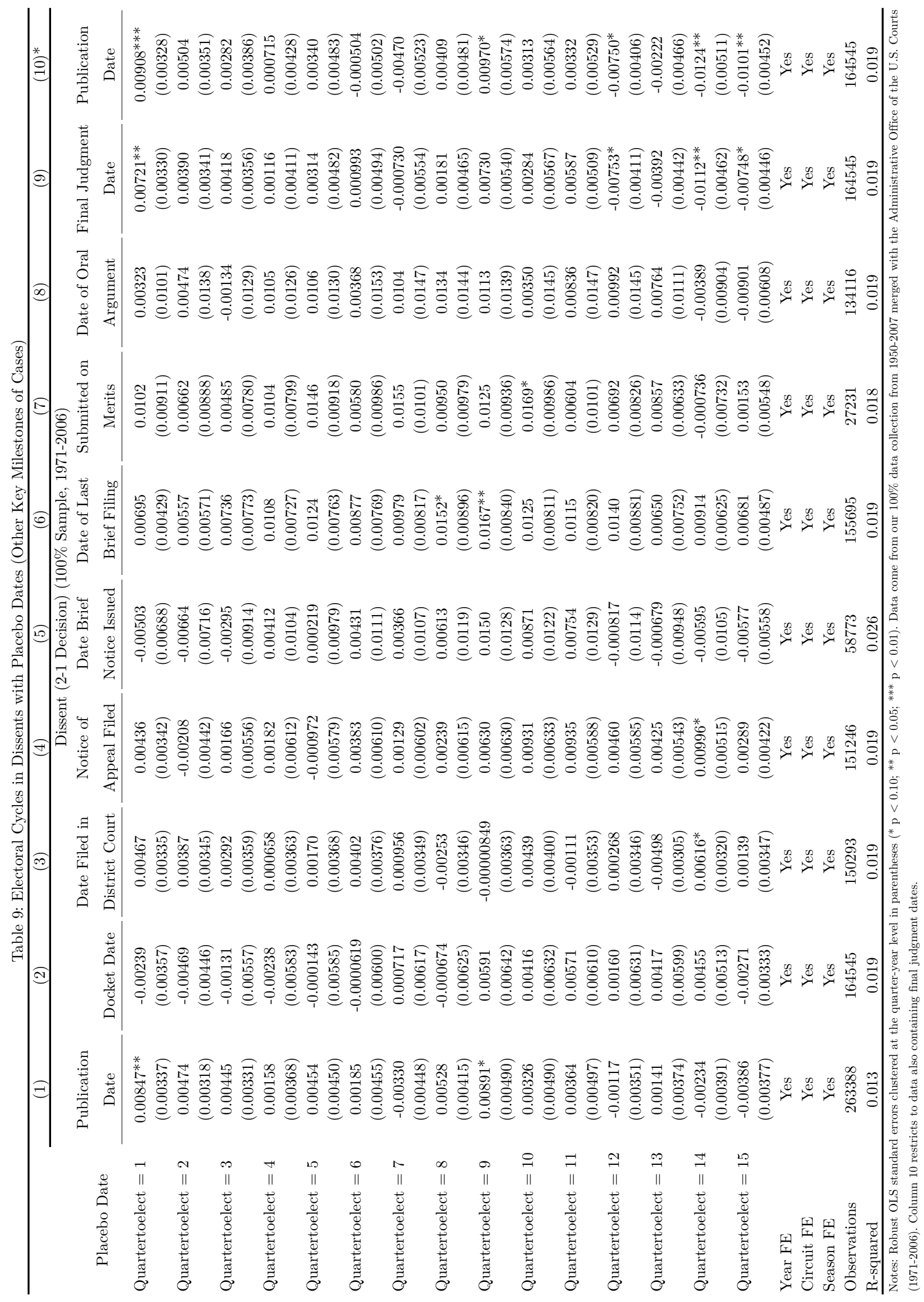


Table 10: Electoral Cycles in Dissents by Type of Presidential Election

\begin{tabular}{|c|c|c|c|c|}
\hline \multirow[t]{2}{*}{ Panel A: 5\% Sample (1925-2002) } & (1) & $(2)$ & $(3)$ & $(4)$ \\
\hline & \multicolumn{4}{|c|}{ Dissent (2-1 Decision) } \\
\hline Mean of dep. var. & \multicolumn{4}{|c|}{0.079} \\
\hline Last Three Quarters & $0.0389 * * *$ & $0.0505^{* * *}$ & $0.0548^{* * *}$ & $0.0521^{* * *}$ \\
\hline & $(0.00835)$ & $(0.00979)$ & $(0.00911)$ & $(0.00907)$ \\
\hline Close Election (Electoral Count $<55 \%$ ) & $0.0830 * * *$ & & & $0.0798^{* * *}$ \\
\hline & $(0.0170)$ & & & $(0.0157)$ \\
\hline Close Election (Electoral Count $<55 \%$ ) & $0.0851^{* *}$ & & & $0.0718^{*}$ \\
\hline * Last Three Quarters & $(0.0395)$ & & & $(0.0396)$ \\
\hline \multirow[t]{2}{*}{ Landslide Election (Electoral Count > 95\%) } & & 0.0218 & & 0.00615 \\
\hline & & $(0.0173)$ & & $(0.0166)$ \\
\hline Landslide Election (Electoral Count > 95\%) & & $-0.0399 * * *$ & & $-0.0201^{*}$ \\
\hline * Last Three Quarters & & $(0.0145)$ & & $(0.0102)$ \\
\hline \multirow[t]{2}{*}{ War } & & & 0.0192 & 0.0192 \\
\hline & & & $(0.0130)$ & $(0.0130)$ \\
\hline War & & & $-0.0605^{* * *}$ & $-0.0500^{* * *}$ \\
\hline * Last Three Quarters & & & $(0.0113)$ & $(0.0110)$ \\
\hline Year FE & Yes & Yes & Yes & Yes \\
\hline Circuit FE & Yes & Yes & Yes & Yes \\
\hline Season FE & Yes & Yes & Yes & Yes \\
\hline Legal Issue FE & Yes & Yes & Yes & Yes \\
\hline Divided (RDD or DRR) FE & Yes & Yes & Yes & Yes \\
\hline Observations & 18686 & 18686 & 18686 & 18686 \\
\hline R-squared & 0.020 & 0.020 & 0.021 & 0.021 \\
\hline
\end{tabular}

Panel B: 100\% Sample (1950-2007)

Dissent Spike: Dissent Rate in Three Quarters Before Election

- Dissent Rate in Three Quarters After Election

Mean of dep. var.

0.0068

(1)

Electoral Count (\%)

Circuit FE

Observations

R-squared

$\begin{array}{cc} & 0.0068 \\ (1) & (2) \\ -0.000192^{* *} & -0.000191^{* *} \\ (0.0000853) & (0.0000857) \\ \mathrm{N} & \mathrm{Y} \\ 160 & 160 \\ 0.018 & 0.078\end{array}$

Notes: Robust OLS standard errors in parentheses $\left.{ }^{*} \mathrm{p}<0.10 ;{ }^{* *} \mathrm{p}<0.05 ;{ }^{* * *} \mathrm{p}<0.01\right)$. Electoral Count is the percentage of the electoral college achieved by the winning political party, which ranges from 50 to 100 . Panel A: Standard errors clustered at the quarter-year level. The explanatory variables of interest are a dummy variable indicating whether a case was decided in the three quarters immediately preceding a presidential election and the interaction with a dummy variable indicating whether the margin of victory in the electoral count was less than $10 \%$ (Column 1), a dummy variable indicating whether the margin of victory in the electoral count was more than 90\% (Column 2), and a dummy variable indicating whether the decision was made during wartime (Column 3 ). Panel B: Each election-circuit is a separate observation. Dissent spike is the difference in the dissent rate in the three quarters before and after the election and is winsorized at the $1 \%$ level. Regressions are weighted by the number of judgments used to compute the dissent spike. Standard errors are clustered at the Election level. 
Table 11: Electoral Cycles in Dissents and Influence of Party of Appointment on Voting Valence Across Time

\begin{tabular}{|c|c|c|c|c|}
\hline & $(1)$ & $(2)$ & $(3)$ & $(4)$ \\
\hline & \multicolumn{2}{|c|}{ Dissent (2-1 Decision) } & \multicolumn{2}{|c|}{ Liberal Vote } \\
\hline & \multicolumn{2}{|c|}{$5 \%$ Sample } & \multicolumn{2}{|c|}{$5 \%$ Sample } \\
\hline & \multicolumn{2}{|c|}{$(1925-2002)$} & \multicolumn{2}{|c|}{$(1925-2002)$} \\
\hline Mean of dep. var. & \multicolumn{2}{|c|}{0.079} & \multicolumn{2}{|c|}{-0.157} \\
\hline Last Quarter & $0.0429^{* *}$ & $0.0429 * *$ & & \\
\hline & $(0.0178)$ & $(0.0178)$ & & \\
\hline Year $>1975 *$ Last Quarter & $0.0439^{* *}$ & $0.0480^{* *}$ & & \\
\hline & $(0.0201)$ & $(0.0222)$ & & \\
\hline \multirow[t]{2}{*}{ Democrat Appointee } & & & $0.0523^{* * *}$ & $0.0513^{* * *}$ \\
\hline & & & $(0.0106)$ & $(0.0110)$ \\
\hline Democrat Appointee & & & $0.0462^{* * *}$ & $0.0398^{* *}$ \\
\hline * Year > 1975 & & & $(0.0159)$ & $(0.0171)$ \\
\hline \multirow[t]{2}{*}{ Born on or after 1940} & & 0.00560 & & $-0.0334^{*}$ \\
\hline & & $(0.0163)$ & & $(0.0200)$ \\
\hline Born on or after 1940 & & -0.0254 & & \\
\hline * Last Quarter & & $(0.0689)$ & & \\
\hline Born on or after 1940 & & & & $0.0714^{* *}$ \\
\hline * Democrat Appointee & & & & $(0.0320)$ \\
\hline Year FE & Yes & Yes & Yes & Yes \\
\hline Circuit FE & Yes & Yes & Yes & Yes \\
\hline Season FE & Yes & Yes & Yes & Yes \\
\hline Legal Issue FE & Yes & Yes & Yes & Yes \\
\hline Divided (RDD or DRR) FE & Yes & Yes & Yes & Yes \\
\hline Quarter-to-Election FE & Yes & Yes & Yes & Yes \\
\hline Observations & 18686 & 18686 & 56058 & 51460 \\
\hline R-squared & 0.022 & 0.022 & 0.087 & 0.088 \\
\hline
\end{tabular}


Table 12: Judicial Experience and Electoral Cycles in Dissents

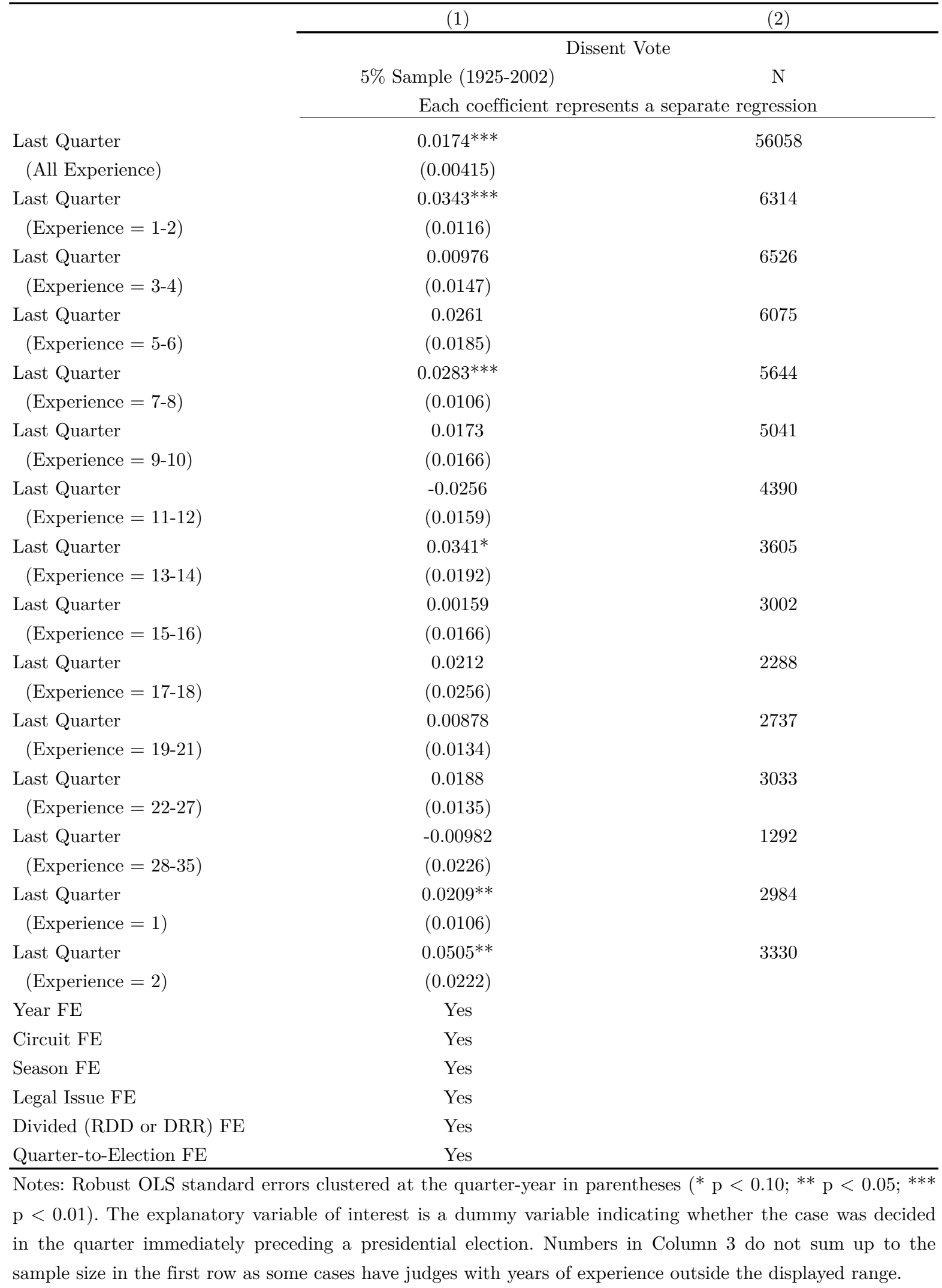




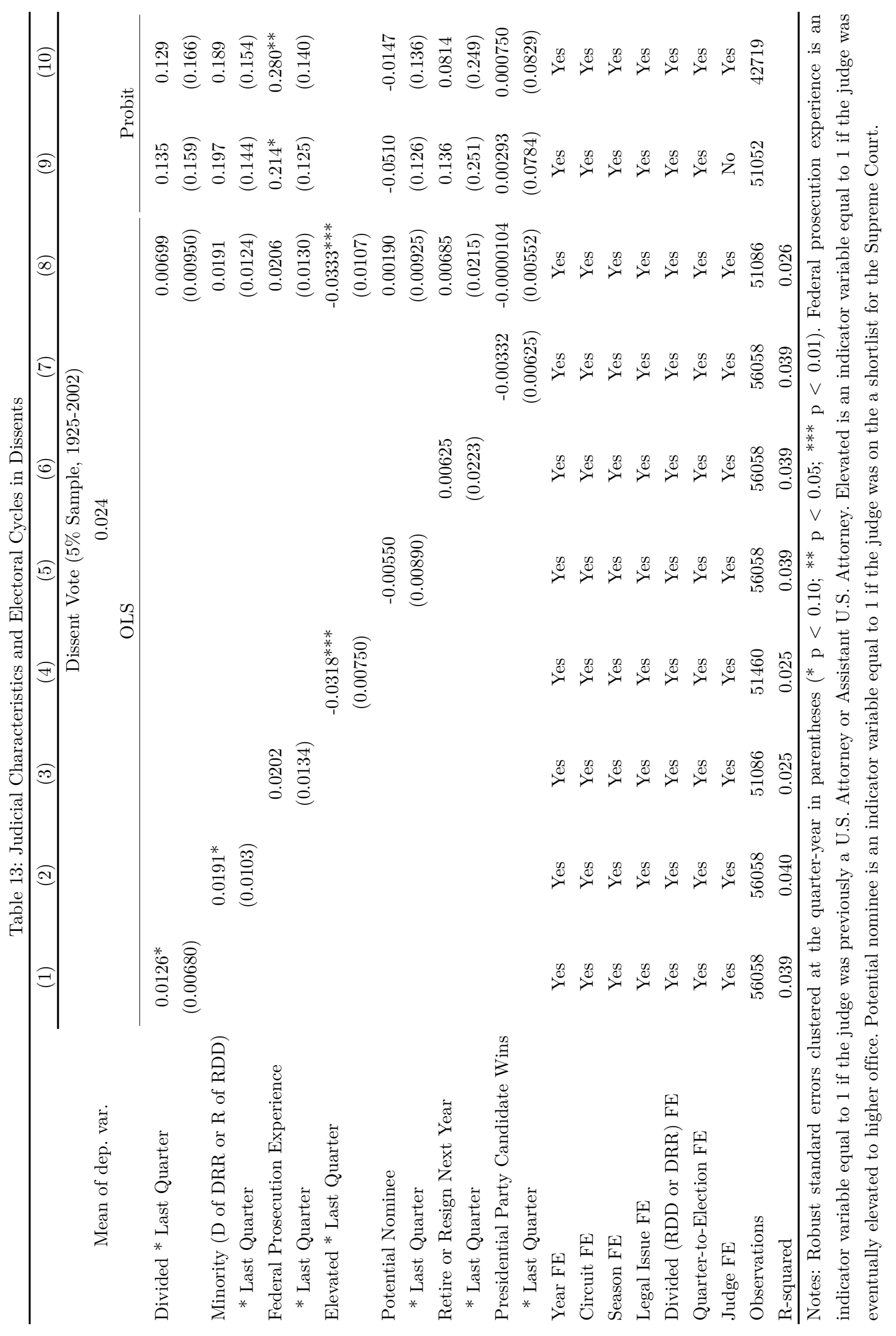




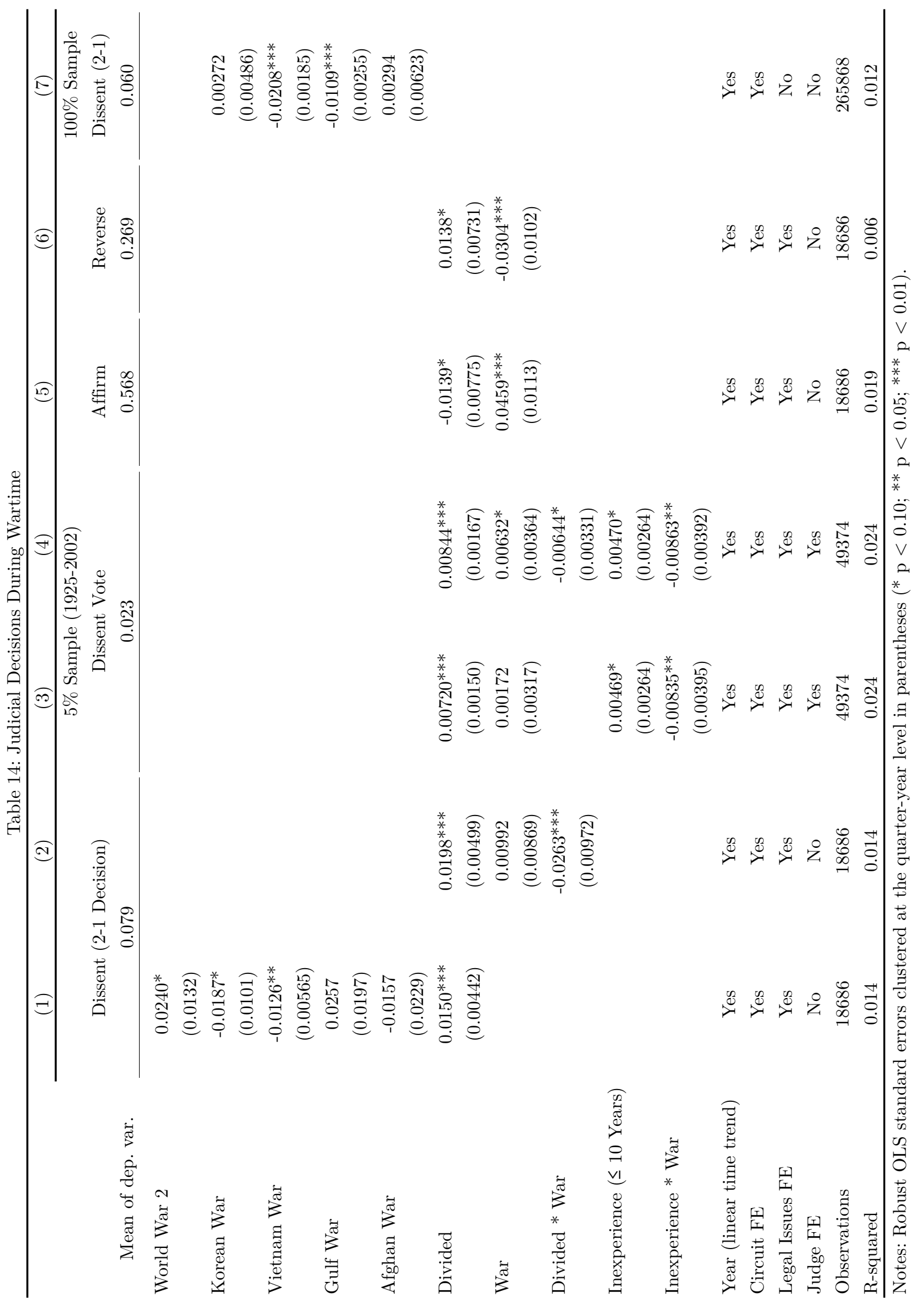


Appendix 
Appendix Table A: Summary Statistics

\begin{tabular}{|c|c|c|c|}
\hline \multicolumn{2}{|c|}{ Panel A: Case Level } & \multicolumn{2}{|c|}{ Panel B: Judge-Vote Level } \\
\hline & 5\% Sample & & $5 \%$ Sample \\
\hline & $(1925-2002)$ & & $(1925-2002)$ \\
\hline \multirow[t]{2}{*}{ Dissent } & 0.0786 & Dissent & 0.0234 \\
\hline & $(0.00197)$ & & $(0.000638)$ \\
\hline \multirow[t]{2}{*}{ Divided (DRR or RDD) } & 0.697 & Majority & 0.768 \\
\hline & $(0.00336)$ & & $(0.00178)$ \\
\hline \multirow[t]{2}{*}{ Criminal } & 0.269 & Previous US Attorney & 0.154 \\
\hline & $(0.00324)$ & or Assistant US Attorney & $(0.00160)$ \\
\hline \multirow[t]{2}{*}{ Civil Rights } & 0.0859 & Democrat & 0.510 \\
\hline & $(0.00205)$ & & $(0.00211)$ \\
\hline \multirow{2}{*}{$\begin{array}{l}\text { First Amendment, } \\
\text { Due Process, Privacy }\end{array}$} & 0.0281 & Appointed by Democrat & 0.491 \\
\hline & $(0.00121)$ & & $(0.00211)$ \\
\hline \multirow[t]{2}{*}{ Labor Relations } & 0.0723 & Presidential Party Candidate & 0.496 \\
\hline & $(0.00189)$ & Wins Election & $(0.00211)$ \\
\hline \multirow[t]{2}{*}{ Economic Activity } & 0.509 & Close Election & 0.048 \\
\hline & $(0.00366)$ & (Electoral Count < 55\%) & $(0.00090)$ \\
\hline \multirow{2}{*}{$\begin{array}{l}\text { Dissent for Procedural, } \\
\text { not Merit Reasons }\end{array}$} & 0.0925 & Age & 62.19 \\
\hline & $(0.0193)$ & & $(0.0393)$ \\
\hline \multirow{2}{*}{$\begin{array}{l}\text { Citations by Subsequent } \\
\text { Opinions }\end{array}$} & 6.143 & Experience & 10.33 \\
\hline & $(0.0693)$ & & $(0.0335)$ \\
\hline Citations by Subsequent & 0.549 & Inexperience & 0.600 \\
\hline Dissents & $(0.00787)$ & (Experience $\leq 10$ years $)$ & $(0.00221)$ \\
\hline \multirow[t]{2}{*}{ Affirm } & 0.568 & Elevated & 0.0161 \\
\hline & $(0.00362)$ & & $(0.000555)$ \\
\hline \multirow[t]{2}{*}{ Reverse } & 0.269 & Retire Next Year & 0.0309 \\
\hline & $(0.00303)$ & & $(0.000731)$ \\
\hline $\mathrm{N}$ & 18686 & $\mathrm{~N}$ & 56147 \\
\hline \multicolumn{2}{|c|}{ Panel C: Judge Level } & \multicolumn{2}{|c|}{ Voting Valence if Democratic Appointee } \\
\hline \multirow[t]{2}{*}{ Resignation } & 0.0230 & & Judge \\
\hline & $(0.00310)$ & Conservative & $47 \%$ \\
\hline \multirow[t]{2}{*}{ Retirement } & 0.124 & Liberal & $36 \%$ \\
\hline & $(0.00870)$ & Mixed & $6 \%$ \\
\hline Retirement, when & 0.0506 & Could not be determined & $11 \%$ \\
\hline Same Party in Power & $(0.00521)$ & $\mathrm{N}$ & 27550 \\
\hline Retirement, when & 0.0732 & \multicolumn{2}{|c|}{ Voting Valence if Republican Appointee } \\
\hline Different Party in Power & $(0.00611)$ & & Judge \\
\hline Resignation, when & 0.0152 & Conservative & $52 \%$ \\
\hline Same Party in Power & $(0.00248)$ & Liberal & $32 \%$ \\
\hline Resignation, when & 0.00781 & Mixed & $7 \%$ \\
\hline Different Party in Power & $(0.00178)$ & Could not be determined & $9 \%$ \\
\hline $\mathrm{N}$ & 2433 & $\mathrm{~N}$ & 28597 \\
\hline
\end{tabular}

Note: Coefficients shown are from an OLS regression on a constant. 
Appendix Table B: Electoral Cycles - Robustness Checks

\begin{tabular}{|c|c|c|c|c|c|c|c|c|}
\hline & $(1)$ & $(2)$ & $(3)$ & $(4)$ & $(5)$ & $(6)$ & $(7)$ & $(8)$ \\
\hline & & & & $5 \%$ Sampl & e $(1925-200$ & & & \\
\hline & & & Disse & nt (2-1 Dec & cision) & & & Concurrence \\
\hline Mean of dep. var. & & & & 0.079 & & & & 0.036 \\
\hline Quartertoelect $=1$ & $0.0680^{* * *}$ & $0.0653^{* * *}$ & $0.0527 * * *$ & $0.0668^{* * *}$ & $0.0868^{* * *}$ & $0.0680^{* * *}$ & $0.0667^{* * *}$ & $0.0195^{* *}$ \\
\hline & $(0.0135)$ & $(0.0146)$ & $(0.0132)$ & $(0.0135)$ & $(0.0221)$ & $(0.0124)$ & $(0.0134)$ & $(0.00767)$ \\
\hline Quartertoelect $=2$ & $0.0341^{* *}$ & 0.0256 & $0.0255^{*}$ & $0.0331^{* *}$ & $0.0457^{* *}$ & $0.0341^{* * *}$ & $0.0329^{* *}$ & $0.0182^{* *}$ \\
\hline & $(0.0145)$ & $(0.0163)$ & $(0.0138)$ & $(0.0145)$ & $(0.0205)$ & $(0.0106)$ & $(0.0144)$ & $(0.00725)$ \\
\hline Quartertoelect $=3$ & $0.0343^{* *}$ & $0.0291^{*}$ & $0.0302^{* *}$ & $0.0335^{* *}$ & $0.0451^{* *}$ & $0.0343^{* * *}$ & $0.0337^{* *}$ & 0.00923 \\
\hline & $(0.0133)$ & $(0.0149)$ & $(0.0134)$ & $(0.0133)$ & $(0.0192)$ & $(0.00956)$ & $(0.0133)$ & $(0.00598)$ \\
\hline Quartertoelect $=4$ & 0.00582 & 0.0135 & 0.00578 & 0.00580 & 0.00669 & 0.00582 & 0.00549 & 0.00495 \\
\hline & $(0.0111)$ & $(0.0135)$ & $(0.0111)$ & $(0.0111)$ & $(0.0133)$ & $(0.0116)$ & $(0.0110)$ & $(0.00733)$ \\
\hline Quartertoelect $=5$ & 0.0251 & 0.0260 & 0.0102 & 0.0245 & 0.0317 & 0.0251 & 0.0250 & 0.00172 \\
\hline & $(0.0159)$ & $(0.0176)$ & $(0.0156)$ & $(0.0159)$ & $(0.0215)$ & $(0.0215)$ & $(0.0158)$ & $(0.0103)$ \\
\hline Quartertoelect $=6$ & 0.0115 & 0.0167 & 0.00302 & 0.0106 & 0.0154 & 0.0115 & 0.0113 & 0.00265 \\
\hline & $(0.0153)$ & $(0.0183)$ & $(0.0155)$ & $(0.0153)$ & $(0.0182)$ & $(0.0119)$ & $(0.0151)$ & $(0.0104)$ \\
\hline Quartertoelect $=7$ & 0.0238 & 0.0290 & 0.0194 & 0.0233 & 0.0286 & 0.0238 & 0.0233 & 0.00626 \\
\hline & $(0.0153)$ & $(0.0186)$ & $(0.0150)$ & $(0.0153)$ & $(0.0195)$ & $(0.0156)$ & $(0.0152)$ & $(0.0100)$ \\
\hline Quartertoelect $=8$ & 0.00870 & 0.00722 & 0.00859 & 0.00903 & 0.00910 & 0.00870 & 0.00850 & 0.00301 \\
\hline & $(0.0142)$ & $(0.0171)$ & $(0.0141)$ & $(0.0141)$ & $(0.0151)$ & $(0.0157)$ & $(0.0141)$ & $(0.00917)$ \\
\hline Quartertoelect $=9$ & -0.00718 & -0.0151 & -0.0218 & -0.00707 & -0.00378 & -0.00718 & -0.00704 & -0.00208 \\
\hline & $(0.0157)$ & $(0.0191)$ & $(0.0157)$ & $(0.0157)$ & $(0.0145)$ & $(0.0199)$ & $(0.0156)$ & $(0.0111)$ \\
\hline Quartertoelect $=10$ & -0.0110 & -0.0191 & -0.0193 & -0.0115 & -0.00754 & -0.0110 & -0.0107 & -0.00521 \\
\hline & $(0.0168)$ & $(0.0199)$ & $(0.0174)$ & $(0.0168)$ & $(0.0144)$ & $(0.0170)$ & $(0.0168)$ & $(0.0119)$ \\
\hline Quartertoelect $=11$ & 0.00269 & -0.0108 & -0.00142 & 0.00259 & 0.00399 & 0.00269 & 0.00332 & -0.00946 \\
\hline & $(0.0167)$ & $(0.0197)$ & $(0.0171)$ & $(0.0167)$ & $(0.0159)$ & $(0.0162)$ & $(0.0165)$ & $(0.0114)$ \\
\hline Quartertoelect $=12$ & -0.00929 & -0.0116 & -0.00912 & -0.00948 & -0.00658 & -0.00929 & -0.00943 & 0.00209 \\
\hline & $(0.0129)$ & $(0.0148)$ & $(0.0129)$ & $(0.0129)$ & $(0.0110)$ & $(0.0155)$ & $(0.0129)$ & $(0.00745)$ \\
\hline Quartertoelect $=13$ & 0.00451 & 0.00913 & -0.0101 & 0.00444 & 0.00477 & 0.00451 & 0.00427 & 0.00360 \\
\hline & $(0.0151)$ & $(0.0171)$ & $(0.0148)$ & $(0.0150)$ & $(0.0138)$ & $(0.0198)$ & $(0.0151)$ & $(0.00795)$ \\
\hline Quartertoelect $=14$ & -0.0159 & -0.0228 & -0.0243 & -0.0166 & -0.0110 & -0.0159 & -0.0156 & -0.00425 \\
\hline & $(0.0147)$ & $(0.0166)$ & $(0.0151)$ & $(0.0146)$ & $(0.0118)$ & $(0.0149)$ & $(0.0147)$ & $(0.00795)$ \\
\hline Quartertoelect $=15$ & -0.0154 & -0.0195 & -0.0194 & -0.0155 & -0.0121 & -0.0154 & -0.0152 & -0.00397 \\
\hline & $(0.0121)$ & $(0.0145)$ & $(0.0127)$ & $(0.0120)$ & $(0.00929)$ & $(0.0141)$ & $(0.0122)$ & $(0.00828)$ \\
\hline Concurrence & & & & & & & $0.0665^{* * *}$ & \\
\hline & & & & & & & $(0.0154)$ & \\
\hline Year FE & Yes & Yes & Yes & Yes & Yes & Yes & Yes & Yes \\
\hline Circuit FE & Yes & Yes & Yes & Yes & Yes & Yes & Yes & Yes \\
\hline Legal Issue FE & Yes & Yes & Yes & Yes & Yes & Yes & Yes & Yes \\
\hline Probability Weights & No & Yes & No & No & No & No & No & No \\
\hline Season (Months 3-5/6-8/9-11/12-2) FE & Yes & Yes & No & Yes & Yes & Yes & Yes & Yes \\
\hline Season (Months 1-3/4-6/7-9/10-12) FE & No & No & Yes & No & No & No & No & No \\
\hline Divided (RDD or DRR) FE & Yes & Yes & Yes & No & Yes & Yes & Yes & Yes \\
\hline Panel (DDD, DDR, DRR, or RRR) FE & No & No & No & Yes & No & No & No & No \\
\hline Probit & No & No & No & No & Yes & No & No & No \\
\hline Cluster Quarter-Year & Yes & Yes & Yes & Yes & Yes & No & Yes & Yes \\
\hline Cluster Circuit & No & No & No & No & No & Yes & No & No \\
\hline Observations & 18686 & 18686 & 18686 & 18686 & 18686 & 18686 & 18686 & 18686 \\
\hline$\underline{\text { R-squared }}$ & 0.021 & 0.021 & 0.022 & 0.022 & & 0.021 & 0.023 & 0.016 \\
\hline
\end{tabular}


Appendix Table C: Electoral Cycles in Dissents - Additional Robustness Checks

\begin{tabular}{|c|c|c|c|c|c|}
\hline & (1) & $(2)$ & $(3)$ & (4) & $(5)$ \\
\hline & & $5 \%$ Samp & $(1925-2002)$ & & $\begin{array}{c}\text { 100\% Sample } \\
(1950-2007)\end{array}$ \\
\hline Mean of dep. var. & & & & & 0.060 \\
\hline & OLS & Probit & Drop 1 Circuit & Keep 1 Circuit & Keep 1 Circuit \\
\hline Quarters to Election & $\begin{array}{c}-0.00284^{* * *} \\
(0.000709)\end{array}$ & $\begin{array}{c}-0.00293^{* * *} \\
(0.000765)\end{array}$ & Each coefficient & epresents a separate & OLS regression. \\
\hline Last Quarter & & & & $0.0680^{* * *}$ & $0.0113^{* * *}$ \\
\hline All Circuits & & & & $(0.0135)$ & $(0.00323)$ \\
\hline Last Quarter & & & $0.0686^{* * *}$ & $0.0747^{*}$ & -0.00368 \\
\hline Circuit 1 & & & $(0.0142)$ & $(0.0429)$ & $(0.0108)$ \\
\hline Last Quarter & & & $0.0679 * * *$ & 0.0778 & 0.00156 \\
\hline Circuit 2 & & & $(0.0142)$ & $(0.0600)$ & $(0.0107)$ \\
\hline Last Quarter & & & $0.0639^{* * *}$ & $0.118^{*}$ & 0.0119 \\
\hline Circuit 3 & & & $(0.0136)$ & $(0.0661)$ & $(0.0137)$ \\
\hline Last Quarter & & & $0.0715^{* * *}$ & 0.0301 & 0.0127 \\
\hline Circuit 4 & & & $(0.0138)$ & $(0.0581)$ & $(0.0153)$ \\
\hline Last Quarter & & & $0.0729 * * *$ & 0.0355 & 0.00888 \\
\hline Circuit 5 & & & $(0.0138)$ & $(0.0296)$ & $(0.00812)$ \\
\hline Last Quarter & & & $0.0627^{* * *}$ & $0.127^{* * *}$ & $0.0348^{* * *}$ \\
\hline Circuit 6 & & & $(0.0130)$ & $(0.0436)$ & $(0.0115)$ \\
\hline Last Quarter & & & $0.0706^{* * *}$ & 0.0509 & $0.0208^{* *}$ \\
\hline Circuit 7 & & & $(0.0142)$ & $(0.0372)$ & $(0.00871)$ \\
\hline Last Quarter & & & $0.0714^{* * *}$ & 0.0252 & 0.0122 \\
\hline Circuit 8 & & & $(0.0143)$ & $(0.0438)$ & $(0.0110)$ \\
\hline Last Quarter & & & $0.0674^{* * *}$ & $0.0876^{* *}$ & $-0.0121^{*}$ \\
\hline Circuit 9 & & & $(0.0135)$ & $(0.0345)$ & $(0.00689)$ \\
\hline Last Quarter & & & $0.0713^{* * *}$ & 0.0459 & 0.00254 \\
\hline Circuit 10 & & & $(0.0149)$ & $(0.0350)$ & $(0.0100)$ \\
\hline Last Quarter & & & $0.0685^{* * *}$ & 0.0706 & $0.0211^{* *}$ \\
\hline Circuit 11 & & & $(0.0139)$ & $(0.0537)$ & $(0.00822)$ \\
\hline Last Quarter & & & $0.0603^{* * *}$ & $0.177^{* * *}$ & 0.0124 \\
\hline Circuit 12 & & & $(0.0145)$ & $(0.0653)$ & $(0.0135)$ \\
\hline Year FE & Yes & Yes & Yes & Yes & Yes \\
\hline Circuit FE & Yes & Yes & Yes & No & No \\
\hline Season FE & Yes & Yes & Yes & Yes & Yes \\
\hline Legal Issue FE & Yes & Yes & Yes & Yes & No \\
\hline Divided (RDD or DRR) FE & Yes & Yes & Yes & Yes & No \\
\hline Quarter-to-Election FE & No & No & Yes & Yes & Yes \\
\hline
\end{tabular}

Notes: Robust standard errors clustered at the quarter-year level in parentheses ${ }^{*} \mathrm{p}<0.10$; ** $\mathrm{p}<0.05$; *** $\mathrm{p}<$ 0.01). The explanatory variables of interest is a dummy variable indicating whether it is the last quarter before an election (Columns 3-5) or a continuous variable for quarters to election (Columns 1-2). Marginal effect from a probit specification of dissent on continuous variable for quarters to election in Column 2. 
Appendix Table D: Panel Composition, Case Type, and Case Load Over Political Cycle

\begin{tabular}{|c|c|c|c|c|c|c|c|}
\hline & (1) & $(2)$ & (3) & $(4)$ & $(5)$ & $(6)$ & (7) \\
\hline & Divided Panel & Criminal & Civil Rights & $\begin{array}{c}\text { First } \\
\text { Amendment, } \\
\text { Due Process, } \\
\text { Privacy }\end{array}$ & $\begin{array}{c}\text { Labor } \\
\text { Relations }\end{array}$ & $\begin{array}{c}\text { Economic } \\
\text { Activity }\end{array}$ & $\begin{array}{c}\text { Monthly \# of } \\
\text { Publications } \\
\text { (AOC 1971- } \\
\text { 1999) }\end{array}$ \\
\hline Mean of dep. var. & 0.697 & 0.269 & 0.086 & 0.028 & 0.072 & 0.509 & 260 \\
\hline Quartertoelect $=1$ & $\begin{array}{l}-0.0100 \\
(0.0196)\end{array}$ & $\begin{array}{l}-0.0168 \\
(0.0221)\end{array}$ & $\begin{array}{l}-0.0111 \\
(0.0156)\end{array}$ & $\begin{array}{c}-0.0140 \\
(0.00996)\end{array}$ & $\begin{array}{c}-0.000990 \\
(0.0114)\end{array}$ & $\begin{array}{c}0.0143 \\
(0.0304)\end{array}$ & $\begin{array}{c}0.501 \\
(8.242)\end{array}$ \\
\hline Quartertoelect $=2$ & $\begin{array}{c}0.0161 \\
(0.0212)\end{array}$ & $\begin{array}{l}0.00356 \\
(0.0215)\end{array}$ & $\begin{array}{l}-0.0131 \\
(0.0144)\end{array}$ & $\begin{array}{l}-0.00190 \\
(0.00952)\end{array}$ & $\begin{array}{l}-0.0174 \\
(0.0126)\end{array}$ & $\begin{array}{c}0.0234 \\
(0.0269)\end{array}$ & $\begin{array}{l}-7.276 \\
(9.106)\end{array}$ \\
\hline Quartertoelect $=3$ & $\begin{array}{l}0.00598 \\
(0.0212)\end{array}$ & $\begin{array}{l}-0.0109 \\
(0.0195)\end{array}$ & $\begin{array}{l}-0.0164 \\
(0.0135)\end{array}$ & $\begin{array}{c}-0.0122 \\
(0.00842)\end{array}$ & $\begin{array}{l}0.00858 \\
(0.0124)\end{array}$ & $\begin{array}{c}0.0248 \\
(0.0247)\end{array}$ & $\begin{array}{c}2.358 \\
(8.693)\end{array}$ \\
\hline Quartertoelect $=4$ & $\begin{array}{l}0.00489 \\
(0.0220)\end{array}$ & $\begin{array}{l}0.00925 \\
(0.0213)\end{array}$ & $\begin{array}{l}-0.0159 \\
(0.0147)\end{array}$ & $\begin{array}{c}0.00653 \\
(0.00867)\end{array}$ & $\begin{array}{l}0.00697 \\
(0.0114)\end{array}$ & $\begin{array}{l}-0.0217 \\
(0.0261)\end{array}$ & $\begin{array}{l}-11.83 \\
(8.653)\end{array}$ \\
\hline Quartertoelect $=5$ & $\begin{array}{l}-0.0305 \\
(0.0311)\end{array}$ & $\begin{array}{l}-0.0242 \\
(0.0293)\end{array}$ & $\begin{array}{r}-0.00742 \\
(0.0174)\end{array}$ & $\begin{array}{r}-0.00931 \\
(0.0107)\end{array}$ & $\begin{array}{l}-0.0195 \\
(0.0147)\end{array}$ & $\begin{array}{c}0.0326 \\
(0.0344)\end{array}$ & $\begin{array}{l}-8.162 \\
(11.05)\end{array}$ \\
\hline Quartertoelect $=6$ & $\begin{array}{r}-0.00880 \\
(0.0302)\end{array}$ & $\begin{array}{l}-0.0109 \\
(0.0267)\end{array}$ & $\begin{array}{r}-0.00751 \\
(0.0184)\end{array}$ & $\begin{array}{r}-0.00821 \\
(0.0106)\end{array}$ & $\begin{array}{c}-0.00586 \\
(0.0159)\end{array}$ & $\begin{array}{c}0.0256 \\
(0.0313)\end{array}$ & $\begin{array}{l}-16.91 \\
(11.78)\end{array}$ \\
\hline Quartertoelect $=7$ & $\begin{array}{l}0.00431 \\
(0.0298)\end{array}$ & $\begin{array}{l}-0.0161 \\
(0.0255)\end{array}$ & $\begin{array}{l}0.00225 \\
(0.0175)\end{array}$ & $\begin{array}{l}-0.00722 \\
(0.00969)\end{array}$ & $\begin{array}{l}0.00697 \\
(0.0165)\end{array}$ & $\begin{array}{c}0.0190 \\
(0.0305)\end{array}$ & $\begin{array}{l}-10.39 \\
(11.58)\end{array}$ \\
\hline Quartertoelect $=8$ & $\begin{array}{c}0.0288 \\
(0.0270)\end{array}$ & $\begin{array}{l}-0.0216 \\
(0.0242)\end{array}$ & $\begin{array}{l}0.000676 \\
(0.0162)\end{array}$ & $\begin{array}{l}-0.00713 \\
(0.00850)\end{array}$ & $\begin{array}{l}-0.00418 \\
(0.0130)\end{array}$ & $\begin{array}{c}0.0216 \\
(0.0262)\end{array}$ & $\begin{array}{l}-10.21 \\
(10.26)\end{array}$ \\
\hline Quartertoelect $=9$ & $\begin{array}{l}0.00651 \\
(0.0308)\end{array}$ & $\begin{array}{r}-0.00947 \\
(0.0292)\end{array}$ & $\begin{array}{l}-0.0205 \\
(0.0202)\end{array}$ & $\begin{array}{l}-0.0131 \\
(0.0109)\end{array}$ & $\begin{array}{l}-0.0209 \\
(0.0155)\end{array}$ & $\begin{array}{l}0.0575^{*} \\
(0.0300)\end{array}$ & $\begin{array}{l}-6.158 \\
(11.85)\end{array}$ \\
\hline Quartertoelect $=10$ & $\begin{array}{l}0.00915 \\
(0.0311)\end{array}$ & $\begin{array}{c}-0.00102 \\
(0.0290)\end{array}$ & $\begin{array}{l}0.00251 \\
(0.0185)\end{array}$ & $\begin{array}{c}-0.0186^{*} \\
(0.0100)\end{array}$ & $\begin{array}{c}-0.0362 * * \\
(0.0148)\end{array}$ & $\begin{array}{c}0.0484 \\
(0.0322)\end{array}$ & $\begin{array}{l}-19.02 \\
(12.21)\end{array}$ \\
\hline Quartertoelect $=11$ & $\begin{array}{r}-0.00562 \\
(0.0287)\end{array}$ & $\begin{array}{c}-0.0372 \\
(0.0293)\end{array}$ & $\begin{array}{r}-0.00187 \\
(0.0164)\end{array}$ & $\begin{array}{c}-0.0210^{* *} \\
(0.00940)\end{array}$ & $\begin{array}{l}-0.0134 \\
(0.0142)\end{array}$ & $\begin{array}{c}0.0703^{* *} \\
(0.0319)\end{array}$ & $\begin{array}{l}-10.85 \\
(11.58)\end{array}$ \\
\hline Quartertoelect $=12$ & $\begin{array}{l}-0.00609 \\
(0.0264)\end{array}$ & $\begin{array}{c}0.0127 \\
(0.0220)\end{array}$ & $\begin{array}{l}-0.0123 \\
(0.0145)\end{array}$ & $\begin{array}{l}-0.0108 \\
(0.00700)\end{array}$ & $\begin{array}{l}-0.0160 \\
(0.0110)\end{array}$ & $\begin{array}{c}0.0305 \\
(0.0217)\end{array}$ & $\begin{array}{l}-11.29 \\
(8.398)\end{array}$ \\
\hline Quartertoelect $=13$ & $\begin{array}{l}-0.0270 \\
(0.0302)\end{array}$ & $\begin{array}{l}0.00922 \\
(0.0239)\end{array}$ & $\begin{array}{l}-0.0152 \\
(0.0168)\end{array}$ & $\begin{array}{l}-0.00570 \\
(0.00855)\end{array}$ & $\begin{array}{c}-0.0248^{* *} \\
(0.0117)\end{array}$ & $\begin{array}{c}0.0396 \\
(0.0248)\end{array}$ & $\begin{array}{l}-6.209 \\
(9.896)\end{array}$ \\
\hline Quartertoelect $=14$ & $\begin{array}{l}-0.00711 \\
(0.0300)\end{array}$ & $\begin{array}{c}0.0176 \\
(0.0234)\end{array}$ & $\begin{array}{l}-0.00223 \\
(0.0158)\end{array}$ & $\begin{array}{l}-0.0126 \\
(0.00893)\end{array}$ & $\begin{array}{l}-0.0189 \\
(0.0124)\end{array}$ & $\begin{array}{l}0.00518 \\
(0.0241)\end{array}$ & $\begin{array}{l}-11.01 \\
(9.421)\end{array}$ \\
\hline Quartertoelect $=15$ & $\begin{array}{l}-0.00282 \\
(0.0307)\end{array}$ & $\begin{array}{r}-0.00209 \\
(0.0226)\end{array}$ & $\begin{array}{l}-0.00727 \\
(0.0164)\end{array}$ & $\begin{array}{c}-0.0209^{* * *} \\
(0.00778)\end{array}$ & $\begin{array}{l}-0.0174 \\
(0.0123)\end{array}$ & $\begin{array}{l}0.0518^{* *} \\
(0.0251)\end{array}$ & $\begin{array}{l}-6.834 \\
(9.101)\end{array}$ \\
\hline Divided (DRR or RDD) & & $\begin{array}{l}-0.0108 \\
(0.00750)\end{array}$ & $\begin{array}{c}0.00151 \\
(0.00472)\end{array}$ & $\begin{array}{c}0.00271 \\
(0.00266)\end{array}$ & $\begin{array}{c}0.00396 \\
(0.00443)\end{array}$ & $\begin{array}{c}0.00396 \\
(0.00770)\end{array}$ & \\
\hline Year FE & Yes & Yes & Yes & Yes & Yes & Yes & Yes \\
\hline Circuit FE & Yes & Yes & Yes & Yes & Yes & Yes & Yes \\
\hline Season FE & Yes & Yes & Yes & Yes & Yes & Yes & Yes \\
\hline Observations & 18686 & 18686 & 18686 & 18686 & 18686 & 18686 & 4344 \\
\hline R-squared & 0.048 & 0.050 & 0.053 & 0.022 & 0.021 & 0.099 & 0.773 \\
\hline
\end{tabular}

Notes: Robust OLS standard errors in parentheses $\left(^{*} \mathrm{p}<0.10 ;{ }^{* *} \mathrm{p}<0.05 ; * * * \mathrm{p}<0.01\right)$. In Columns 1-6, data comes from $5 \%$ Sample (1925-2002) and standard errors are clustered at the quarter-year level. The outcome variable in Column 1 is a dummy variable equal to 1 if the case was heard by an ideologically divided panel. The outcome variables in Columns 2-6 are dummy variables indicating the type of legal issue addressed in the case. The outcome variable in Column 7 is the number of opinions; observations are at the month-year-circuit level. The explanatory variables of interest are dummy variables indicating the number of quarters remaining before the upcoming presidential election (16 quarters to the election is the omitted dummy variable). The sample comes from the Administrative Office of the U.S. Courts. 


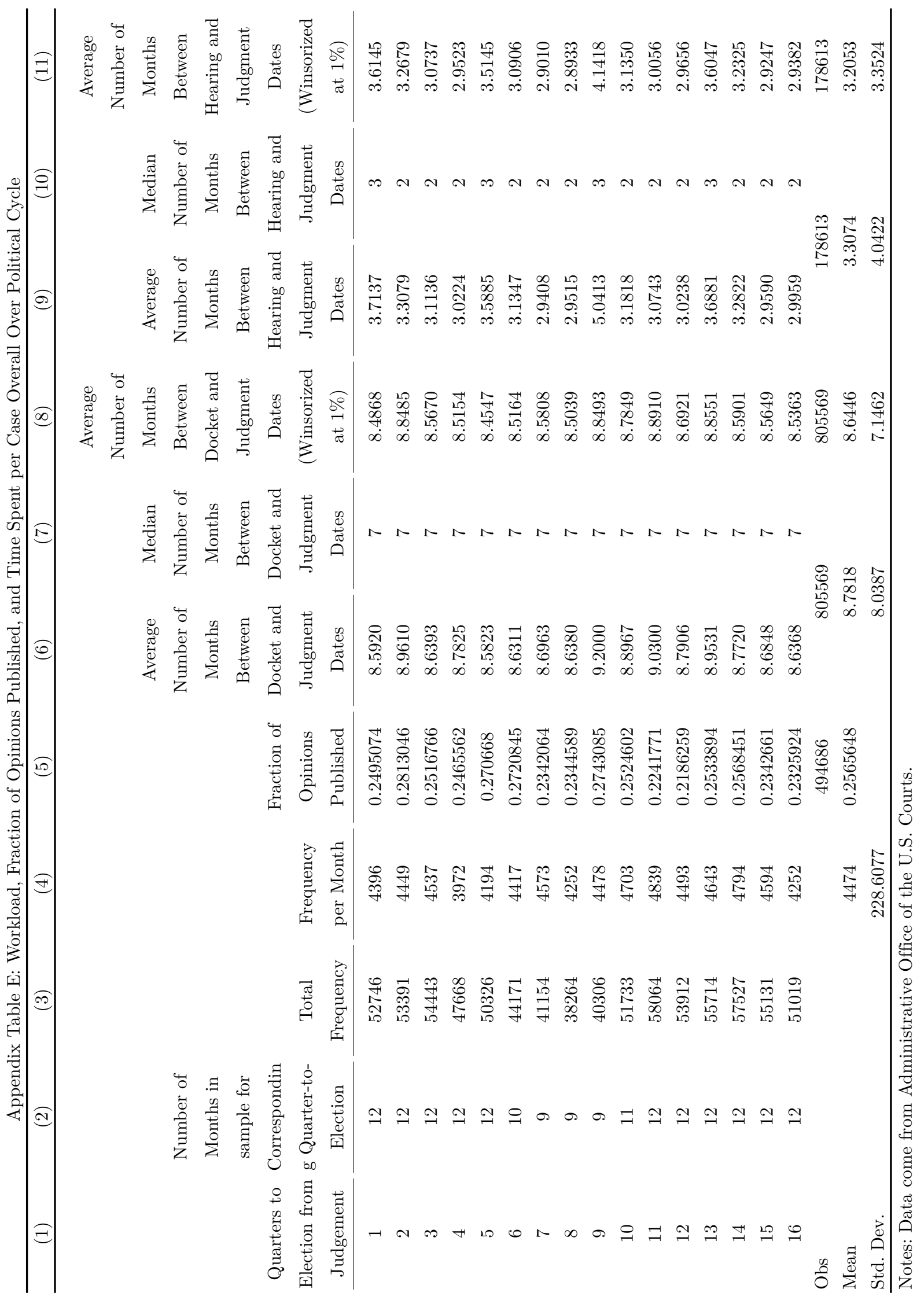


Appendix Table F: Electoral Cycles in Dissents by Presidential Appointment

\begin{tabular}{|c|c|c|}
\hline \multirow{4}{*}{$\begin{array}{c}\text { Keep } 1 \text { set of presidential } \\
\text { appointees at a time }\end{array}$} & $(1)$ & $(2)$ \\
\hline & \multicolumn{2}{|c|}{ Dissent Vote } \\
\hline & 5\% Sample (1925-2002) & $\mathrm{N}$ \\
\hline & \multicolumn{2}{|c|}{ Each coefficient represents a separate regression } \\
\hline \multirow[t]{2}{*}{ T. Roosevelt } & -0.00465 & 315 \\
\hline & $(0.00390)$ & \\
\hline \multirow[t]{2}{*}{ Taft } & -0.0220 & 154 \\
\hline & $(0.0352)$ & \\
\hline \multirow[t]{2}{*}{ Wilson } & 0.00285 & 1567 \\
\hline & $(0.0137)$ & \\
\hline \multirow[t]{2}{*}{ Harding } & -0.00260 & 353 \\
\hline & $(0.00840)$ & \\
\hline \multirow[t]{2}{*}{ Coolidge } & -0.00925 & 2366 \\
\hline & $(0.00953)$ & \\
\hline \multirow[t]{2}{*}{ Hoover } & 0.00488 & 2585 \\
\hline & $(0.0107)$ & \\
\hline \multirow[t]{2}{*}{ F. Roosevelt } & -0.00221 & 6055 \\
\hline & $(0.00603)$ & \\
\hline \multirow[t]{2}{*}{ Truman } & 0.0110 & 3006 \\
\hline & $(0.00908)$ & \\
\hline \multirow[t]{2}{*}{ Eisenhower } & -0.00115 & 6109 \\
\hline & $(0.00638)$ & \\
\hline \multirow[t]{2}{*}{ Kennedy } & 0.0156 & 2585 \\
\hline & $(0.0136)$ & \\
\hline \multirow[t]{2}{*}{ Johnson } & 0.00336 & 5563 \\
\hline & $(0.00915)$ & \\
\hline \multirow[t]{2}{*}{ Nixon } & 0.0127 & 4836 \\
\hline & $(0.00903)$ & \\
\hline \multirow[t]{2}{*}{ Ford } & -0.0154 & 1239 \\
\hline & $(0.0293)$ & \\
\hline \multirow[t]{2}{*}{ Carter } & 0.00389 & 5320 \\
\hline & $(0.0116)$ & \\
\hline \multirow[t]{2}{*}{ Reagan } & $0.0225^{* * *}$ & 6185 \\
\hline & $(0.00699)$ & \\
\hline \multirow[t]{2}{*}{ Bush } & $0.0463^{* * *}$ & 2011 \\
\hline & $(0.0109)$ & \\
\hline \multirow[t]{2}{*}{ Clinton } & $0.0463^{*}$ & 1091 \\
\hline & $(0.0260)$ & \\
\hline Year FE & Yes & \\
\hline Circuit FE & Yes & \\
\hline Season FE & Yes & \\
\hline Legal Issue FE & Yes & \\
\hline Divided (RDD or DRR) FE & Yes & \\
\hline
\end{tabular}




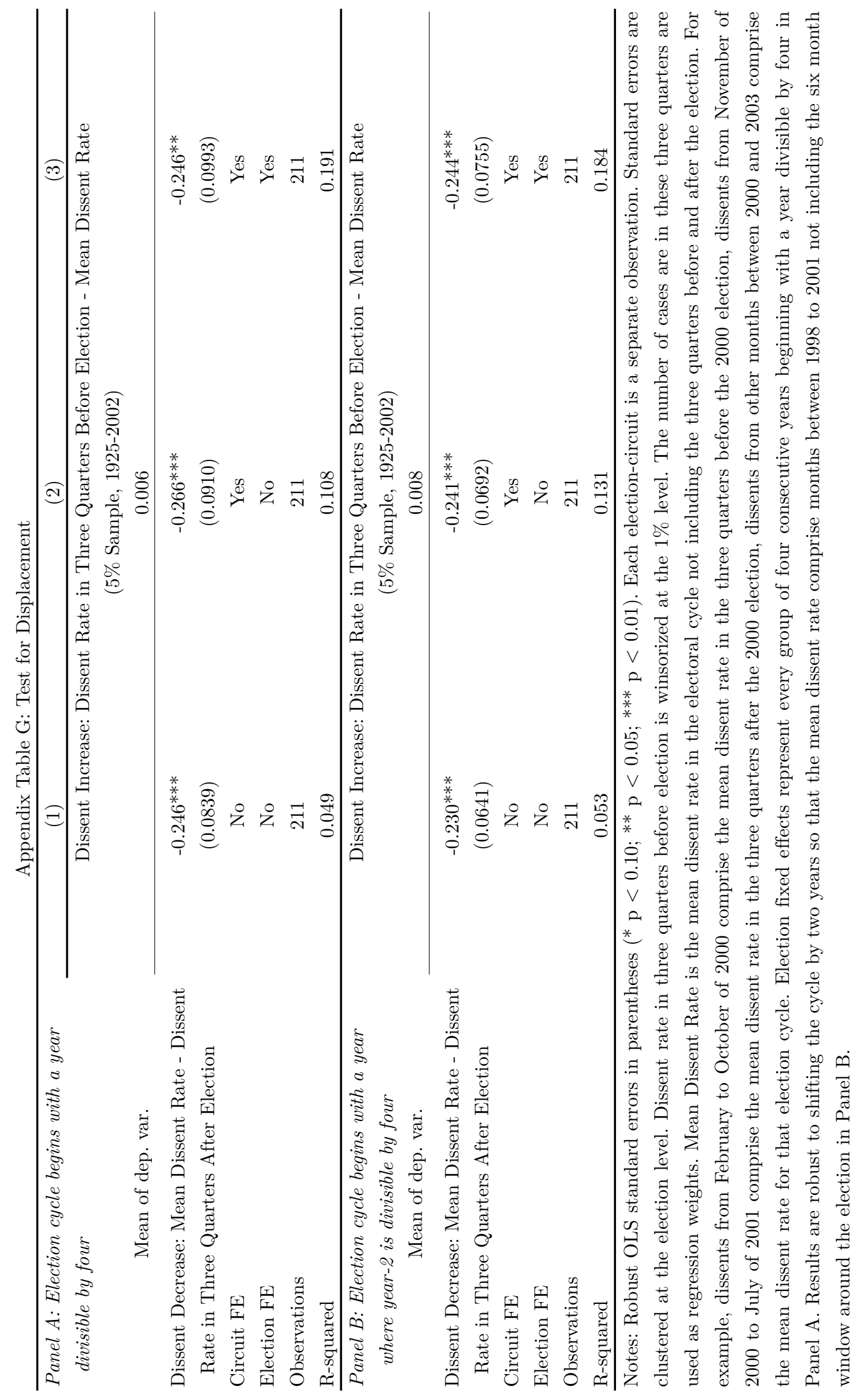




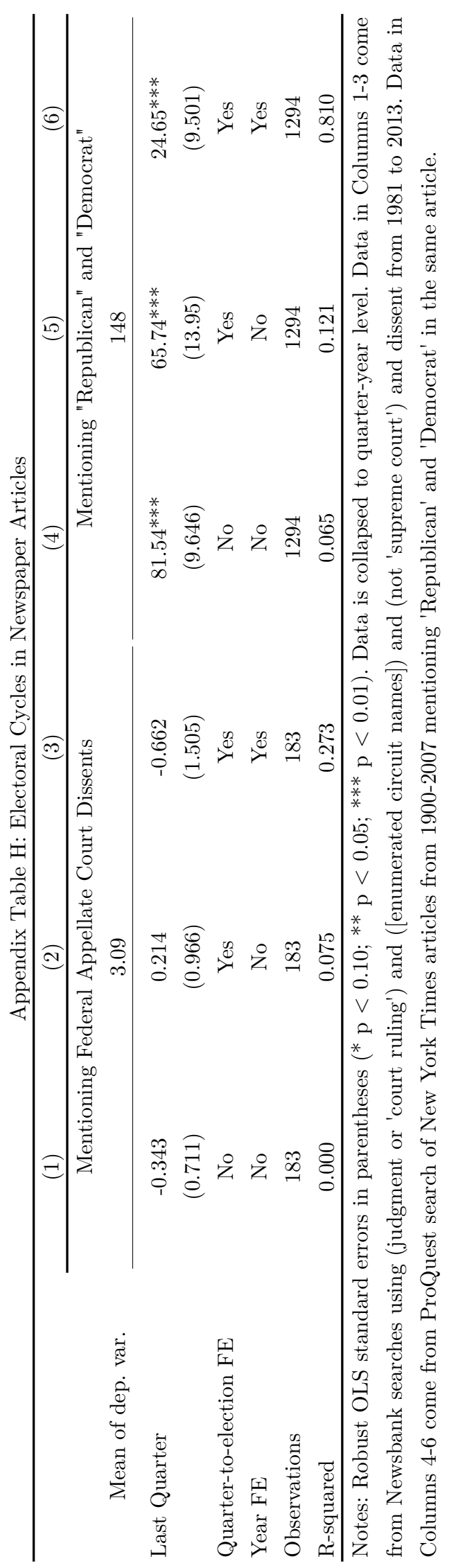


Appendix Table I: Electoral Cycles in Dissents by Type of Election

\begin{tabular}{|c|c|c|c|c|}
\hline & $(1)$ & $(2)$ & $(3)$ & $(4)$ \\
\hline & \multicolumn{4}{|c|}{ Dissent Vote } \\
\hline & \multicolumn{4}{|c|}{ 5\% Sample (1925-2002) } \\
\hline Mean of dep. var. & \multicolumn{4}{|c|}{0.024} \\
\hline \multirow[t]{2}{*}{ Quarter before Presidential Election } & $0.0152^{* * *}$ & & & $0.0101^{* *}$ \\
\hline & $(0.00417)$ & & & $(0.00476)$ \\
\hline \multirow[t]{2}{*}{ Quarter before Senator Election } & & $0.00801^{* *}$ & & $0.00901^{* *}$ \\
\hline & & $(0.00402)$ & & $(0.00434)$ \\
\hline \multirow[t]{2}{*}{ Quarter before Governor Election } & & & -0.00146 & -0.00176 \\
\hline & & & $(0.00393)$ & $(0.00428)$ \\
\hline Year FE & Yes & Yes & Yes & Yes \\
\hline Circuit FE & Yes & Yes & Yes & Yes \\
\hline Season FE & Yes & Yes & Yes & Yes \\
\hline Legal Issue FE & Yes & Yes & Yes & Yes \\
\hline Divided (RDD or DRR) FE & Yes & Yes & Yes & Yes \\
\hline Quarter-to-Election FE & Yes & Yes & Yes & Yes \\
\hline Judge FE & Yes & Yes & Yes & Yes \\
\hline Observations & 56058 & 56058 & 56058 & 56058 \\
\hline R-squared & 0.039 & 0.039 & 0.039 & 0.039 \\
\hline
\end{tabular}




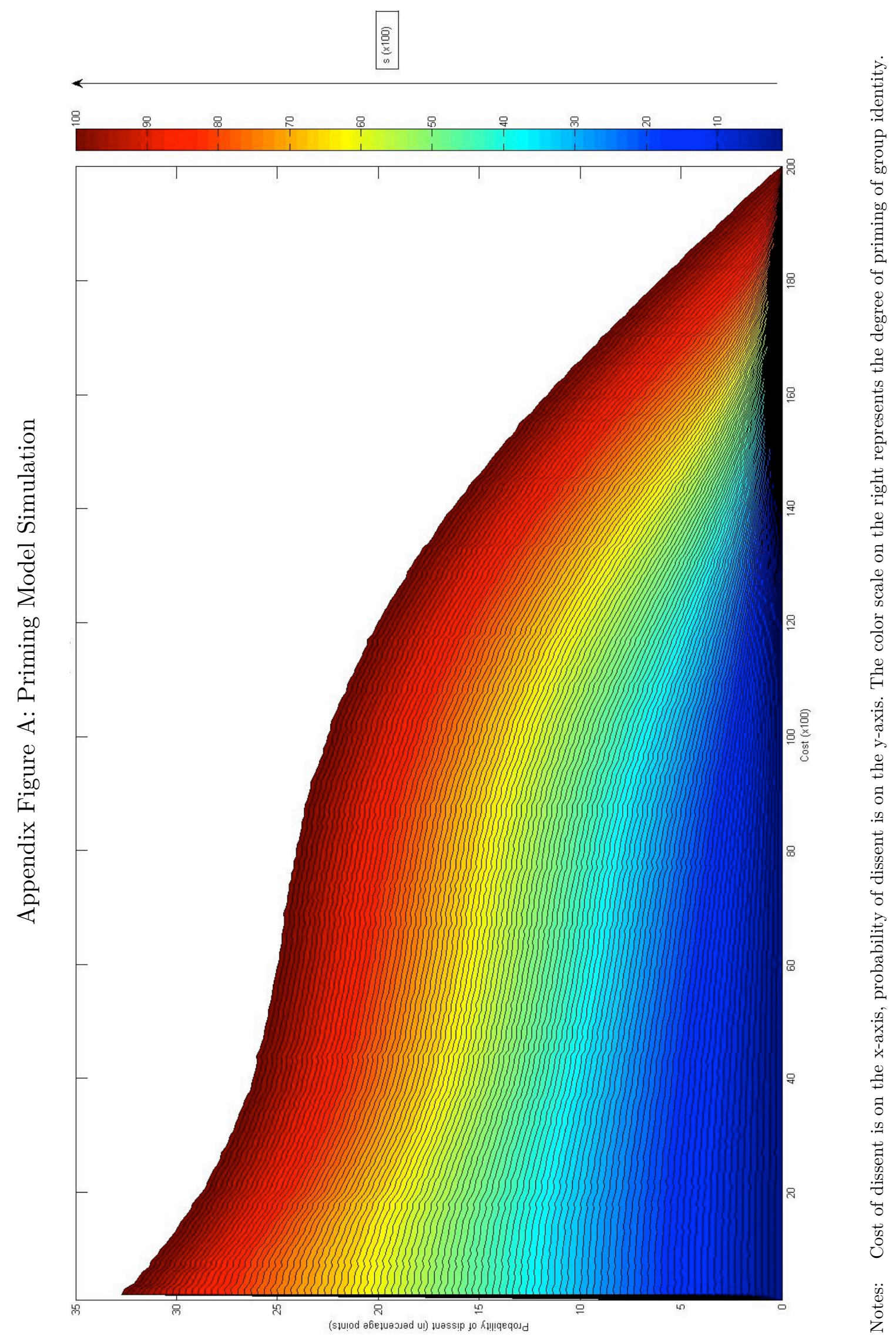

